NBSIR 80.2201

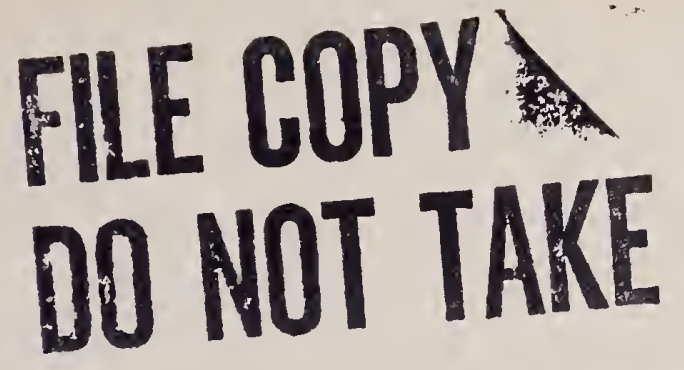

\title{
Coordinated Measurement Services at the National Bureau of Standards
}

Autnors:

Brian C. Belanger

David E. Edgerly

Aloert D. Tholen

(Introduction by Arthur O. Macoubrev)

Directorare of Measurement Services

Mational Measurement Laboratory

National Zureau of Standards

U.S. Department of Commerce

Washington, D.C. 20234

October 1380

issued Decenver 1980

Prenared for:

Mational Bureau of Stancards U.S. Department of Commerce

Washington, D.C. 2.0234 
1 


\section{COORDINATED MEASUREMENT \\ SERVICES AT THE NATIONAL BUREAU OF STANDARDS}

Authors:

Brian C. Belanger

David E. Edgerly

Albert D. Tholen

(Introduction by Arthur O. McCoubrey)

Directorate of Measurement Services

National Measurement Laboratory

National Bureau of Standards

U.S. Department of Commerce

Washington, D.C. 20234

October 1980

Issued December 1980

Prepared for:

National Bureau of Standards

U.S. Department of Commerce

Washington, D.C. 20234

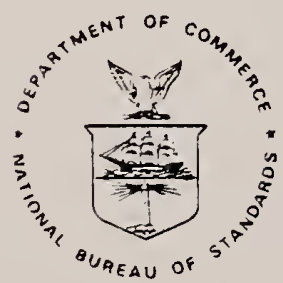

U.S. DEPARTMENT OF COMMERCE, Philip M. Klutznick, Secretary Jordan J. Baruch. Assistant Secretary for Productivity, Technology, and Innovation NATIONAL BUREAU OF STANDARDS, Ernest Ambler, Director 


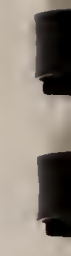


Coordinated Measurement Services at the

National Bureau of Standards

TABLE OF CONTENTS

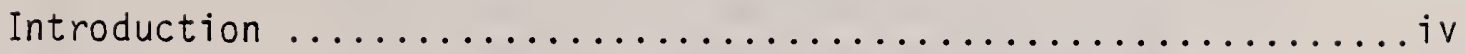

Office of Weights and Measures

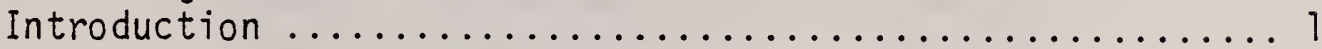

Problem on National Level ................... I

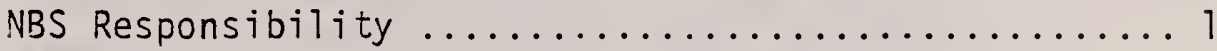

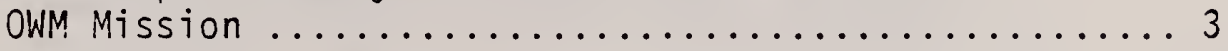

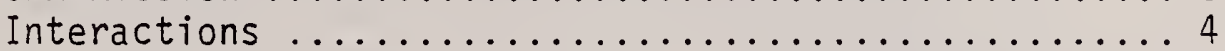

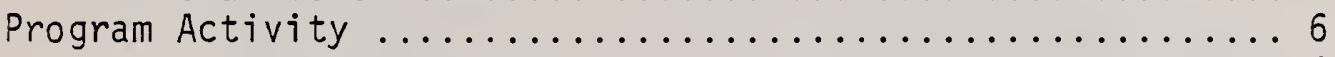

Major Objectives $\ldots \ldots \ldots \ldots \ldots \ldots \ldots \ldots \ldots \ldots 6,6$

Technical Activities ......................6 6

Railroad Track Scale Calibration Program ......6 6

Education Programs .................... 7

Study of State Needs .................. 7

Automating Preparation of Handbooks .......... 7

State Laboratory Programs ................ 8

Type Approval ...................... 8

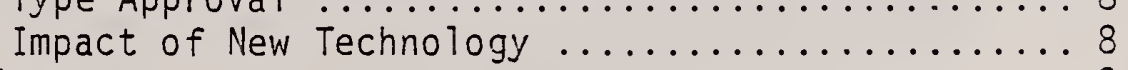

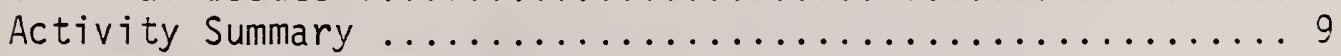

Sponsored Conferences/Supported Conferences ........ 9

Invited Talks ............................. 10

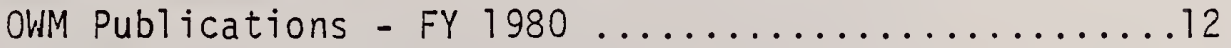

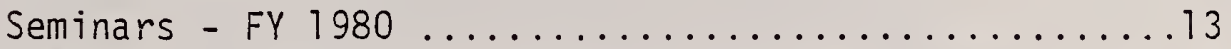

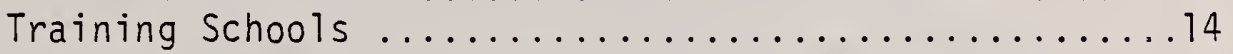

Technical and Professional Committee Participation

and Leadership ............................ 15

Consulting and Advisory Centers ................ 17

Office of Measurement Services

Introduction - Mission, Functions, and Interactions ......18

Program Activity - Calibration and Measurement Services ...20

MAP Program Development .........................21

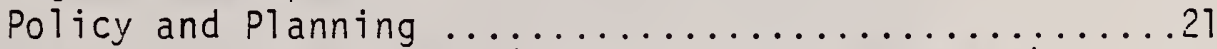

Statistical Consulting (Center for Applied Math).....2i

Electrical Measurements (Center for Absolute

Physical Quantities) .........................22

Temperature Measurements (Center for Absolute

Physical Quantities) ........................23

Spectrophotometry Measurements (Center for

Radiation Research) .....................26

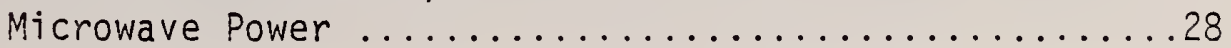

X-Ray Radiation Exposure to $150 \mathrm{KeV}$ (Center

for Radiation Research) .....................29

Force Measurements (Center for Mechanical

Engineering and Process Technology) .............29 


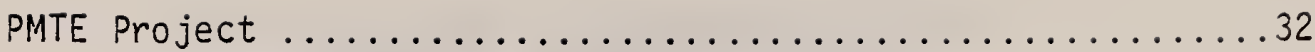

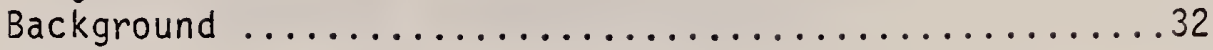

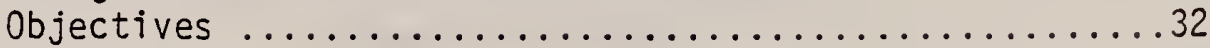

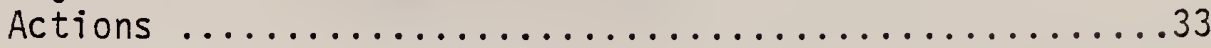

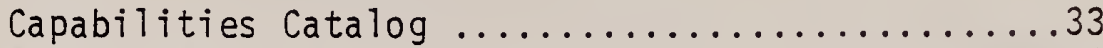

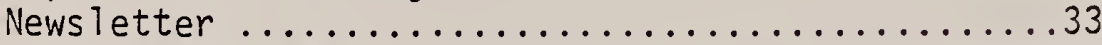

Cost Effectiveness Studies .................34

Automatic Test Equipment (ATE) Activities .......35

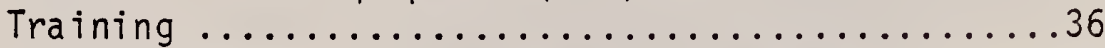

Standardization of Calibration Procedures .......36

Standard Terms and Definitions ...............37

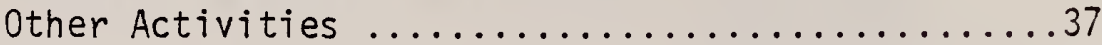

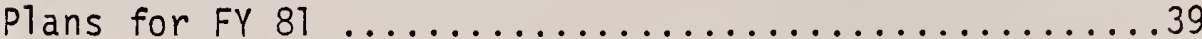

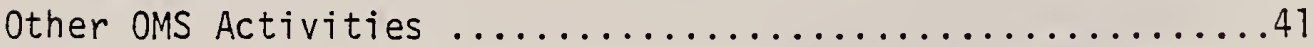

Office of Domestic and International Measurement Standards

Introduction ................................46

Background .............................

ODIMS Mission ............................46

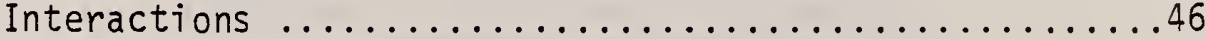

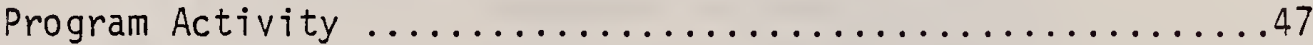

Major Objectives ........................47

Technical Activities ......................47

United States Participation in OIML ..........47

Coordinating NML Involvement in Domestic and

International Voluntary Standards Activities ....49

Supporting Bilateral and Multilateral Scientific and Technological Programs for NML Cooperation

with Foreign Institutions $\ldots \ldots \ldots \ldots \ldots . . . \ldots 50$

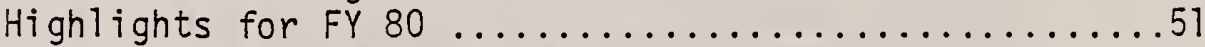

U.S.A. Participation in OIML......................

Sixth International Conference of Legal

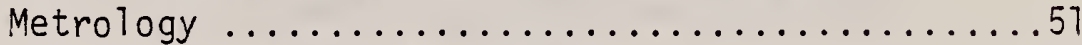

USA Initiative on Electronics ...............52

Approved Work PIans for OIML PSI7 -

"Measurement of Pollution" and for PS20 -

"Prepackaged Products" ....................53

Draft OIML International Recommendations

Reviewed by the United States During FY $80 \ldots \ldots 54$

OIML Meetings Attended by United States

Celegations During FY 80 
Coordinating NML Involvement in Domestic and

International Voluntary Standards Activities ........56

OMB Circular A-119 "Federal Participation in

Voluntary Standards" and Proposed Procedures

for Listing Voluntary Standards Bodies .........56

NML Policy on High-Impact Standards Issues ......57

American National Standards Institute

Service Fee System ......................57

Supporting Bilateral and Multilateral Scientific

and Technological Programs for NML Cooperation

with Foreign Institutions ..................... 58

U.S./Yugoslav Cooperative SäT Agreement ..........58

NBS Special Foreign Currency Program (SFCP)

Projects in Egypt .......................58

Technical Assistance Programs ...................58

Meetings in Support of Bilateral Science

and Technology Agreements .................59

Meetings in Support of Technical Assistance

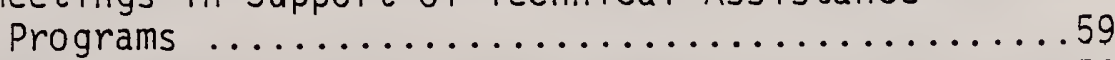

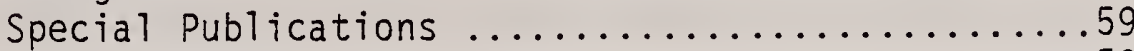

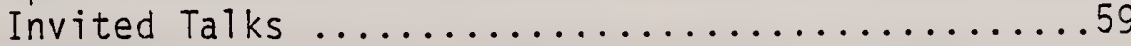

\section{APPENDICES}

1. DRAFT PLAN FOR TRAINING AND EDUCATION PROGRAMS IN $\ldots \ldots \ldots 1.1$ MEASUREMENT SCIENCE (August 29, 1980)

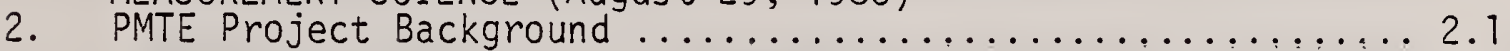

3. PMTE UPDATE (December 1979 and June 1980) .............. 3.1

4. COST EFFECTIVENESS STUDY TO DETERMINE ALTERNATIVES ........ 4,1 TO OUT OF SERVICE CALIBRATION OF PMTE WITHIN THE FEDERAL GOVERNMENT (August 12, 1980)

5. COST EFFECTIVENESS STUDY TO DETERMINE METHODS FOR $\ldots \ldots \ldots .5 .1$ OPTIMIZING CALIBRATION INTERVALS FOR PMTE WITHIN THE FEDERAL GOVERNMENT (August 12, 1980)

6. OMB Circular--Federal Participation in Voluntary $\ldots \ldots \ldots .6 .1$ Standards (January 17, 1980)

7. Federal Register Notice (June 2, 1980) ................ 7.1 Implementation of Federal Voluntary Standards Policy; Proposed Procedures for Listing Voluntary Standards Bodies Eligible for Federal Agency Support and Participation, and for a Department Sponsored Voluntary Dispute Resolution Service for Procedural Complaints Against Listed Voluntary Standards Bodies 


\section{Coordinated Measurement Services \\ at the \\ National Bureau of Standards \\ Introduction}

The realization of accuracy for measurements made throughout the United States requires traceability to national reference standards which are maintained by the National Bureau of Standards (NBS). The services of NBS which are necessary for traceability, broadly classified as measurement services, are generated in the scientific and technical Centers of the National Measurement Laboratory (NML) and the National Engineering Laboratory (NEL), the major operating units of NBS having measurement related assignments. NBS measurement services flow from their many internal sources outward to meet the needs of users widely distributed throughout the nation. Special program offices within AML function to coordinate these services and to provide responsive points of contact for those who need them. Functions of these offices include calibrations, services for the assurance of measurement quality, measurement practice publications, assistance to external institutions in the training and education of metrologists and the promotion of good measurement system operations throughout the United States. These coordinating offices are ${ }^{7}$ :

- Office of Weights and Measures (OWM) - responsible for the measurement service requirements of state and local government agencies.

${ }^{1}$ Additional NML measurement service program offices discussed elsewhere are:

- Office of Standard Reference Materials

- Office of Standard Reference Data 
- Office of Measurement Services (OMS) - responsible for the measurement service requirements of private industry and other agencies of the Federal Government.

The programs of NML also include, in addition to measurement reference standards and related measurement services, the participation of many professional staff members in the work of voluntary standards writing committees, the development of international standards for legal measurement practice, and international cooperative research. The objectives of these activities are to promote the incorporation of good measurement practice into domestic voluntary standards for products and methods, the incorporation of United States practices in international voluntary and legal measurement standards and domestic benefits from measurement related research in other nations. The coordination of all of these activities within $\mathrm{NML}^{2}$ is the responsibility of the following:

- Office of Domestic and International Measurements Standards (ODIMS) responsible for oversight and coordination of NML participation in domestic and international voluntary standards development, international standards of legal measurement practice, and research cooperation with foreign institutions.

The coordinating activities of OWM, OMS, and ODIMS are integrated together through close association of all programs within the Directorate for Measurement Services (DMS). The following pages of this document describe the activities, objectives, and plans for each of these three

${ }^{2}$ The coordination of domestic standards activities in NEL is the responsibility of the Office of Engineering Standards. 
offices in detai1. This information was prepared for the DMS Evaluation Panel of the National Academy of Sciences/National Academy of Engineering. It is published here with the hope that it wi 11 also be useful to a wider interested readership. 


\section{Office of Weights and Measures}

Technical Activities

1. Introduction

1.1. Problem on National Level

Although the Constitution empowers Congress to fix the standards of weights and measures, the United States is unique among the nations of the world in that no compliance method for controlling weights and measures is exercised at the national level. The only basic actions of the Federal Government in this field have been the Mint Act of 1828 establishing early standards and an act of 1866 legalizing the metric system of measurement in this country. Many courts, both State and Federal, have ruled that as long as Congress does not exercise its power in this area, the rights of the individual States are not diminished. Thus, the regulation of weights and measures in commerce and industry has been left largely to the States and their political subdivisions to administer.

More than 775 separate jurisdictions exist in this country including States, countries, and cities. It is the responsibility of the State and local officials to see that equity prevails in all commercial transactions.

\subsection{NBS Responsibility}

The task of monitoring our national standards remained in the Treasury Department throughout the nineteenth century under the direct supervision of a small office known as the Office of Standard Weights and Measures. In 1901 Congress renamed this small office the National Bureau of Standards and greatly increased its functions and activities. The functions of NBS that are directly related to weights and measures fall into three categories: (1) the custody of the standards, (2) the metrological services, and (3) the advisory services to the States and industry. The Bureau provides the States calibration services that result in precise values for their basic reference standards of mass, length, and capacity.

Since NBS has no enforcement authority in the weights and measures area, it consequently, plays a unique role in weights and measures administration. The primary goal of the States is enforcement while the primary goal of NBS is to provide technical services to the States necessary to bring about nationwide uniformity in weights and measures enforcement. The Bureau provides this technical service to the States through its Office of Weights and Measures. This service is all the more important today considering the revolution in technology taking place. For example, weights and measures officials are being faced with certifying the accuracy of scales tied to laser product code scanners and price computers or of digital readout gasoline pumps with microprocessor interfacing. The Office of Weights and Measures must provide technical 
leadership in these areas. Uniform testing equipment and procedures must be developed, model legal requirements provided, and a training program carried on with the guidance of the National Bureau of Standards.

Under our system of State and local enforcement of weights and measures laws and regulations, it would seem that nonuniformity would be inevitable. Such is not the case largely due to the program of cooperation with the States carried on by NBS through the Office of Weights and Measures. Most notably, OWM sponsors the National Conference on Weights and Measures, a voluntary organization of Federal, State, and local officials and has annually conducted this national forum since 1905. This office, through the National Conference on Weights and Measures, plans and conducts a program of assistance to State and rocal weights and measures officials, business, and industry in the many phases of weights and measures supervision. The range of services provided includes drafting of new legislation, interpretation of laws, development of specifications, tolerances, and testing methods, and the design of testing equipment.

In the Directorate for Measurement Services today, there is great potential for synergism as a result of the combined efforts of the Office of Weights and Measures with the Office of Measurement Services and the Office of Domestic and International Measurement Standards. For example, the National Conference on Weights and Measures will influence and be influenced by the International Organization of Weights and Measures in many aspects of U.S. legal metrology. In addition, the National Conference of Standards Laboratories will be called upon increasingly (as was the National Conference on Weights and Measures in the past) to serve as a forum for State metrology laboratories serving their industries. Weights and measures has a long history and a bright future. 


\subsection{OWM Mission}

The State Weights and Measures Program provides technical services to ensure accurate and equitable commercial transactions involving quantity measurements and standard weights and measures regulations, procedures, and associated devices used in the 50 States. The Organic Act of the National Bureau of Standards (15USC271) specifically authorizes:

- the testing, calibration, and certification of standards and standard measuring apparatus;

- the study and improvement of instruments and methods of measurements;

- the investigation and testing of railroad track scales, elevator scales, and other scales used in weighing commodities for interstate shipment;

- cooperation with the States in securing uniformity in weights and measures laws and methods of inspection;

- the preparation and distribution of standard samples such as those used in checking chemical analyses, temperature, color, viscosity, heat of combustion, and other basic properties of materials; also the preparation and sale or other distribution of standard instruments, apparatus, and materials for calibration of measuring equipment. chart:

The major functions of the office are delineated on the organization

(1) National Conference and Training. The Office of Weights and Measures (OWM) sponsors the National Conference on Weights and Measures (NCWM), a voluntary organization of weights and measures officials who meet annually to study and resolve weights and measures issues. The keys to the weights and measures system in the U.S. are cooperation and communication. Thus, a major part of this function is the facilitation of communication and information among the individual regulatory jurisdictions and NBS. The Metric Conversion Act of 1975 specifically requests the Secretary of Commerce to work with the NCWM to "assure that State and local weights and measures officials are (i) appropriately involved in metric conversion activities and ( $i i)$ assisted in their efforts to bring about timely amendments to weights and measures laws..."

A training program and numerous publications for the NCWM membership are important parts of this program.

One of the most important methods of achieving uniformity in weights and measures is to develop, under the auspices of the NCWM, standardized or "model" regulations with the jurisdictions that must enforce such regulations and industries and the public affected by such regulations. States can then voluntarily adopt such models for their own use and have confidence that such regulations represent concensus standards and will not interfere with interstate commerce. These model regulations are studied and updated or added to annually by the IVCWM. 
(2) Technical Services for States. Major outputs of the NCWM are Handbook 44 "Specifications, Tolerances and Other Technical Requirements for Commercial Weighing and Measuring Devices"; Handbook 112 "Examination Procedure Outlines for Commercial Weighing and Measuring Devices", and other technical handbooks, memoranda, and procedures. These publications are updated annually by the NCWM with technical advice from OWM. NBS publishes these documents for the NCWM. OWM provides interpretations and other consultation on them and the devices to which they pertain on a daily basis. OWM also provides evaluations, on a cost recovery basis, of new device designs with respect to the performance standards contained in Handbook 44. Test procedures and techniques are developed for such devices through this program.

(3) Technology Transfer. The OWM provides long range program development to identify projected technology needs of the state and local governments and to plan for satisfying of those needs in a timely manner. This technology transfer derives to a large extent from research programs in the NBS centers (see "Interactions"). A technological revolution is now taking place. High speed dynamic measurements using microprocessor control and other sophisticated electronic component systems are becoming common in the marketplace. State weights and measures officials are being faced with certifying the accuracy of scales tied to laser product code scanners and price computers, grain moisture measurement devices, digital readout gasoline pumps, all of which may or may not be electromagnetically or otherwise compatible with their environments.

(4) State Traceability Service. In 1966, Congress appropriated funds to equip the 50 States, D.C., Puerto Rico, and the Virgin Islands with artifact standards and equipment for mass length and volume measurements in U.S. customary and metric units. This program was completed October 1978. An integral part of that program is the continuing technical support provided by OWM in the maintenance and upgrading of State metrologists competence through seminars, workshops, correspondence programs, handbooks and daily responses to telephone and mail inquiries.

Many states are being requested to provide broadened support to their commercial and industrial constituencies.

In order to maintain credibility in these laboratories as traceable to NBS and to prepare them for measurement demands by their local industries in the future, a new Laboratory Auditing Program has been designed.

\subsection{Interactions}

Within NBS: OWM interacts with many technical groups within NBS, providing a delivery mechanism for their work and translating their scientific and technical products into understandable, problem specific responses for the OWM constituency. For example, the artifact standards 
and equipment now in the possession of the States were calibrated by NBS experts. The codes and handbook on LPG vapor and liquid test and equipment were developed in close cooperation with the cryogenics experts at NBS Boulder. The handbook on package testing methods was developed with the Statistical Engineering Division. The methods developed for testing grain moisture meters are being devised with humidity experts at NBS.

Currently, coordination is directed toward development of new technology for laboratory and field use at the State level specifically: (1) a mass comparitor, and (2) fluid meter proving.

The Office of Weights and Measures is developing an increasing programmatic relationship with a large number of organizational units within NBS, particularly those involved in research which might lead to improved and new capabilities for use by States in their laboratory and field activities. These organizations are:

Office of the Director of Administrative and Information Systems

(Particularly Divisions 344 and 346) Development of new MAP computer programs, and conversion of publications to word processing.

Center for Absolute Physical Quantities

(Particularly Divisions 521, 522, and 523) Electrical and temperature calibration services at the State level. Development of mass comparator.

Center for Thermodynamics and Molecular Science (Particularly Division 544) Assistance to States in establishing pressure calibration services.

Center for Electronics and Electrical Engineering (Particularly Division 723) Assisting States in dealing with EMI/RFT phenomena.

Center for Mechnical Engineering and Process Technology

(Particularly Division 732) Need by States for technology to deal with high speed, high quantity fluid measurement and meter proving.

Office of International Relations

participants in visits of foreign weights and measures and standards officials. Conducts annual weights and measures workshops for foreign weights and measures officials.

OWM works with a multitude of businesses and associations (maiting list numbers approximately 8,000), other Federal agencies and departments (including USDA, FGIS, FTC, FDA, DOT, DOD and OIML).

Outside NBS: OWM's constituency are the State and local weights and measures jurisdictions. As a result, there is very close and continuous interaction with reguiatory officials, regulated industries, device manufacturers, service companies, other Federal agencies and the public. For example, packaging and food manufacturers, scale companies, device repair firms, consumer organizations, fabric and grain mills, railroads, 
the U.S. Department of Agriculture, and a host of other groups contact OWM and are contacted by OWM and working with OWM on issues of specific interest throughout the year. Internationally, OWM coordinates U.S. weights and measures input to International Organization of Legal Metrology (OIML) actions. OWM is technical advisor for OIML Pilot Secretariat 7 "Measure of Mass."

\section{Program Activity}

Major resources of OWM are devoted to providing technical leadership to weights and measures agencies and, through them, to their constituencies. In addition to sponsoring the National Conference on Weights and Measures, OWM participates in and addresses all the regional weights and measures association conferences, many State meetings, trade and consumer association conferences and individual industry meetings (see Paragraph 4 of this Section). Daily written correspondence on general and specific weights and measures issues is produced by the staff of OWM. For example, in the category of information, over 800 letters were composed in FY 1980 (see Par. 4.7). In FY 1980, training was conducted involving most of the 50 States and nearly 1500 industry and government officials participating (see Par. 4).

\subsection{Major Objectives}

(1) NCWM: to make legal metrology uniform among the States and local jurisdictions by providing delivery mechanisms for weights and measures technical and standards information, including the adoption of model legislation and guidelines and assisting the States in their metrication activities.

(2) Technical Services for States: to provide technical advice for updating and applying device and user codes, procedures, specifications and guidelines.

(3) Technology Transfer: to promote uniformity in dealing with anticipated new technology by developing new technical procedures, measurement techniques, and devices for use by State agencies.

(4) State Traceability Services: to provide traceability to national reference standards and measurement assurance by providing oversight, evaluation, and guidance to State weights and measures laboratories.

\subsection{Technical Activities}

\subsubsection{Railroad Track Scale Calibration Program}

Operation of the Railroad Track Scale Calibration Program has been transferred to the U.S. Department of Agriculture, Federal Grain Inspection Service (FGIS) as of October 1, 1979. FGIS will assume operation of the NBS Clearing facilities (and master scale) in FY 1981. 
Detailed planning for transfer of the equipment and the clearing facility (and master scale) includes training of FGIS personnel in calibration of large mass standards and establishment of related measurement assurance program.

\subsubsection{Education Programs}

Progress has been made toward establishment of measurement science and practice curriculum at the university level, in continuing education, undergraduate and graduate programs. The primary effort involves NBS, the NCWM, the NCSL, Texas A \& M University, the University of Texas at Dallas, Ohio State University, State officials and business interests. Development of education programs in measurement sciences includes the conduct of a workshop/seminar involving university, industry, Federal, and State regulatory officials and the establishment of an Advisory Council on Education (see Appendix G-1).

\subsubsection{Study of State Needs}

A study of the needs for accurate and uniform physical or chemical measurements at the State level, which derived from Government laws and regulations, has been established and will be conducted with close coordination with State and indigenous industry representatives. The most important and critical factor for planning for the future of OWM is the need to obtain a clear understanding of the evolving weights and measures system (regulatory, industrial and public) in the U.S. and how NBS can plan to maximize its services within such a system. No one knows exactly how the sectors interact from State to State, what methods and legal arrangements are superior, and how such a system should develop or change in the coming years. As a result, OWM reacts to perceived needs without a perfect grasp on where to lead the Nation in the future. A carefully planned and comprehensive study of weights and measures in the U.S. is critically needed. It is difficult to discuss any definite long range plans of the OWM without the information which such a study would provide. The study is scheduled for completion during the next twelve months. The National Measurement Laboeatory is dedicating assistance for conduct of the study augmenting OWM efforts in the weights and measures area. (See Appendix G-2).

\subsubsection{Automating Preparation of Handbooks}

Success has been realized in the use of word processing for the production and updating of OWM publications (Handbook 44, and new Handbook 130 are now in their second editions since the first steps were taken). The 1980 edition of Handbook 44 was updated and published by mid-August (1ess than two months after the changes were adopted by the NCWM). Additional NBS publications (including replacements for Handbook 67, NCWM proceedings, and Handbook 112) wi11 be put into word processing: a 11 wi11 be updated annually as a result of this new capability (Handbook 57 was issued March 1959 and has not been updated since; Handbook 112 was issued in June 1973 and has not been updated since). 


\subsubsection{State Laboratory Programs}

The State metrology program has been redesigned to incorporate measurement assurance techniques and regionalization including computing routines for processing and exchange of state developed data describing the effectiveness of the new techniques and the services delivered by the States (see Appendix G-3).

\subsubsection{Type Approval}

The bilateral agreement between NBS and California in which each recognizes results of prototype examinations conducted by the other (thus avoiding duplicative examinations) and through which California has succeeded in changing state legislation to permit reciprocity with other jurisdictions is working. Currently, the two organizations are working toward resolution of some details which have surfaced in the implementation phase. Plans have been made to develop bilateral agreements with other States and agencies (i.e., FGIS) for conduct of prototype examination of devices.

\subsection{Impact of New Technology}

OWM has several "optimization tasks" underway (see prior pages). Through its portion of the DMS Long Range Plan, OWM is developing a systematic approach to its measurement services and measurement standards which recognizes the revolution in technology now taking place. High speed dynamic measurements featuring A/D conversion and microprocessors are becoming commonplace in industry and in the marketplace. Some weights and measures officials are being faced with certifying the accuracy of scales tied to laser product code scanners and price computers, of digital-readout gasoline pumps and fabric meters, etc., al1 of which may or may not be electromagnetically or otherwise compatible. They look to OWM to provide technical leadership for dealing with these challenges.

The small computer revolution will impact OWM activities in a variety of ways. Data handling for measurement assurance programs via computer networks (already implemented) and centralized data collection and analysis to facilitate uniformity in weights and measures enforcement are only two promising areas where such technological changes could favorably alter the way in which NBS deals with those who need traceability to national standards and those who wish to insure uniformity of national and international measurement standards.

\section{Critical Issues}

Issues concerning the weights and measures system, its ability to anticipate and prepare for satisfying future needs include:

(1) Continuing education as well as new educational programs in measurement practice and science at the undergraduate and graduate level. Concurrent with development of these proarams is the need to revise the staffing and training policies of state and local governments to capitalize on these new opportunities through program planning and budgeting. 
(2) The need for expansion of State weights and measures laboratory capabilities is anticipated. Specific needs will be identified as a result of the "needs" study. In anticipation of new technical demands, State measurement centers interlinking Federal, regional and industrial measurement capabilities are being planned and the Laboratory Audit Program is being redesigned.

(3) A Comprehensive Plan, "Type Approval for Measuring Devices," is being prepared with the NCWM identifying the roles of State and Federal agencies, industry, and others.

4. Activity Summary

4.1. Sponsored Conferences

- National Conference on Weights and Measures Interim Committee Meetings - January 14-18, 1980 - NBS
(1) 6 Committees

(2) 2 Task Forces

- National Conference on Weights and Measures - June 23-27, 1980, Washington, D.C.

\section{Supported Conferences}

- Southern Weights and Measures Association Conference - October 22-25, 1979, Kansas City, Missouri.

- Northwest Weights and Measures Association Conference - March 3-7, 1980, Minneapolis, Minn.

- Northeastern Weights and Measures Association Conference - Apri1 28-30, 1980, Springfield I1l.

- Western Weights and Measures Association Conference - September 8-12, 1980, Juneau, Alaska. 


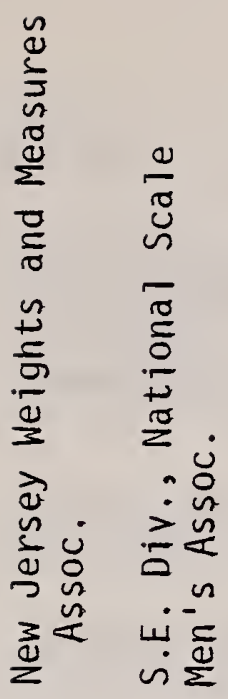

$\stackrel{\frac{0}{4}}{\stackrel{5}{\frac{9}{2}}}$

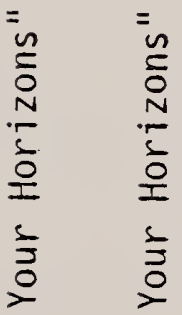

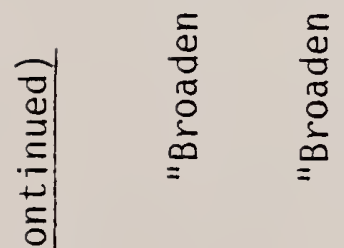

త్ర

章

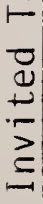

$\begin{array}{ll}\infty & \infty \\ \frac{\infty}{\sigma} & \frac{0}{\sigma}\end{array}$

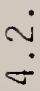




\subsection{Office of Weights and Measures' Publications}

- NBS Special Publication 566 - Report of the 64th National Conference on Weights and Measures 1979, Report Editors Harold F. Wollin, Louis E. Barbrow, and Ann P. Heffernan, Government Printing Office.

- NBS Handbook 130, Model State Laws and Regulations, 1979, and 1980 editions, Government Printing Office.

- NBS Handbook 44, Specifications, Tolerances, and Other Technical Requirements for Weighing and Measuring Devices, 1978 and 1980 editions, Government Printing Office.

- NBS Special Publication (number unknown) - Report of the 65th National Conference on Weights and Measures 1980 , Report Editors - Harold F. Wollin, Louis E. Barbrow and Ann P. Heffernan, Government Printing Office. 
4.4. Seminars

Specifications, Tolerances, and Other

Considerations

Southern Regional Metrology Seminar

Northeast Regional LPG Liquid and Vapor Meter Proving Seminar

Western Regional Metrology Seminar
March 3-5, 1980

St. Paut, Minn.

May 15-23, 1980

Atlanta, Ga.

May 20-22, 1980

Albany, N.Y.

Aug. $10-15,1980$

Denver, Colo. 
General (Laws \& Regulations, Handbook 44, and Test Procedures) Mass. School

General (Laws \& Regulations, Handbook 44, and Test Procedures), Ohio School

General (Laws \& Regulations, Handbook 44 and Test Procedures) Indiana School

General (Laws \& Regulations, Handbook 44, and Test Procedures), Mountain States Regional School

Genera 1 (Laws \& Regulations, Handbook 44, and Test Procedures), Southern Regional

School

General (Laws \& Regulations, Handbook 44, and Test Procedures), NSMA

General (Laws \& Regulations, Handbook 44, and Test Procedures), Western Regional School

Package Checking Procedures, Michigan Training Conference

General (Laws \& Regulations, Handbook 44 and Test Procedures), New Jersey School

General (Laws \& Regulations, Handbook 44 , and Test Procedures), Northern Regional School

General (Laws \& Regulations, Handbook 44, and Test Procedures), Virginia School

General (Laws \& Regulations, Handbook 44, and Test Procedures), Northeast Regional Conference

General (Laws \& Regulations, Handbook 44, and Test Procedures), Ohio School

General (Laws \& Regulations, Handbook 44, and Test Procedures), New York Conference

General (Laws \& Regulations, Handbook 44, and Test Procedures), New York School

General (Laws \& Regulations, Handbook 44, and Test Procedures), New Jersey Conference

General (Laws \& Regulations, Handbook 44, and Test Procedures), Midwest Regional School
September 2-5, 1979

Lennox, Mass.

October 9-12, 1979

Toledo, Ohio

Jan. 14-18, 1980

Indianapolis, Inc.

February 12-14, 1980 Denver, Colo.

February 26-28, 1980 Jackson, Miss.

May 20-22, 1980

Columbus, Ohio

March 25-27, 1980

Olympia, Wash.

May 28-30, 1980

Belleaire, Mich.

Apri1 8-10, 1980

Trenton, N.J.

Apri1 15-17, 1980

Billings, Mont.

Apri1 22-24, 1980 Charlottesville, va.

Apri1 28-May 1, 1980 Springfield, I11.

May 6-9, 1980

Columbus, Ohio

June 9-12, 1980

Niagara Falls, N.Y.

August 4-8, 1980

Morrisville, N.Y.

Sept. 2-4, 1980

Atlantic City, N.J.

Sept. 22-26, 1980

Mitche11, Indiana 
4.6. Technical and Professional Committee Participation and Leadership

Name
Barbrow, L.E. American Society for Testing \& Materials
American National Metric Council

Brickenkamp, C. International Organization for Legal Metrology

Interagency Committee on Net Wt. (members: USDA, FDA, FTC, NBS)

American Institute of Physics American Assn. for the Advancement of Science

American Crystallographic Assn. National Conference on Weights \& Measures (Liaison Committee)

Hasko, Stephen Society of Automotive Engineers, Inc.

American Nat'1 Standards Inst.

Interagency Committee on Net Wt. Compressed Gas Association

National Conference on Weights \& Measures

Oppermann, H. International Organization of Legal Metrology

National Conference on Weights and Measures

Smith, R.N.
National Conference on Weights and Measures
E43 Metric Practice E43.10 Technical SC E43.10.01 Units Sec. Metric Practice Com (Secretary)

U.S. Advisory Com.

U.S. Technical

Advisor on P.S. 18, P.S. 1 Chairman

Task Force on Grain Moisture Measurement

Fuel Supply Systems Speedometer \& Tachometer R109 Gas Displacement Metering

Cryogenic Flowmetering Monitoring Committee Committee on Liaison

Pilot Secretariat 7 "Measures of Masses"; U.S. National Working Group "Scales \& Weighing Systems"

Pilot Secretariat 7 "Measures of Masses"/ Reporting Secretariat 7; U.S. National Working Group "In-Service Exam."

Metrology Workshops

Committee on Education, Administration, and Consumer Affairs 
Tholen, A.D.

Warntof, O.K.

Wollin, H.F.
American Association for the Advancement of Science Operations Research Society of America

National Scale Men's Assoc.

International Organization of Legal Metrology

National Conference on Weights and Measures

Institute of Weights and Measures

International Organization of Legal Metrology

National Scale Men's Assoc. Alfred Tech

American Society of Mechanical Engineers

National Conference on Weights and Measures

International Organization of Legal Metrology

American National Metric Council

National Conference on Weights and Measures
Member of ICLM

Member of Executive Com. of Board of Directors

U.S. Technical Advisor;

Pilot Secretariat 7

Pilot Secretariat 22

Scholorship Committee Advisory Committee

Scale Committee

Committee on Specifications and Tolerances

U.S. Advisory Committee

Weights and Measures Sector Committee Executive Secretary 


\subsection{Consulting and Advisory Centers}

State agency representatives and industry call upon the Office of Weights and Measures' staff on a continuous basis to consult and advise them on general and specific issues in weights and measures. The office of Weights and Measures (OWM) is the consulting center for weights and measures issues, problems, and advice nationwide. An estimated $25 \%$ of the time of the staff is involved in this support service. 
1

,

.

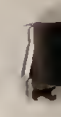

,

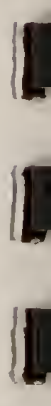

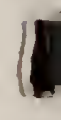

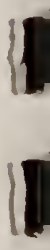

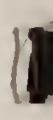

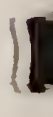

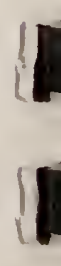

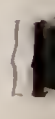

I 



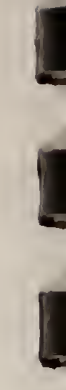




\section{Technical Activities \\ Office of Measurement Services}

\section{Introduction}

\subsection{Mission}

The Office of Measurement Services plays an important role as a coordinator and catalyst within NBS and to a considerable extent within the broader measurement community for resolving issues involving traceability, measurement accuracy, and efficient management of precision measurement and test equipment (PMTE). OMS provides leadership to industry, scientific and technical institutions, and to other Federal agencies with respect to improving their measurement programs. OMS coordinates measurement traceability services for dimensional, electrical, electromagnetic, radiometric, thermodynamic and other measurements.

In discharging these responsibilities, OMS must be fully cognizant of new trends in measurement science such as the proliferation of complex automated testing equipment (ATE), requirements for dynamic rather than static measurements, requirements for new types of measurements (e.g., optical fiber characteristics), the increasing use of microprocessors in "smart" instruments, and new approaches to measurement standards (e.g., Josephson junction voltage standards). Trends such as these will, in the long run, be likely to lead to restructuring of the ways in which NBS disseminates measurement services. By serving on committees, participating in technical conferences, and arranging workshops, etc., the OMS staff strives to maintain a high level of awareness of the direction in which the measurement community is heading and to use this information effectively in working with NBS line management to insure that NBS's services are responsive to the changing needs of the measurement community.

\subsection{Functions}

The principal responsibilities of OMS are:

- To administer the NBS calibration program.

- To manage a program for the development of new Measurement Assurance Program services (MAP's).

- To coordinate improvements in the management and use of precision measuring and test equipment in the Federal Government.

- To develop policies and procedures for MBS Measurement Services.

- To disseminate information on NBS policy on subjects such as traceability, calibrations, and MAP's. 
- To serve as the NBS focal point for key outside organizations concerned with the above issues, such as the National Conference of Standards Laboratories (NCSL), and the Joint Technical Coordinating Group on Metrology and Calibration of the Department of Defense.

An important part of OMS's function is to increase awareness within the technical community of NBS's programs and philosophy in the calibration and measurement assurance areas. In particular, it is felt that the MAP philosophy can be important to a variety of standards writing groups concerned with measurement quality control. Accordingly, OMS places a high priority on disseminating information on the MAP approach to measurement quality by participating actively in standards committees and other groups concerned with measurement quality.

\subsection{Interactions}

The principal interactions between OMS and NBS technical activities fall within the Center for Absolute Physical Quantities (CAPQ), the Center for Electronics and Electrical Engineering (CEEE), the Center for Mechanical Engineering and Process Technology (CMEPT), the Center for Applied Mathematics (CAM), and the Center for Radiation Research (CRR). Joint activities with these centers are described in the sections which follow.

OMS's contacts outside NBS are wide-ranging. The National Conference of Standards Laboratories (NCSL) is the organization that best represents OMS's customers, hence OMS maintains close liaison with the NCSL Board of Directors and with the NCSL membership. The Department of Defense is the largest single user of NBS measurement services. Accordingly, OMS maintains close ties with the DOD calibration community through the Calibration Coordination Group (CCG) and its subgroups. OMS also interacts with the higher level DOD group, the Joint Technical Coordinating Group on Metrology and Calibration (JTCG-METCAL) of the Joint Logistics Commanders. In addition, OMS is represented on the JLC's Panel on Automatic Testing.

The NBS PMTE Project (Precision Measuring and Test Equipment) was formed to coordinate improvements in the management and use of PMTE in the Federal

Government. (A description of the activities of the PMTE Project is given later in this report.) From time to time the PMTE Project provides information to the Office of Management and Budget and the General Accounting Office concerning progress with this activity. The PMTE Project maintains a continuing liaison with the headquarters level people responsible for precisicn measurement and test equipment in other Federal agencies.

Other organizations with which OMS interacts include:

- Voluntary Standards Organizations (ASTM, ANSI, ASOC, OIML)

- Other national standards laboratories (e.g., exploring the "reciprocal traceability" issue with the National Physical Laboratory in England). 
- The Industry/Joint Services Automatic Test Project (IUSATP)

- The Government-Industry Data Exchange Program (GIDEP)

2. Program Activities

2.1. Calibration and Measurement Services

During the past year the administration of the calibration program was reorganized and streamlined. (OMS provides services for processing and control of measurement services orders and records for services offered to the public via publication in NBS Special Publication 250. OMS a1so prepares new editions of SP 250 as needed and publishes regularly updated 1 ists of fees and services as SP 250 Appendices.) These activities were merged to a large degree, with the overall administration of the directorate. The net result is that 4 positions have been replaced by 2 positions. This will result in a more efficient operation and has already resulted in a reduction in the amount of staff time devoted to these activities.

OMS has been developing plans with the NBS management for addressing the issues which were raised in last year's report about termination of services, priority setting, and quality assurance. Although no final proposals have been agreed to at this point, it does appear that a consensus is emerging on the important steps that need to be taken to improve the calibration services. A task force, appointed by $\mathrm{Dr}$. Ambler, recently reported on many of the management issues which they felt needed to be addressed in this area. OMS has been asked by the Director to review the financial status of the calibration programs and recommend action to overcome any financial deficiencies which may be uncovered.

Due to the fact that this document is being submitted for publication before the end of the fiscal year, we do not have the information to complete the calibration activity tables for FY80. We do know that as of the end of August, our income is slightly higher than last year so we anticipate that this will be true for the full year. An estimate is given in the following table:

Calibration Workioad Summary

Total Activity and Income

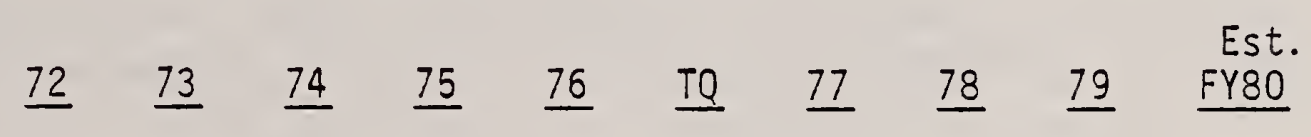

Total Dollars

(Millions)

$1.6 \quad 1.8$

1.8

1.8

2.1

$0.4 \quad 1.8$

1.8

2.1

2.2

No. of

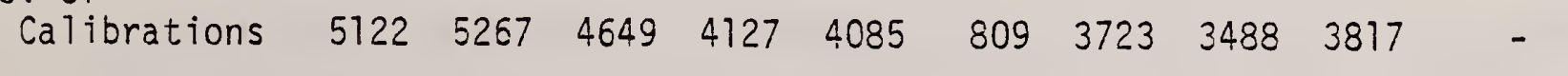




\subsection{MAP Program Development}

As discussed in NBSIR 80-2066 (1ast year's report on DMS activities), there was a significant increase in FY80 of funding for the development of MAP programs. Unfortunately before the new projects could be initiated, there was a "hiring freeze". This seriously affected our plans for FY80 and had its greatest impact on our plans in the area of electrical measurements.

\subsubsection{Policy and Planning}

There have been no changes in OMS policy regarding the priority for development of MAP services for the public. The current services in some cases are operating at capacity so that no new customers can be accommodated. In other cases there have been long delays due to equipment failures and lack of trained personnel. OMS is working with the technical groups and NBS management to see what can be done to relieve this situation. These problems have raised a policy issue which is, "given the constraints on resources what criteria should NBS apply in order to ensure that the customers with the highest priority needs are satisfied". We have not reached any conclusions yet, but we clearly nesd to do more coordinated planning. This issue is not confined only to MAP services but also arises in the area of calibrations.

THE REPORTS ON MAP ACTIVITIES CARRIED OUT IN THE TECHNICAL DIVISIONS WHICH FOLLOW HAVE BEEN EXCERPTED FROM MATERIAL SUBMITTED AS REPORTS TO OMS FOR FY80.

\subsubsection{Statistical Consulting (Center for Applied Mathematics)}

OMS continues to support personnel from the Statistical Engineering Division to assist the technical divisions in developing MAP's, and in addition, they act as consultants on statistical problems which arise in the calibration programs.

Highlights from these activities for FY80 are:

- Publication of NBS Technical Note 1127 "National Bureau of Standards Mass Calibration Computer Software".

- Participation in repeated sessions of a seminar "Linewidth Measurement on Integrated Circuit Photomasks and Wafers," July 15-18, and July 22-25.

- Completion of a section in a report by the Center for Electronics and Electrical Engineering on "Statistical Analysis of Interlaboratory Linewidth Study".

- Presentation of a three-day seminar on "Gage Block Measurement Assurance", May 20-22.

- Report to Orton Foundation on "Improvements in Testing and Production Procedures", after visit by NBS team. 
- Completion of a prel iminary report to Army and Navy on Measurement Assurance Program for the Calibration of Bolometers.

\subsubsection{Electrical Measurements (Center for Absolute Physical Quantities)}

The Electrical Measurements and Standards Division's programs have been under severe stress during the past fiscal year as the reductions due to the 1978 Zero Based Budgeting. Decisions became effective this FY and much of the staff's time has been taken in training people to assume the duties of those leaving. Following are status reports on milestones for this fiscal year:

- Completion of facility for testing 10-volt reference standards: This facility is completed and is making measurements at the 1-2 ppm uncertainty level. Recent work has resulted in the identification of problems whose el imination will make sub-ppm level measurements feasibie.

- Completion of Technical Note on Voltage MAP's: Incomplete. Deferred until 1981.

- Installation and testing of hardware for automated data collection from customers: Completed early this FY.

- Software for automated data collection: Unlikely to be completed until next FY.

- Adapt Volt Ratio MAP to Scaling MAP: Currently evaluating solid-state voltage standards with which to do this. Staff shortages have delayed pilot MAP attempt until early in FY82:

- Preliminary ac voltage and current MAP's completed and data evaluated. Two transportable standards, each switchable from 25 to 250 volts were constructed and evaluated for this transfer. The evaluation indicated that problems with range resistors caused an insufficiently-flat frequency response to be useful. Due to insufficient staff, the actual transfer will not take place until after the new hire is on board.

- Addition of new groups to regional MAP operations.

- San Francisco initial intercomparison completed; transfer expected in September.

- Two initial intercomparisons done by Second Los Angeles group. The first was a failure. After coaching, a second comparison was completed satisfactorily. The first transfer will take place in September.

- The NY-NJ groups are inactive.

- A new group has been formed in the Portland area and given software.

- Techniques for extension of volt transfer interval: The analysis of data indicated the initial L.A. group could go as long as five years between transfers if a suitable means for them to intercompare could be found. After an intercomparison with Zener diodes failed to give adequate 
precision, the decision was made to interchange check standards. The exact details for this have not been worked out, but the group plans another transfer in the fall. They will implement a plan subsequent to that.

In addition the following have been accomplished:

- A least-squares analysis program has been adopted for use in analyzing Volt Transfer Program data.

- A $16 \mathrm{kw}$ electron-beam power supply was installed to support simultaneous and independent operation of three sources in the thin-film facility in order to support Josephson device production. The $K 50$ thin-film system was modified from sputter to multiple-hearth electron beam vaporization to fabricate lead-alloy junctions.

- Successful lead-alloy Josephson devices were fabricated.

- An etchant for lead but not its indium gold alloy was developed.

- The problem of matching the resoriance frequency of a junction to a fixed microwave source frequency was solved.

- Junctions were fabricated for all commercial voltage standards.

- The first commercial standard was delivered after acceptance testing here.

- A contract will be let to E. Williams for a definitive tutorial publication on ac voltage and current measurements.

\subsubsection{Temperature Measurements (Center for Absolute Physical Quantities)}

As noted in last year's report, the MAP work has been divided into two general areas--thermometry in the range covered by the new EPT-76 temperature scale ( 1976 Provisional $0.5 \mathrm{~K}$ to $30 \mathrm{~K}$ Temperature Scale), and platinum resistance thermometry $(14 K-904 K)$.

These two areas overlap in the temperature range $14 \mathrm{~K}$ to $30 \mathrm{~K}$, but as a practical matter, they involve different measurement technology. The lowtemperature work was introduced into the MAP activity in direct response to requests from the major suppliers of cryogenics equipment and thermonetry. They have asked NBS to establish a program by which their calibration services can be based on the new international temperature scale for crvogenics.

The platinum resistance thermometer work involves the provision of a costeffective calibration program for standard platinum resistance thermometers (SPRT) for the laboratories making measurements at the most accurate level, and assistance to industry in setting technically sound standards for less-accurate industrial platinum resistance thermometers (IPRT's). 
Within the Temperature Division, the two projects are tied together by a common interest in the development of automatic data acquisition equipment for calibration, and by a common need for cost-effective calibration methods which provide adequate accuracy to the user. The computer-based data acquisition system is under development in the low temperature laboratory, but it will serve the MAP work throughout the whole range of temperature covered in this report. work.

The following paragraphs review the accomplishments of the past year in MAP

\subsubsection{Low Temperature MAP}

\section{Cryostat}

Preliminary runs prior to FY80 revealed serious problems with the performance of the EPT-76 cryostat. During the first quarter of FY 80 improvements were made to the radiation shielding of the cryostat, and an extensive experimental run was performed during which time intercomparison data were obtained on ten germanium resistance thermometers (GRT), 2 platinum resistance thermometers (PRT), one rhodium-iron resistance thermometer (RIRT), one platinum-cobalt resistance thermometer, and 2 superconducting fixed point devices. The cryostat was found to operate successfully over the EPT-76 range of $0.5 \mathrm{~K}$ to $30 \mathrm{~K}$, and actually reached temperatures as low as $0.33 \mathrm{~K}$. Further improvements to the cryostat are expected to be only minor ones, and are contemplated mainly to make its operation more economical.

- Data Acquisition System

An analysis of the above described intercomparison data, begun during the second quarter of $F Y 80$, revealed that some serious problems stiil existed in the hardware and software of the data acquisition system and in the desion of the experiment. As a result FY80 Milestones were delayed.

Efforts during much of FY80 were directed at identifying and correcting the problems that still existed in the data acquisition system. In addition, the system was expanded to improve overall efficiency.

- Realization of EPT-76

- Two calibrated GRT from the above intercomparison experiment were loaned to a typical (NBS) user. Over the temperature range of interest, $0.33 \mathrm{~K}$ to $0.67 \mathrm{~K}$, the agreement of the two GRT was a iways within $0.7 \mathrm{mK}--$ much better than the desired resolution for the experiment of one percent. In addition to these results, NBS participation in the experiment provided some insight into the problems of resistance thermometry measurement encountered by the typical user. 
- A paper was submitted to the 1980 Comite Consultatif de Thermometric meeting which reported on findings on the statistical smoothness of the EPT-76 scale by analyzing data from five calibrated GRT's.

\subsubsection{Platinum Resistance Thermometry}

The platinum resistance thermometry MAP work is concerned with two measurement accuracy ranges: (a) SPRT' $s$, which are the standard instruments of the IPTS-68 in the range -259.34 to $630.74^{\circ} \mathrm{C}$, with which accuracies of $+1 \mathrm{mK}$ can be achieved over most of the temperature range; and (b) industrial PRT' $\bar{s}$ which are used from -200 to $1000^{\circ} \mathrm{C}$. The accuracy of industrial PRT's depends largely upon the design and temperature range of use. Also, the thermometry experience of the staff of different companies varies over a broad range; those with little experience require considerable consultation help.

There are many laboratories (possibly 24) in the United States that calibrate SPRT's at accuracy levels of $0.01 \mathrm{~K}$ or better. Their temperature standards are based on SPRT's calibrated at the NBS. The SPRT-MAP work in progress was developed principally for this group. Thus far, fourteen laboratories have participated in the program; two have participated twice.

The recently initiated IPRT-MAP work requires considerable development. First, systematic information must be obtained on the performance of industrial PRT's, and then sufficiently stable thermometers must be obtained for the MAP work. In addition, the staff members that are involved in industrial thermometry have relatively less training in metrology than those involved with SPRT's. Hence, more consultation time is required. Because of the recent increase in the number of thermometer manufacturers there are now about 24 companies that are interested in the ASTM round robin work.

During FY80 the SPRT-MAP, which has been in progress for a number of years, was provided to the Travenol Laboratories, a pharmaceutical manufacturing company where temperature control is highly critical in its processing operations. Before the SPRT's were shipped to the company for the MAP measurements, their personnel visited the NBS. They were provided consultation on how to maintain internal measurement assurance and documentation using check thermometers and reference SPRT's calibrated at the NBS. Their documentation process was reviewed before shipping the SPRT's to them for the MAP comparison. The results were well within the $\pm 0.01^{\circ} \mathrm{C}$ accuracy that was desired.

There are at present two laboratories waiting for the SPRT-MAP service. Although this will be the second time for one of the latoratories, the principal staff had changed since the first MAP. The new staff could not find the results of the first MAP so a copy will be sent them. Telephone consultation (so far on three occasions) has been given them on the thermometry MAP.

The above experiences showed that the thermometry MAP concept paper under preparation must reach an audience of broad range of training in thermometry. The paper will cover not only the principles but also details of measurements and documentation. 
The IPTS-68 is based on fixed points, interpolation instruments, and interpolation equations. The available data suggest that different SPRT's that meet the IPTS-68 specifications agree between the fixed points within about $1 \mathrm{mK}$ above $0^{\circ} \mathrm{C}$ and within about 2 or $3 \mathrm{mK}$ below $0^{\circ} \mathrm{C}$. An apparatus is now partially assembled for comparison of SPRT's in the range 90 to 900K. The work has been dormant for several years. If time permits, efforts will be made during FY81 to complete the assembly and test the apparatus for performance. When the apparatus becomes operational, it will be suitable also for automatic comparison calibration of thermometers using computer controlled measurement techniques.

There is very little systematic information on the performance of industrial PRT's. They are designed to be more rugged than SPRT's in exchange for lower stability and accuracy than the SPRT's. The instability arises from several design features of industrial PRT's. Since metal instead of glass is used for the thermometer sheath, the user often handles the thermometer without adequate care and causes the calibration to change or even causes the thermometer to fail. Measurements with metal sheathed thermometers that are out of calitration because of severe "bumping" is known to be not uncommon.

As part of the ASTM round-robin measurements to determine how well different industrial standards laboratories are able to test industrial PRT's according to the ASTM E-644 resistance thermometer test standard, the circulation of stainless steel sheathed SPRT's was started. However, it was found after recalling the SPRT's when measurements were obtained by four laboratories that the calibrations of all of the SPRT's had changed more than that allowable for suitable evaluation of the measurement process. Although many more NBS measurements will be required, the SPRT's are now being shipped "back and forth" between the NBS and the participating laboratories. This procedure will permit immediate evaluation of the measurement data of a laboratory.

To determine whether the thermometer assembly design causes the results to scatter, a number of thermometer elements have been obtained. They will be mounted inside fused silica sheaths. If these PRT's prove to be adequately stable they will be used for industrial PRT-MAP.

\subsubsection{Spectrophotometry Measurements (Center for Radiation Research)}

MAP activities of the Radiometric Physics Division for FY80 will be reviewed in the following three categories of activity:
a. general study,
b. new MAP transport package development, and
c. dissemination.

- General Study (for keeping up with recent methods, regulations, and needs)

Staff members have attended the Surface Analysis Workshop, the Precision and Accuracy in Measurement and Calibration Workshop, the Optical Radiation measurement seminar and the Topical Conference on Basic Optical Properties of Materials. The second draft of "Measurement Quality Control and the Use 
of NBS Measurement Assurance Program (MAP) Services" by Dr. B. C. Belanger, is being circulated among staff members.

Staff members have participated in several committee and technical meetings, such as: American Society for Testing Materials Committee E-12 on Appearance (diffuse reflection and retroreflection), Comittee D-01.26 on Optical Properties (diffuse reflection and retroreflection), Committee F-22 on High Visibility of Materials (retroflection), Inter Society Color Council (diffuse reflection), Council for Optical Radiation Measurement (diffuse reflection and retroreflection), and International Commission on Illumination Technical Committee TC-2.3 on Methods of Measuring Photometric Characteristics of Materials (diffuse reflection and retroreflection).

Due to 7 imited travel funds, only four laboratories have been visited: $3 M$ Co. (retroreflection and diffuse reflection), Graphic Arts Research Center (diffuse reflection). Hunter Labs. (diffuse reflection and retroreflection), and Gardner Lab. (diffuse reflection and retroreflection).

- New MAP Transport Package Development

- Retroreflectance CIL MAP

The retroreflectometer has been completely characterized. Candidate materials (high intensity beaded sheetings and cube corners) have been measured for temperature $\left(15^{\circ} \mathrm{C}, 24^{\circ} \mathrm{C}\right.$, and $\left.32^{\circ} \mathrm{C}\right)$ and pressure $(25,30$, and 37 inches $\mathrm{Hg}$ ) effects. High intensity beaded sheetings have also been studied under several different incident and observation angles. The studies for the engineering grade sheetings and cube corners are delayed due to a fatigue problem that developed in one of the detectors. We have purchased a new detector and are waiting for the delivery of the detector mount. These studies are to be completed at the end of FY8O.

The color filters to be used as part of the MAP package to check spectral accuracy are being polished by the optical shop to our specifications. The filter holders have been designed by us and the ma in shop has completed the construction. Due to the delay in the delivery of the color filters and in their polishing by the Optical Shop, the transmittance measurements of these filters will be delayed three months.

- Diffuse Reflectance MAP

The diffuse reflectance package will contain one set of neutral density filters and two sets of reflectors. The reflectors (porcela in enamel on steel) have nominal reflectance of $87,65,35,10$, and 2 percent, and one black glass for $45^{\circ} / 0^{\circ}$ reflectance measurements. Two sets of these reflectors have been measured in the visibie spectral region and bi-directional reflections have been investigated. 
Several sets of neutral density filters have been polished to our specification by the Optical Shop. Special filter holders have been designed by our staff members and the NBS Shop has completed the construction. Measurements of these filters are delayed due to limited staff. Thus, the completion of the Diffuse MAP Package will be delayed three months.

- Dissemination

A paper, "Reflectance Properties of Pressed Tetrofluoroethylene Powder", has been presented at the Topical Conference on Basic Properties of Materiais held at NBS in May 1980. The surmaries of this paper are also published in NBS SP 574 "Basic Optical Properties of Materials, Summaries of Papers". Some of our other publications directly or indirectly relating to MAP activities during FY80 are:

- "The NBS Reference Retroreflectometer", App1. Opt. 19(8), 1253, 1980.

- $\quad$ "Photometry and colorimetry of Retroreflection: State-of-Measurement Accuracy Report", NBS Tech Note 1125, July 1980.

- "NBS Specular Reflectometer-Spectrophotometer" App1. Opt. 19(8), 1268, 1980.

- "Didymium Glass Filters for Calibrating the Wavelength Scale of Spectrophotometers--SRM 2009, 2010, 2013, and 2014", NBS SP 260-66 (October 1979).

An article about planned MAP activities has been published in the Optical Radiation News, NBS April 1980.

2.2.6. Microwave Power (Center for Electronics and Electrical Engineering)

FY80 plans for the RMAP in coaxial bolometric power featured a strong beginning toward an internal MAP for the NBS microwave power calibration systems. Also, we expected to design an initial round-robin with RMAP participants and circulate the transfer standard bolometers.

Significant progress was made on instituting our internal microwave power MAP. Using primarily the data from measurements on the bolometers lised in the DOD MAP, we were able to obtain estimates of the long-term random variations for both the coaxial and waveguide measurement systems. As more data are obtained, these estimates are being updated and the Statistical Engineering Laboratory is designing new experiments to yield more information. While a good start has been made, much remains to be done. Check standard bolometers for all bands have been purchased and are in use with our present systems. The design employed will be applicable to the new dual six-port systems.

The circulation of transfer standard bolometers to the RMAP participants will not be done this fiscal year. Rather, a trip to the west coast is planned 
to visit three or four of the participant standards laboratories. These visits are necessary in order to adequately design the initial measurement procedure to be followed by the participants and to explain more as to what they can expect from a MAP.

The MAP's with the DOD primary standards laboratories have not progressed as fast as we had hoped. For example, data from the Army and Navy coaxial bolometer initial round was received at NBS in October 1979, but the reports have not yet been issued. The delay was due in part to the need to measure the MAP bolometers on at least three occasions at NBS before beginning the analysis. These were completed by the end of April 1980, and the anaiys is by SEL waS completed a short time later. However, SEL people have not released the report because they would like it reviewed by their counterparts at NBS Gaithersburg who have had more experience with MAP's.

The Air Force 10-1000 $\mathrm{MHz}$ second-round MAP report was delayed to allow at least three measurement occasions on the MAP bolometers at NBS. The report has been sent to the Air Force and the instructions for the second-round $1-18 \mathrm{GHz}$ coax MAP are being written.

\subsubsection{X-Ray Radiation Exposure to $150 \mathrm{KeV}$ (Center for Radiation Research)}

Ionizing radiation of this type for medical diagnostic purposes represents the largest, by far, source of exposure to the general public of man made radiation. The states by and large are responsible for regulating these exposures. A well-developed measurement system traceable to national standards does not exist throughout the states. It is the objective of this project to determine if a highly leveraged regional measurement assurance system can work.

Activities in this project involve two categories: The Radiation Fhysics Division will identify and characterize ionization chambers and associated electrical equipment to be used as transport standards for the proposed measurement services. Due to the hiring freeze, this part of the project was delayed. Toward the end of the year a person was reassigned to this project and plans have been developed for FY8I.

The second part of this project for FY8O is a survey of industrial and other secondary laboratories to determine their needs for measurement assurance services. This survey was conducted by the Office of Radiation Measurements.

\subsubsection{Force Measurements (Center for Mechanical Engineering and Process Technology)}

A Customer Data Base is being developed. The objective is to develop, for each customer, a hard copy file of essential technical data about the customer's use of the service we provide. This should include a descriptive identification of the systems that we calibrate, a description of the loading conditions and the environmental conditions, and a statement of the performance requirements of the customer's application. Input to this data base has come from numerous telephone calls and from conferences with visitors and guest workers in our lab. 
NBS staff have met with representatives of Boeing, Hydril Corp., MTS Corp., Lebow, Sandia, Interface, Alinco, and the Maryland State Police. NBS staff have also met with technical managers who are responsible for force measurement in the national labs of the Netherlands, Italy, France, and Belgium.

The literature about force measurement is not at all well developed. This area has a high priority during FY81. A paper "Inherent Problems in Force Measurement" was presented at the IMEKO Force Measurement Session of the 4th SESA International Conference on Experimental Mechanics in May. There are plans to present a paper at the Instrument Society of America conference next April. An extensive compilation of basic information on force measurement in loose leaf notebook form is being collected. It will not be published in this form although it will be very useful in writing papers, developing workshops or seminar material, and in instructing new employees, guest workers, and others.

A microcomputer based data system has recently been built. It interfaces with the NBS central computer and with CRT terminals that will eventually be located in each force lab. Data can be entered during a calibration, analyzed, and then plotted on the CRT relative to a fitted model and along with the statistical parameters. As the Calibration History Data Base is implemented, the new data will be analyzed in comparison with prior calibration of the same force measurement system. The data system also has a report quality hard copy printer that will eventually produce the complete calibration report.

Some force measurement systems are so severely resolution limited that the use of ordinary statistical methods can be misleading. A resolution limited condition may or may not be apparent from a remainder plot of the data relative to an assumed model. Cliff Spiegelman of the Center for Applied Mathematics has been developing statistical methods that would appropriately describe the response of these systems.

The micrometer screws ordinarily used to indicate the deflection of proving rings are severely resolution limited and inefficient to use. What is needed is a self balancing, machine readable, electronic deflection sensing system. A few years ago, James Whetstone (Fluid Engineering) made a significant start in developing an LVDT/ratio transformer system that would probably do the job. This equipment has recently been transferred to the force lab arid the project will continue.

There are important customer needs for the in-place calibration of larce capacity (greater than 1,000,000 lbf) special purpose force machines. NBS provided the necessary compression transfer standards and assisted on-site in the calibration of a 4,000,000 1 bf capacity dynamic force machine at the DOE Mine Safety Lab near Fittsburgh. NBS has been developing plans with the Hydril Corporation (deep oil well drilling equipment) for similar on-site assistance using our compression transfer standards. The need for this type service (from NBS or some other source) will probably increase. To be able to provide this on-site service, or to provide the necessary calibration support for someone else to provide the on-site service, NBS needs to upgrade its stock of compression transfer standards, and we need to develcp the capability for largeforce tensile calibration and transfer. It may be that an alternate form of Force MAP will be needed for these large-force applications. 
Some conceptual planning has been carried out in anticipation of holding a Force Measurement Seminar, possibiy in eariy FY82. Plans are not far enough along to justify an announcement in the 1981 NBS Precision Measurement Seminar brochure. 


\subsection{PMTE Project}

\subsubsection{Background}

The Precision Measuring and Test Equipment (PMTE) Project is an organizational element of the Office of Measurement Services (OMS). It was established by the NBS in 1978 in response to a request from the Director, Office of Management and Budget (OMB). Its principal responsibilities as assigned by OMB are as follows:

- Assume the lead for coordinating improvements in the Government's management and use of PMTE.

- Assist Federal agencies as necessary to identify areas for improvement.

- Recommend to OMB such actions as are needed to improve the management and use of PMTE.

Additional information on the origin of the PMTE Project is provided in Append ix G-3.

\subsubsection{Objectives}

The principal goal of the PMTE Project is "to improve the effectiveness and reduce the cost of Federal-wide PMTE operations". This goal has been defined by the project as including the following specific objectives related to the coordinating of improvements to Federal-wide PMTE operations:

- To improve the communications and exchange of information (management and technical) among individuals and facilities involved in management or use of PMTE.

- To identify and ga in broad adoption within Federal agencies of particularly effective existing technologies and management techniques.

- To increase use of other agency and/or contractor metrology and ca! ibration capabilities.

- io reduce the growth rate of Federal metrology and calibration facilities.

- To assess the effectiveness of current PNTE programs of other agercies.

- To identify and develop joint plans for addressing the high priority problems or needs common among several agencies.

- To recommend to OMB and the other agencies actions needed to improve the management and use of PMTE. 


\subsubsection{Actions}

In its first two years of operation, the PMTE Project has directed most of its resources toward short-term actions aimed at optimizing existing systems. However, a high priority has also been given to longer term actions which will hopefuliy lead to the development and introduction of new and innovative approaches toward accomplishing the cal ibration function and other management and technical functions related to PMTE management and use.

\subsubsection{Capabilities Catalog}

The second edition of the "Catalog of Federal Metrology and Calibration Capabilities", NBS Special Publication 546 was prepared and submitted for publication. The catalog is intended to encourage cooperation and exchange of services or equipment among agencies. If successful in these areas, it will reduce the growth rate of Federal metrology and calibration facilities. The catalog lists laboratories, their locations, capability, and names and telephone numbers of points of contact. To provide geographical distribution, the laboratories are listed by States, and are also shown on a single map by coded number. This edition of the catalog contains listings on 269 laboratories from the DOC, DOD, DOE, DHHS, DOT, FCC, and NASA.

\subsubsection{Newsletter}

Two issues of "PMTE UPDATE", were prepared and published. This is a newsletter which is distributed to Federal metrology and calibration laboratories, laboratory and staff level managers, and other interested parties throughout the Federal PMTE community, including several U.S. military organizations in Japan, Korea, Okinawa, and Germany. The "PMTE UPDATE" is intended to improve communications within the PMTE community by providing timely information on new developments, publications and meetings, describing successful strategies of PMTE management and use, and by providing a forum for discussing issues of current interest to the community. For example, the most recent two issues included informative articles on:

- Reverse traceability--as implemented by DOE's Oak Ridge facility, the ability to determine which instruments were calibrated with a given standard so that, if the standard is found to be out of tolerance, corrective action can be taken.

- Use of the Government-Industry-Data-Exchange Program (GIDEP). GIDEP provides calibration procedures, failure experience data, and other information for the improvement of quality and reliability and the reduction of costs.

- U.S. Army video tape training program to aid calibration technicians in the proper operation, maintenance, and calibration of equipment and standards. 
- UTtrasonic Nondestructive evaluation--a review of the NBS efforts in this important area with an emphasis on new standards under development.

- Calibration software management--how a Navy facility (Naval Avionics Center) has implemented a program for management of calibration software. Software "certification" can be as important as hardware "calibration" in assuring the quality of automated measurement. The Naval Avionics Center program is described in a publication which is available upon request from that activity.

- A modulation factor standard developed at NBS to support the FAA's requirements for a measurement capability for ILS or VOR navigation systems.

- Changes in NBS measurement services.

- How NCSL is working to develop training programs for calibration technicians. Another article included information on NCSL's efforts in laboratory automation.

- Periodic updating of information on the activities of the PMTE Project, including one article specifically related to the progress of the costeffectiveness studies. Every effort is made to encourage interest in, and participation in, the various activities of the PMTE Project.

- Standards Information Service--an MBS program to provide up-to-date information on standards and standardization activities. This service is based on a reference collection of over 240,000 standards, specifications, test methods, and recommended practices, both foreign and domestic.

The "PMTE UPDATE" has been well received by its many readers, and several have taken the time to send written comments on its benefits to the PMTE community. Circulation was initially just under 600 . It has since risen to approximately 1200 and is still growing. Copies of the two recent issues are provided in Appendix G-4.

\subsubsection{Cost Effectiveness Studies}

PMTE cost-effectiveness studies, sporsored and funded by NBS and conducted by the Raytheon Service Company, were completed in the following two areas:

Feasibility and cost-effectiveness of increasing the use of in-situ calibrations, calibration checks, measurement assurance programs, or other a) ternatives to out-of-service equipment calibrations for measurement quality assurance and control in the Federal government. In this study, successful alternatives to out-of-service equipment calibration were identified. Each alternative was evaluated to the extent possibie, considering the limited availability of cost and performance data, to 
determine the benefits and/or costs of Federal-wide adoption. The executive brief of this study, including its findings and recommendations is provided in Appendix G-5.

- Cost-effectiveness of optimizing calibration recall intervals and algorithms for PMTE. This study examined situations where adjustment of calibration recall intervals for different types of PMTE has improved measurement quality or reduced costs without degrading measurement quality. It also examined the advantages of Federal-wide guidelines for setting and adjusting PMTE calibration intervals. The executive brief for this study is provided in Appendix G-6.

In the performance of these studies, questionnaires were distributed to some 50 Federal activities and 23 Federal calibration facilities were visited

to gather technical and cost data related to the government's management and use of PMTE. Members of the PMTE Project staff accompanied the contractor cr many of these visits and monitored the company's performance throughout the contract.

The results of these studies are expected to point the way towards significant improvements and cost reductions in the management and use of PMTE throughout the Federal government.

\subsubsection{Automatic Test Equipment (ATE) Activities}

Coordinated an NBS proposal and the subsequent establishment of a multiple year NBS/DOD JLC program for evaluating traceability for DOD ATE.

1. NBS (CEEE) work for the last Quarter FY80 involved development of a work plan for calibration/performance verification of several ATE systems of the same type. This work was funded by the USAF MATE Program Office.

2. NBS (CEEE) work for FY81 will be to acquire and characterize recessary portable standards and to carry out the measurement experiments set forth in the plan developed in FY80. This work will be co-funded by the USAF MATE Program office and DOD CCG.

3. NBS work in subsequent FY will be determined by the outcome of the above work.

- Coordinated and served as NBS focal point for NBS (CEEE) work on development of a sensor handbook for the DOD JLC AT Panel. This work was funded by the Army and carred out by Paul Lederer of CEEE.

- Coordinated development of preliminary plans for CEEE (Lederer) follow-on work reiated to the sensor handbook.

- Actively participated in the establishment of the NSIA Ad Hoc Panel on ATE which is chartered to follow implementation of I/JSATP recommendations, monitor the JLC AT Panel activities, and provide advice to the JLC. 
- Actively participated as a panel member and presenter at the first NSIA/JLC annual ATE Program Review.

- Actively participated as the NBS invited representative to the JLC AT Panel. Attended "Autotestcon '79", September 1979, in Minneapol is, Minnesota. This is an international automatic testing conference.

- Participated in the NBS Seminar: "Metrology of Modern Electronic Instrumentation", a seminar which considered the metrology probiems of automated measurement systems. May 13-15, 1980.

Attended an NBS Lecture Series: "Testing Strategies for Complex Electronic Systems", which addressed fault models, testability measures, self-checking circuit design, design for testablity, and self-diagnosing systems. August 11-15, 1980.

\subsubsection{Training}

Cooperated with the NCSL in the development of technician training programs. This is especially important in that training has been identified by several agencies as one of their highest priority problems.

- Participated in an NCSL survey to establish the priority topics for metrology/calibration training.

- Coordinated and developed meetings between NCSL and key NBS representatives to initiate preparation of a course on temperature mea surement.

- Ccoperated with NBS and NCSL efforts to attract college/university interests in establishing metrology education programs.

- Hosted visits of NCSL representatives and faculty members from an academic institution to encourage their adoption of training program objectives.

\subsubsection{Standardization of Calibration Procedures}

During FY80, a project was established to examine and compare differences between multiple procedures written/published by several agencies for the same item, assess the technical and economic significance of the differences, and attempt to estimate the benefits/costs of total or partial standardization. The first phase of this work, which consisted of examination of five procedures for calibration of the Tektronix 475 oscilloscope, was completed and showed that a great deal of technical similarity exists between procedures. The second phase will be a more in-depth look at multiple procedures for several other PMTE items. 


\subsubsection{Standard Terms and Definitions}

The initial draft of a handbook on this subject was completed. It is essentially a compilation of the many terms and definitions currently published and/or used by the Federal agencies. Subsequent issues may only include one standard definition for each term.

\subsubsection{Other Activities}

- Provided assistance to the U.S. Air Force Logistics Command Inspector General's Office in its inspection of the Aerospace Guidance and Metrology Center (AGMC). This effort was mutually beneficial, as it afforded the PMTE Project an opportunity to learn more about particularly effective Air Force PMTE concepts, and resulted in management improvement suggestior:s for the AGMC.

- Assisted the DOT in reviewing the capability and status of FAA and USCG calibration laboratories and facilities.

- Actively participated as a Member of the Executive Steering Group and presenter at the Annual (1980) Worldwide Conference of the DOD Defense Retail Interservice Support (DRIS) Program.

- Actively participated and made a presentation at the annual DOE Calibration Managers Conference, St. Petersburg, Florida.

- Visited several Federal and private sector metrology and calibration facilities:

Department of Defense

Army Metrology and Calibration Center, Redstone Arsenal, AL

Air Force Aerospace Guidance and Metrology Center, Newark, $\mathrm{OH}$

Air Force Tinker Air Force Base, OKlahoma City, OK

Department of Energy

Bendix Corporation, Kansas City Division, Kansas City, MO

General Electric Neutron Devices Company, St. Petersburg, FL

Department of Transportation

National Aviaion Facilities Experimental Center, Atlantic City, NJ

Coast Guard Electronic Engineering Center, Wildwood, Nu

FAA Aircraft Services Base and FAA Depot, OKlahoma City, OK 
National Aeronautics and Space Administration

Goddard Space Flight Center, Greenbelt, MD

Goddard Spacecraft Data Network Depot, Columbia, MD

Private Industry

Lockheed Missile and Space Company, Sunnyvale, CA

Boeing Aerospace Company, Seattle, WA

Rockwell International, Autonetics Division, Anaheim, CA

- As a result of the above visits and other interactions, we identified and/or further verified the following several specific opportunities for improvement in Federal PMTE Management and use:

1. Calibration Productivity--our observations noted a low of 100 actions per person per year to a high of 1300 actions per person per year at facilities having similar although not identical mixes of workload.

2. Average Calibration Time--we saw a range of 0.5 hour to more than 7 hours for the same mechanical item in one case and 0.5 hour to 15 hours in another case involving an electronics item, with less pronounced variations in many more cases.

3. Terms and Definitions--the PMTE terms we are all familiar with just don't mean the same thing to everyone.

4. Calibration Procedures--differences between procedures for the same item appear to be more philosophical than technical in nature.

5. Calibration Intervals--ranging from 90 days to two years for the same model PMTE item.

6. Traceability for Automatic Test Equipment (ATE)--the current concepts for establishing measurement traceability are somewhat questionable.

7. Calibration Training--remains a serious problem. Training is difficult to obtain-Trained technicians are hard to retain.

8. Management Practices--are weak or virtually non-existent at some facilities. Management information is often limited.

- Expanded the PMTE Interagency Group to inciucie representatives from the FCC, DHHS, (PHS), and DOC agencies other than the NBS. Held quarterly meetings of the Interagency PMTE Committee, which afforded policy and planning level representatives of the Federal agencies an opportunity to exchange

information on PMTE problems and successes. These meetings were also used 
to identify and prioritize problems for action or investigation by the PMTE Project. For example:

1. Staff slots for interagency agreements--Most agencies are willing to do work for another agency, but only if the work is accompanied by the additional staff slots required to do it. The staff ceiling for each agency is tightly controlled, therefore, the additional slots may have to be transferred from the benefitting agency. The PMTE Project has identified procedures for transfer of slots, for the duration of the interagency agreement, between the DOD and civil agencies. We are presently attempting to conduct a test case which will involve transfer of slots. The outcome of this test case may well determine the extent to which calibration work can be exchanged among the Federal agencies (carryover from previous year).

2. Need for exchange of management and technical information. In resporise to requests for guidance or information on how "other" agencies and/or the private sector have handled certain problems, the PMTE Project has disseminated documented policy and procedures on the following areas:

-- DOD draft standard calibration label/tag system

-- Army management information system

-- JLC five year plan for ATE

-- Navy "MEASURE" management information system

-- NBS calibration and measurement services

-- Calibration intervals

-- Measurement assurance programs

-- NCSL conference proceedings

\subsubsection{Plans for FY81}

In addition to continuing present efforts (e.g., interagency meetings/workshops, routine updates to the capability catalog, PMTE UPDATE, visits, etc.), the PMTE Project will undertake the following tasks or actions during FY81:

- Reports from the contracted-out cost-effectiveness studies will be coordinated with other agencies, and an action plan for improvement developed. Actions resulting from these studies may include long-term improvements extending over the next 5-10 years.

- Special reports/handbooks will be developed and issued on:

1. Basel ine assessment and progress of Federal agency PMTE programs.

2. Standardization of calitration procedures.

3. Standard PMTE Terms and Definitions. 
4. Guidelines for establishing a calibration program, systematically determining calibration requirements, and intervais, and application of limited calibration, calibrate before use (CBU), etc.

- The capabilities catalog will be further expanded to include the laboratories of other Federal agencies.

- The number of Federal agencies involved in PMTE interagency coordination will be increased to include other agencies having significant PMTE activities. The need for formal chartering of the interagency PMTE Group will be examined in depth. If the need exists, a formal charter will be drafted, coordinated with in NBS and with other agencies, and forwarded for approval/signature at the DOC or OMB level.

- Specific goals (short and long-term) for improvement will be developed and/or updated for each problem or opportunity discussed herein or surfaced during the year (e.g., productivity, intervals, recall, management practices, ATE traceability, etc.).

- A positive feedback or management indicator system will be developed for measuring the effectiveness of the PMTE Project and other agency PMTE programs.

- Recently collected data on variations in average calibration times and calibration intervals will be analyzed and evaluated to provide a better understanding of the variations-- in the hope that both productivity and quality can be improved.

These plaris will be adjusted as necessary and to the extent possible to accommodate the high priority requirements of other Federal agencies which may emerge during the year. 


\subsection{Other OMS Activities}

OMS has been deeply involved in ASTM Committee E-46 on Quality Systems since its inception. (Brian Belanger is Chairman of the E-46.91, the Interface Subcommittee.) E-46 intends to provide guidelines to all of ASTM concerning the incorporation of adequate quality provisions in ASTM standards and test methods. Among other topics, E-46 will be concerned with measurement quality and calibration, and thus, NBS will have an excellent opportunity to contribute to the development of guidelines on measurement quality control that will be widely used.

The ANSI Z-1 Committee on Quality Systems, for which ASQC holds the secretariat, has formed a writing group for quality standards for calibration systems and measurements. This activity is being carried out under the auspicies of the Metrology Technical Committee (MTC) of ASQC. Brian Belanger of OMS is a member of both the standards writing group and the MTC, and Chairman of a Task Group to develop tutorial material for the standard on random errors, systematic errors, and control charts. Both in this activity and in the E-46 work, the role of OMS is to contribute whatever technical input it can directly and to keep interested parties in other parts of NBS appraised of the progress of the work and involve those NBS persons having relevant expertise in this work as appropriate.

Brian Belanger of OMS serves as Chairman of the U.S. Working Group for Reporting Secretariat 6 of Pilot Secretariat 22 of the International Organization of Legal Metrology (OIML). One goal of OMS's involvement in RS 6 is to make the recommendations which it ultimately will develop as consistent as possible with U.S. domestic standards such as those under development in ASQC and ASTM. Additionally, OMS will strive to incorporate the views of key U.S. organizations such as the Scale Manufacturers Association and the Scientific Apparatus Manufacturers Association. During FY80 meetings of the U.S. National Working Group for RS 6 were held and a draft International Document was developed on a consensus basis. This document was presented to the collaborating countries at a meeting in Paris in April. While the U.S. draft generated considerable controversy, it does appear that a document can be developed that will be acceptable to all concerned parties. OMS intends to prepare a revised draft during FY80 incorporating the suggestions discussed at the Paris meeting.

The plan for expanded NBS/ASTM collaboration discussed in last year's report (NBSIR 80-2026) was approved by both NBS and ASTM during FY80 with only minor modifications. NBS staff members from DMS met with ASTM Headquarters Staff during FY80 and several steps have been taken to implement the provisions of the NBS/ASTM agreement. These include:

- Brian Belanger has been working closely with Committee E-28 to obtain their input for NBS planning of MAP's in the force area. Belanger briefed E-28.01 (Calibration of Mechanical Testing Machines and Apparatus) at their June meeting in Chicago and plans for a possible workshop on force measurements are being considered. 
- ASTM awareness of and participation in OIML activities is now much enhanced. Mr. Joseph Palmer of ASTM participated in activities of the U.S. Advisory Committee for OIML during FY80.

- Discussions have been initiated between NBS, ASTM Headquarters Staff, and ASTM Committee leaders to explore alternatives to NBS calibration services.

OMS participated in the NBS/Montgomery County Public Schools Science and Technology Enrichment Program (Belanger and Leedy in FY80). Lecture/demonstrations on measurement standards were made to several elementary schools, junior high schools, and high schools during the school year. This activity will continue in FY81.

Each year OMS publishes and distributes a brochure describing NBS measurement seminars given by NBS technical divisions.

Brian Belanger and Jack Vogt of OMS were asked to represent NBS at the Third NATO Symposium on Quality and its Assurance held in Washington DC on June 2-6, 1980. Discussions which took place during this Symposium indicated that people involved in multinational NATO projects had observed problems associated with measurement discrepancies that may be due to inadequate coordination of National reference standards for highly derived units. For example, in the multinational project to develop the "TORONADO" jet fighter for NATO forces, concerns were noted in areas such as accelerometers, fluid metering, and hardness measurements. This suggests that OMS's efforts to investigate reciprocal traceability as discussed in last year's Panel Report continue to be important. Other commitments prevented any appreciable progress in this area during $F Y 80$, but it is hoped that more attention may be devoted to this topic during FY81.

At the request of the Center for Materials Science, the Office of Measurement Services assembled an interdisciplinary team of NBS personnel to assist the Orton Foundation in reviewing, and if possible, upgrading its measurement quality assurance. The Edwin Orton Jr. Ceramic Foundation, a non-profit foundation located in Columbus, Ohio, provides technical support for the entire U.S. ceramics community, ranging from large corporations to individual hobbyists. Orton manufactures and sells each year approximately 40 million pyrometric cones, a device used to monitor the combined efforts of temperature, time, and atmosphere, in the firing of ceramics. The team assembled by OMS, which visited Orton in April, included people from both NEL and NML. The final technical report to Orton was compiled and edited by OMS and was considered by Orton to be extremely helpful to them in improving its cone calibration and production processes.

OMS also contributed to NBS's EEO/Affirmative Action activities during FY80. Brian Belanger addressed a combined meeting of the Georgia Tech Chapters of the National Society of Black Engineers and the Society of Women Engineers on the Georgia Tech campus in May. In JuTy, OMS arranged to have Dr. A. Esogbue of Georgia Tech (faculty advisor to the NSBE) visit NBS and present a seminar. During his visit, OMS hosted a highlight tour of NBS so Dr. Esogbue would be in a better position to counsel minority students at Georgia Tech regarding careers at NBS. 
OMS continues to be very active in NCSL. OMS staff members participate in a number of NCSL committees (e.g., Kieffer: Measurement Assurance, National Measurement Requirements; Leedy: Education and Training). Brian Belanger was Conference Co-Chairman for the 1980 Workshop and Symposium at the Bureau and the OMS Administrative Staff contributed much to the successful hosting of this meeting by NBS.

\section{Activity Summary}

3.1. Invited Talks

Belanger

ASTM Committee E-28.01 Meeting, Chicago, IL, "Measurement Assurance Program for Force Measurements", June 25, 1980.

Joint Meeting of Georgia Tech Chapters of National Society of Black Engineers and Society of Women Engineers, Georgia Tech University, Atlanta, GA, "An Overview of NBS Research Activities", May 22, 1980.

Annual Meeting, Acoustical Society of America, Atlanta, GA, "Traceability", (panel discussion), April 23, 1980.

Measurement Science Conference, San Luis Obispo, CA, "Measurement Challenges for the $1980^{\prime} \mathrm{s}^{\prime \prime}$, (lead-off talk for panel discussion), November 30, 1979.

Kieffer National Conference of Standards Laboratories, NBS Gaithersburg, "NBS Measurement Assurance Services", (panel chairman), September 22, 1980.

Vogt Third Annual NASA Calibration Workshop, "PMTE Project Update", and "PMTE Cost-Effectiveness Studies", October 17-19, 1979.

Department of Energy Meeting of the Standards Laboratory Managers, "PMTE Project", November 6-7, 1979.

Annual Worldwide Defense Retail Interservice Support (DRIS) Meeting, "Federa1-wide PMTE Program", January 15-16, 1980.

\subsection{Publications by OMS Personnel}

1. "National Bureau of Standards Mass Calibration Computer Software", R. N. Varner and R. C. Raybold, NBS Technical Note 1127, July 1980.

2. "Catalog of Federal Metrology and Calibration Capabilities", K. Leedy, NBS Special Publication 546, September 1980. 
3. "Challenges in Achieving ATE Traceability to NBS", Proceedings of AUTOTESTCON Conference, Minneapolis, MN, B. Bell, M. Souders, B. Belanger, and R. Kamper, September 1979.

4. "Laboratory Performance Evaluation Services of the U.S. National Bureau of Standards", B. Belanger, J. Bryson, and G. Uriano, Proceedings of the Testing Laboratory Performance Evaluation and Accreditation Conference, September 25-26, 1979.

5. "Traceability in the USA: An Evolving Concept", B. Belanger, OIML Bulletin No. 78, page 7, March 1980.

6. "Prospects for a Model Program for Realization of Traceability in Low-Level Radioactivity Measurements", D. E. Edgerly and B. C. Belanger, Proceedings of Meeting of International Commission for Radionuclide Metrology.

\subsection{Technical and Professional Committee Activity}

Belanger Member, ASTM Committee E-46--Quality Systems, (Chairman, Interface Subcommittee, and Chairman, Nominating Subcommittee.

Belanger Member, U.S. National Working Group for OIML Pilot Secretariat 22, and U.S. National Advisory Committee for OIML, (Chairman, Reporting Secretariat 6).

Belanger Member, ANSI Committee Z-1 Writing Group for Standards for Calibrations Systems and Measurements (Chairman of Task Group).

Belanger Member, ASQC Metrology Technical Committee

Belanger Member, Task Group II (Metrology and Calibration of Industry Joint Services Automatic Test Project.

Belanger Member, NCSL Measurement Assurance Committee

Edinger

Member, GIDEP Metrology Committee

Kieffer

Member, NCSL Measurement Assurance Committee

Kieffer

Member, NCSL National Measurement Requirements Committee

Leedy

Member, Special Committee on General Purpose Electronic Test Equipment, Radio Technical Commission for Aeronautics.

Leedy

Member, NCSL Committee on Automatic Test Equipment

Vogt

Invited Participant, Department of Defense Joint Logistics Commander's Panel on Automatic Testing 
Vogt

Vogt

Vogt

Member, Government Advisory Group, GIDEP, (Government-Industry Data Exchange Program)

Member, Steering Group for NSIA ad hoc Committee on Automatic Test Equipment

Executive Coordinating Agent and Member, Executive Steering Group for Department of Defense Retail Interservice Support (DRIS) Program 




\section{Introduction}

\subsection{Background}

During the reorganization of NBS in 1978, Bureau management decided to establish standards coordination offices within each Major Operating Unit (NML, NEL, ICST) as a means of increasing the sensitivity of 1 ine managers and standards participants to external pressures (e.g., OMB Circular Al19, ANSI Service-Fee System, proposed FTC Rule on Standardization, MTN International Standards Code), and as a management tool in disseminating policy and information concerning standardization activities. A high level Standardization Advisory and Coordination Committee was also established, with representation from the MOUs, to bring standards matters, as appropriate, to the attention of the NBS Director and Executive Board.

The Office of Domestic and International Measurement Standards (ODIMS) is the designated NML standards coordination office. ODIMS also manages the responsibilities of NBS in connection with United States participation in the International Organization of Legal Metrology (OIML), and serves as the NML focal point through which support is provided to the Associate Director for International Affairs in the conduct of cooperative scientific programs with other nations.

\subsection{ODIMS Mission}

The Office plans, administers, and actively participates in an extensive program directed towards:

-- Managing assigned NBS responsibilities to represent the United States in the International Organization of Legal Metrology (OIML);

-- Coordinating the NML involvement in domestic and international voluntary standards activities, including maintaining current and complete information on such standards activities, especially as regards the commitment of NAL resources;

-- Coordinating and facilitating NML staff participation in international cooperative scientific and technological programs in support of the Office of the Associate Director for International Affairs; and

-- Supporting, as required, the Associate Director for Measurement Services.

\subsection{Interactions}

In support of the objectives of United States participation in OIML, there is strong liaison with all interested and affected parties including: the National Conference on Weights and Measures; industry associations and private corporations involved or interested in scientific and measuring instruments; and, Federal agencies having legal metrology mandates. Some of 
these interactions are institutionalized through a U.S. Advisory Committee for International Legal Metrology with representation from the interests mentioned above. There is also strong liaison with the national metrology services of the 46 nations who are OIML members.

ODIMS supports and interacts with tasks and programs of NML Centers and Divisions where staff participate in domestic and international measurement standards activities. It establishes and maintains contacts with private sector standards bodies (ASTM, ANSI, SAE, NCCLS, etc.) as appropriate.

In support of bilateral/multilateral programs for cooperation in science and technology, there are interactions with NML tasks and programs to identify and establish appropriate projects, and there is interaction with the various counterpart scientific organizations and institutions of other nations. Contact with the Department of State and with various U.S. Embassies and Consulates is also necessary.

\section{Program Activity}

2.1. Major Objectives

-- Improve U.S. trade opportunities in the scientific and measuring instrument field by removing technical and administrative differences in legal metrology standards, and by promoting the harmonization of U.S. and OIML legal metrology requirements;

-- Improve the management and coordination of iML resources committed to standards activities;

-- Promote and facilitate NML participation in bilateral/multiiateral cooperative exchanges in science and technology in support of U.S. foreign policy objectives and the basic mission of NBS.

\subsection{Technical Activities}

\subsubsection{United States Participation in OIML}

In carrying out the Bureau's assigned task of managing United States participation in OIML, the Office of Domestic and International Measurement Standards plans and directs a variety of activities intended to maintain a strong U.S. presence in OIML. Of priority effort is the development of positions (including preparing and accrediting delegations to OIML technical meetings) which satisfy U.S. interests as regards:

a. the identification of opportunities for U.S. measurement practices to be embodied in OIML International Recommendations;

b. the prevention of impediments to U.S. trade that can result from restrictive technical or administrative requirements in International Recommendations;

c. the development of International Recommendations which accommodate the reality of a decentralized system of legal metrology such as found in the United States (Europeans generally assume a centralized legal metrology system); and, as regards 
d. the development of sound management and administrative policies which will ensure that OIML operates as a viable international organization and that it effectively coordinates its aims and objectives with those of other international organizations (BIPM, ISO, IEC) having similar objectives.

United States presence in OIML is geared to strong technical level participation in almost half of its 200 committees and subcommittees (called Pilot and Reporting Secretariats), that are studying measurement problems and that are preparing solutions to such problems in the form of model technical regulations proposed for adoption as International Recommendations. U.S. participation in OIML generally takes one of three forms:

a. Nation in Charge of a Secretariat

This commits the U.S. to form a national committee to study a particular measurement problem; to develop a first draft International Recommendation on the subject; and, to assume leadership in working with other interested OIML nations to move the draft International Recommendation to final adoption. The U.S. administers twenty-nine (29) such secretariats at present and ODIMS is responsible for organizing and monitoring the progress of the work of these secretariats in behalf of the U.S. Appointing technical advisors to direct the work; assisting in organizing National Working Groups; contacting affected industry groups, Federal agencies, standards bodies, and State and local agencies; translating: of documents; scheduling of international meetings; and, accrediting U.S. delegations to such meetings are typical activities carried out by ODIMS in directing this work.

b. Collaborating Nation Participating in the Work of an OIML Secretariat Administered by Another Nation

This commits the U.S. to active participation in the development of an International Recommendation for a given topic area including attendance at international meetings, commenting on the technical adequacy of prepared drafts, and voting. At present, the U.S. collaborates in the work of approximately seventy (70) such OIML Pilot and Reporting Secretariats. 0DIMS manages this activity by receiving all drafts sent to the U.S. for comment, identifying appropriate technical experts to review such drafts, undertaking translations of documents where necessary, assembling, and coordinating U.S. positions where appropriate, and forwarding such positions to the respective OIML secretariat. When appropriate ODIMS staff play a direct or leading role in reviewing drafts, generating U.S. positions, and in serving on U.S. delegations. When international meetings are scheduled, ODIMS assembles, accredits, briefs and debriefs U.S. delegations to such meetings.

\section{c. National Representative in OIML Plenary Meetings and Conferences}

The U.S. is an active member of the International Committee of Legal Metrology (CIML), the body that oversees and directs the technical program of OIML. Dr. Arthur MCCoubrey, NML Associate Director for Measurement Services, is the U.S. Representative to this body. The CIML meets at least every eighteen months. The actions taken by the CIML do not obligate its members under the OIML Convention. The U.S. also participates as a ful1-voting member in meetings of the International Conference of Legal Metrology, which sets policy for OIML, adopts a quadrennial budget, and 
officially sanctions International Recommendations as final documents. The International Conference meets every four years and its decisions obligate member nations under the Convention. ODIMS oversees the development of U.S. positions to be taken during these plenary meetings. In carrying out these activities ODIMS works with the U.S. Advisory Committee for International Legal Metrology, with the various U.S. technical advisors and interest groups that have provided input to U.S. positions, and with the Department of State.

\subsubsection{Coordinating NML Involvement in Domestic and International Voluntary Standards Activities}

Twenty-three percent of the professional staff of the National Measurement Laboratory (NML) hold memberships in standards-writing activities of national and international organizations, both in the private sector and in government. These memberships are distributed among 62 U.S. (private sector and governmental) organizations and 21 international (voluntary and intergovernmental) organizations. NBS has traditionally been involved in standardization activities for a variety of reasons:

1. Staff scientists recognize standards as important delivery mechanisms for their research programs;

2. Standards committees bring together a core competence of technical and scientific interests from various institutions and segments of the economy that provide NBS scientists and programs valuable external 1inkage; and,

3. Standards organizations recognize the technical strength and objectivity of NBS scientists and actively seek their participation as an important balance between private sector and government interests.

The policy of the Bureau is that participation in outside standardization activities is a decision that rests with line managers (Division Chiefs). Memberships on standards committees must be mission-related and the Division Chief, in approving such memberships, signifies that resources are available for maintaining an adequate level of participation. The role played by ODIMS, therefore, is not one of centrally managing standards committee memberships, but one of supporting NML management through the following means:

1. Assessing the impacts of proposed external standards programs and policies and recommending NML responses to such initiatives;

2. Maintaining a complete and accurate data base on standards committee assignments within NML;

3. Maintaining contact with standards organizations of importance to NML programs; and,

4. Providing advice, as needed, to IML managers and participants on standardization matters. 
2.2.3. Supporting Bilateral and Multilateral Scientific and Technological Programs for NML Cooperation with Foreign Institutions

As the principal scientific and technical measurement laboratory in the United States, NBS is highly regarded both nationally and internationally for its competence, mission, and accomplishments. Much of NBS' good reputation internationally comes from active staff participation in international programs and forums. Benefits of these activities accrue to NBS and its staff through associated development of strong individual and institutional relationships and thereby strengthen NBS' national and international role in standardization.

International activities of NBS and the staff can be roughly categorized as follows:

- International Organizations. NBS staff widely participate in international topical conferences, meetings of scientific and technical organizations, and standards-writing organizations. Personal contacts in these forums often lead to frequent direct communications, visits, and collaborative working arrangements. At NBS, the Guest Worker Program facilitates long-term collaborative work assignments for foreign scientists and engineers.

- Bilateral and Multilateral Agreements. On behalf of the United States, the State Department maintains bilateral agreements and multilateral treaties in science and technology with many nations. NBS participates in several of these arrangements that afford international contacts for the staff. For example, NBS is the designated representative of the United States in the Treaty of the Meter that has more than 40 other member nations as signatories. Bilateral scientific and technical agreements in which NBS has actively participated include those with Canada, Japan, France, Germany, Italy, the United Kingdom, Australia, Mexico, Spain, and Brazil. NBS represents the United States in the U.S./U.S.S.R. Working Group for Metrology which comes under the broad agreement in science and technology between the U.S. and the Soviet Union. Recently, a bilateral agreement in metrology was signed by the U.S. and the People's Republic of China and is expected to call forth specific activity by NBS and counterpart PRC institutions. Bilateral agreements are under negotiation individually with Yugoslavia and Hungary. The Yugoslav agreement is expected to strengthen and expand existing cooperative programs between NBS and Yugoslav institutions.

- Technical Assistance. Other agency support has been given to NBS by the Agency for International Development (AID) for infrastructure development in standardization for developing countries. In particular, AID has funded NBS programs for conducting workshops, surveys, seminars, and training in standardization for representatives from developing countries. Standards institutions in Korea and Brazil supported by AID funding have sought and obtained long-term training assignments at NBS. ODIMS, in cooperation with the Egyptian National Institute for Standards (NIS), has developed an NBS proposal to AID for assisting NIS over a 5-year period beginning in FY 81 .

- Grants. NBS has taken the opportunity to seek and apply funds under the Special Foreign Currency Program (SFCP; PL-480). These funds have been used in several countries to support projects that complement or supplement ongoing programs at iABS. To date, SFCP projects have been established in Egypt, India, Israel, Pakistan, Poland, and Yugoslavia. Funds are no longer available in Israel, Poland, or Yugoslavia but bilateral agreements have succeeded the SFCP in all three nations. ODIMS was instrumental in establishing 5 new IIBS/SFCP projects in Egypt during 1979. 
The NBS Associate Director for International Affairs has administrative and oversight responsibility for the whole range of foreign relations activities of the Bureau staff. ODIMS mainly provides assistance to NBS Management and staff in developing and coordinating bilateral and multilateral programs of interest to NML scientists and programs. Most of these programs generally require negotiations both within the United States and in other countries. Within the U.S., the State Department and other Federal agencies are often involved. In other countries, counterpart governmental agencies and scientific and technical institutions need to be consulted. Centralized staff support for NML in ODIMS provides an efficient and effective means for maximizing benefits to NBS through such agreements. Sometimes circumstances will dictate that it is more appropriate to involve NML staff outside ODIMS in establishing foreign agreements; however, ODIMS must still maintain pertinent information on Bureau policy and internal resources for guiding effective negotiations. Other important services of ODIMS in this regard are in putting together proposals for both grants and other agency funding for foreign assistance programs.

3. Highlights for FY 80

\subsection{USA Participation in the International Organization of Legal Metrology (OIML)}

\subsubsection{Sixth International Conference of Legal Metrology}

The Sixth International Conference of Legal Metrology was held June 16-20, 1980, in Washington, D.C. with the United States as host government.

Of the 46 member nations of OIML, 34 sent delegations. Three corresponding member nations and fourteen international organizations were represented by observers. Additionally, Canada and the People's Republic of China, who are in the process of joining OIML, sent delegations to observe. The United States delegation consisted of the following persons:

Dr. Edward L. Brady, NBS, Head of Delegation

Dr. Arthur 0. McCoubrey, NBS, USA Representative to CIML

Mr. David E. Edgerly, NBS, member

Mr. Charles H. Vincent, NCWM, member

Mr. Daryl Tonini, Scale Manufacturers Association, member

Mr. Frank Lancetti, State Department, member

From a business standpoint, the Conference reached agreement on ail of the major points of its agenda. Discussions were for the most part meaningful, to the point, and free of "political" overtones. The International Bureau of Legal Metrology (BIML), as secretariat of the Conference, and the various member nation delegates, seemed very well pleased with the physical arrangements and with the social amenities provided by the United States as host country.

The objectives of the USA delegation were not fully realized in the results of the Conference. There were disappointments in not being able to resolve technical problems in the standards dealing with fluid meters and fiuid metering systems and with high speed weighing systems used in packaging processes for a wide variety of commercial products. As a result, these standards were approved 
by OIML with technical requirements different from USA practices and serious enough to result in trade problems. NBS in concert with industry is continuing efforts to ameliorate these technical problems and is hopeful that compromises can be found. It is clear, however, that the USA is still somewhat disadvantaged in OIML because of the unanimity with which Common Market members speak on technical matters. Experts from the nine countries of the EEC (the same experts that sit as country reps in OIML) meet often to discuss and resolve measurement problems as part of the Common Market technical directives program designed to foster free trade within the Community. Because there are only nine nations as opposed to 46 in OIML, the EEC can generally move quickly in resolving problems and we frequently face situations in OIML where EEC countries are unwilling to listen and accept technical solutions to measurement problems because a different solution has already been decided within the Community. Accordingly, the United States is forced to negotiate technical problems on two fronts - within OIML and, indirectly as mentioned above, within the Common Market. Progress is being made, but it wi 11 require continued, strong pursuit of technical objectives by NBS in concert with private industry.

\subsubsection{USA Initiative on Electronics}

In July 1980, the United States circulated within OIML a first pre-draft International Recommendation on Electronic Weighing Devices. The draft was developed within a relatively short time frame in order to take advantage of the opportunity presented by the inability of the EEC to resolve differences of opinion regarding the need for requirements pertaining to the "self checking" of electronic devices. The OIML draft now being circulated for comment resolves the issue of "self checking" in the following manner:

"General Provisions for Metrological Integrity

Electronic weighing devices or main elements shall have the metrological integrity required for the use to which they are intended. This integrity may be achieved by one of the following methods:

- By a design and construction that will result in devices and elements which conform to requisite standards of performance which can be predicted by means of tests specified in this recommendation.

- By incorporating checking facilities in the device or element which will detect and indicate a lack of metrological integrity, as verified by means of tests specified in this recommendation.

- By a combination of these methods.

The choice of one of these methods is left to the applicant."

The underlying principle is that whether or not an electronic element contains a self checking device or devices, the element or weighing device shall be tested in like manner and under identical conditions. It is hoped that this approach will be successful within OIML and will eventually be accepted as the basis for an EEC Directive. A meeting of the OIML International Working Group on electronic weighing devices will be held in Paris in March 1981, to review the proposed International Recommendation. It is expected that representatives of the EEC will take an active part in that meeting. 
3.1.3. Approved Work Plans for OIML PS17 - "Measurement of Pollution"

As the secretariat nation responsible for both PS17 on pollution and for PS20 on prepackaged products, the United States submitted proposed work plans for both secretariats to the International Committee of Legal Metrology (CIML) during its meeting in Washington this past June. Both work plans were accepted by the CIML.

PS17, on pollution measurement, will consist of the following Reporting Secretariats:

RS 1 - Measurement of pollutants in air

RS 2 - Measurement of pollutants in water

RS 3 - Measurement of radionuclide radiation

RS 4 - Measurement of pesticides and toxic substances

RS 5 - Measurement of noise pollution

The U.S. Environmental Protection Agency (EPA) will establish and manage the National Working Group responsible for operating the Pilot Secretariat. RS 1, dealing with air pollution, will be the responsibility of the Federal Republic of Germany which also has responsibility for the ISO air pollution secretariat (ISO/TC146). RS3, dealing with radiation, will be the responsibility of the United Kingdom. Responsibility for the other Reporting Secretariats has not yet been decided. The first Pilot Secretariat 17 International Working Group meeting will be held April 7-10, 1981, in Paris, at which time all interested OIML member nations and a number of liaison international organizations involved in the pollution field will get together to discuss priorities of activity within PS17. The work is considered to be of extreme importance to many OIML nation governments who are now involved in establishing performance standards for pollution monitoring instrumentation.

PS20, on prepackaged products, will consist of the following Reporting Secretariats:

RS 1 - Information on package labels

RS 2 - Metrological assurance of package quantity of contents declarations.

The U.S. National Working Group, which will be responsible for operating the pilot Secretariat, is in the process of being established by ODIMS. It will consist of representatives of FDA, FTC, USDA, State and local weights and measures officials, and private industry. RS 1, dealing with package labelling requirements, will be the responsibility of the Federal Republic of Germany. RS 2, dealing with methods for determining the accuracy of net quantity of contents declarations through statistical sampling means, will be the responsibility of Switzerland. The Swiss have just circulated a draft OIML International Recommendation on statistical sampling of prepackaged products. This draft will be reviewed by the United States and by other OIML member nations. An international meeting to discuss the draft will probably take place in 1981 . 
3.1.4. Draft OIML International Recommendations Reviewed by the United States During FY 80

Secretariat

PS4/RS 1

PS4/RS3

PS4/RS5

PS4/RS5

PS4/RS7

PS5/RS13

PS5/RS13

PS5/RS13

PS7/RS4

PS7/RS5

PS7/RS5

PS8/RS5

PS10/RS2

PS11/RS4

PS11/RS4

PS11/RS4

PS11/RS7

PS13/RS7

PS21/RS1

PS21/RS2

PS21/RS4

PS21/RS5

PS22/RS1

PS22/RS2

PS22/RS5

PS23/RST

PS23/RS2
Title of Document and Responsible Nation

End Standards of Length (USSR)

Instruments for Measurement of Length (France)

Hierarchial System for Angle Measuring Instruments (Poland)

Methods of Reproduction and Transmission of Plane Angle Units (Poland)

Geometric Metrology Dictionary (Poland)

Meters for Liquids (other than water) with Measuring Chambers (FRG/France)

Volume Meter Equipped Measuring Assemblies for Liquids Other Than Water. Chapter 1: General Provisions (FRG/France) Volume Meter Equipped Measuring Assemblies for Liquids Other Than Water: Chapters II and III. (FRG/France)

Technical Regulation of Non-Automatic Weighing Machines (France/FRG)

Continuous Totalising Weighing Machines (Great Britain)

Checkweighing and Weight Grading Machines (Great Britain)

Hexagonal Weights, Ordinary Accuracy Class, From $100 \mathrm{~g}$ to $20 \mathrm{~kg}$ (Belgium/Great Britain)

Speedometers, Mechanical Odometers, and Chronotachygraphs for Automobiles - Metrological Regulations (Poland)

Indicating Pressure Gauges - Vacuum Gauges and Pressure Vacuum Gauges (USSR)

Recording Pressure Gauges - Vacuum Gauges and Pressure Vacuum Gauges (USSR)

Metrological Characteristics of Elastic Sensing Elements Used in Measurement of Pressure. Determination of Methods (USSR)

Barometers (UK)

Terminology Concerning the Measurement of Electrical and Magnetic Quantities (Democratic Republic of Germany)

Standardized Metrological Characteristics of Measuring Instruments (USSR)

Standardized Metrological Characteristics of Dynamic Properties of Measuring Instruments (USSR)

Metrological Characteristics of Measuring Systems: Regulation Principles (USSR)

Requirements for the Methods of Control of Metrological Characteristics of Measuring Instruments (USSR)

Fields of Use of Measuring Instruments Subject to Mandatory Verification (FRG)

Principles for the Selection of Parameters and Characteristics for the Examination of Working Measuring Instruments (Democratic Republic of Germany)

Principles of Metrological Supervision (Czechoslovakia)

Metrological Characteristics of Standards and Calibration Devices (Czechoslovakia)

Principles of Approval, Conservation and Use of Standards (Czechoslovakia) 
Secretariat

PS23/RS3

PS23/RS4

PS23/RS5

PS26/RS4

PS26/RS4

PS27/RS1

PS27/RS3

PS27/RS5

PS30/RS1

PS30/RS2
Title of Document and Responsible Nation

Documentation for Standards (Czechoslovakia)

Methods of Certification of Verification Devices (FRG)

Principles for the Establishment of Hierarchy Scheme for Measuring Instruments (France)

Electrocardiographs: Methods and Means of Verification (USSR)

Electroencephalographs: Methods and Means of Verification (USSR)

Legal Certified Reference Materials, Terms, and Definitions. (USSR)

Legal Certified Reference Materials Metrological Characteristics General Concepts and Standardization (USSR)

Legal Certified Reference Materials. General Principles for Application (USSR)

$\mathrm{pH}$ Scale for Aqueous Solutions (USSR)

Standard Solutions Reproducing Conductivity of Electrolytes (USSR)

3.1.5. OIML Meetings Attended by United States Delegations During FY 80

\begin{tabular}{|c|c|c|c|}
\hline Date & Committee & Title & Place \\
\hline Oct. 79 & PS5/RS16 & Water Meters & Tel Aviv, Is \\
\hline Nov. 79 & PS26 & $\begin{array}{l}\text { Measuring Instruments Used in the Field of } \\
\text { Public Health }\end{array}$ & $F R G$ \\
\hline Nov. 79 & PS5/RS20 & $\begin{array}{l}\text { Verification Devices for Liquid Measuring } \\
\text { Instruments and The ir Calibration }\end{array}$ & Tokyo, Japan \\
\hline March 80 & - & $\begin{array}{l}\text { Ad Hoc Working Group on OIML Certification } \\
\text { System }\end{array}$ & Paris, France \\
\hline March 80 & PS22 & Principles of Metrological Control & Paris, France \\
\hline March 80 & $P S 22 / R S 1$ & $\begin{array}{l}\text { Fields of Use and Vomenclature of Instru- } \\
\text { ments Subject to Periodic Verification }\end{array}$ & Paris, France \\
\hline March 80 & PS22/RS6 & $\begin{array}{l}\text { Principles Making Possible Assurance of } \\
\text { Effectiveness of Metrological Control }\end{array}$ & Paris, France \\
\hline March 80 & - & $\begin{array}{l}\text { Planning Meeting for Sixth International } \\
\text { Conference of Legal Metrology }\end{array}$ & Paris, France \\
\hline Apri1 80 & PS26/RS4 & Bio-electrical Measuring Instruments & Kislovodsk \\
\hline April 80 & PS21/RS1 & $\begin{array}{l}\text { Standardized Metrological Characteristics } \\
\text { of Measuring Instruments While Measuring } \\
\text { Quantities Constant in Time }\end{array}$ & Tali in, USSR \\
\hline
\end{tabular}

of Measuring Instruments While Measuring

s. 
Aprii 80

PS21/RS2

May 80

$\mathrm{PST} / \mathrm{RS} 1$

June 80

June 80

Sept. 80
Standardized Metrological Characteristics of Measuring Instruments While Measuring Quantities Varying With Time

Vocabulary of Legal Metrology, Fundamental Terms

17 th Meeting of the International Committee of Legal Metrology

Sixth International Conference of Legal Metrology

Water Meters
Tallin, USSR

Paris, France

Washington, D.C.

Washington, D.C.

Paris, France

(International meetings where USA participated as OIML observer or representative.)

Feb. 80 ISO/TCl64/SCl Uniaxial Testing Machines

June 80

Sept. 80

ISO/TC164/SC

Internationa General Meeting

Sept. 80
IEC/TCI3/SCB
Electrical Measuring Instruments
Paris, France

Stockholm, Sweder

Boras, Sweden

Palo Alto, Cal ifornia

3.2. Coordinating NML Involvement in Domestic and International Voluntary Standards Activities

3.2.1. OMB Circular A-119 "Federal Participation in Voluntary Standards" and Proposed Procedures for Listing Voluntary Standards Bodies

The Office of Management and Budget Circular A-119, issued January 17 , 1980, sets government policy for Federal participation in the development and application of voluntary standards (copy attached as Appendix G-7). The Circular encourages Federal employee participation in and Agency support of voluntary standards bodies which conduct their standards activities in accordance with the eleven due process and other criteria contained in A-119. The Circular charges the Secretary of Commerce with the responsibility for developing and maintaining (current a list of voluntary standards bodies which indicate a desire to be 1 isted and which certify to the Secretary that they are in compliance with the due process and other criteria contained in A-119. Further, the Circular requires that voluntary standards bodies must be 1 isted as a precondition to Federal participation unless such participation is required by law. Pursuant to his responsibilities under A-119, the Secretary of Commerce published on June 2, 1980, proposed rules regarding the 1 isting of voluntary standards bodies (copy attached as Appendix G-8). The comment period for the proposed 1isting procedures ended on September 2, 1980. An informa1 hearing on the procedures was held August 27 at the Department of Commerce, during which witnesses from thirteen (13) private sector orqanizations testified (largely in opposition) to the proposed rules. 


\subsubsection{NML Policy on High-Impact Standards Issues}

In connection with a recent review of MOU standards committee participation management, Dr. Ambler and the NBS Executive Board asked the NBS Standardization Advisory and Coordination Committee (SACC) to develop specific recommendations for treating standards-related issues which, for one reason or another, need higher level management attention than is normally required. Based upon a report by SACC to the Executive Board, criteria for identifying high impact standards activities were recommended and approved, and NML instituted a new policy, effective in July, for treating high-impact standards activities. It was agreed that a standards issue should be judged "high-impact" if one or more of the following criteria are met:

a.) It may be brought to the attention of the NBS Director, the Assistant Secretary, or the Secretary by one or more outside groups, such as Congress, a trade association, an industrial firm, or an influential individual.

b.) It contains the potential for outside criticism, positive or negative, of NBS by credible persons or organizations. Whether such a potential exists may not always be obvious. However, the judgment of the person closest to the issue that is, the NBS staff member participating in the standards committee, etc., is usually reliable.

c.) It requires broad coordination across laboratory or agency boundaries. In many cases, coordination with one or two persons will be all that is necessary; this can readily be handled by the individual participant. In other cases, coordination, or resolution of differing positions, may require the involvement of higher level management.

d.) It generates a need for policy guidance regarding appropriate limits of NBS responsibility, whether technical or financial.

e.) It would have a significant impact (positive or negative) on the U.S. industrial position in an area where technology is moving rapidly.

As part of the NML policy regarding high-impact standards activities, ODIMS will meet at least annually with NBS Division Chiefs to review standards activities as a means of verification of committee participation for the NBS-wide Standards Information system and as a means of ensuring continued awareness of the policies regarding high-impact issues.

\subsubsection{American National Standards Institute Service Fee System}

NBS recently completed its negotiations with ANSI regarding the payment of fees for NBS staff members serving on various committees and activities within the structure of the new ANSI Service Fee System. A contract was drawn and payment of some $\$ 10,000$ to ANSI was approved by NBS. As part of the contract, NBS will become an organizational member of ANSI. 
3.3. Supporting Bilateral and Multilateral Scientific and Technological Programs for NML Cooperation with Foreign Institutions

\subsubsection{U.S./Yugos lav Cooperative S\&T Agreement}

a. Staff attended the U.S./Yugoslav Joint Board meeting in Belgrade from December $3-6$, 1979. At that time, a proposal was presented of 14 cooperative projects between NBS and Yugoslav institutions. This amounted to about $\$ 130 \mathrm{~K}$ of the \$1M available for the first year of the program (1980).

b. Staff attended the meeting on Apri1 8 - 11, 1980, at the U.S. Department of State of the U.S./Yugoslav Joint Board where the NBS proposal was approved. Other proposals for future cooperation were also presented at that time.

c. The cooperative S\&T program was approved by the Yugoslav government in July 1980 and is now in effect.

d. A total 1981 budget for the Cooperation is expected to be about $\$ 2.4 M$ of which NBS may obtain about 13\%. NBS is preparing proposals for consideration at the Joint Board meeting that is to take place in November 1980.

\subsubsection{NBS Special Foreign Currency Program (SFCP) Projects in Egypt}

Five NBS SFCP projects developed by the staff with project-level manager's support were approved through DoC and State Department in October - November 1980. These projects are for three years and will amount to a total of approximately \$400K.

\subsubsection{Technical Assistance Programs}

a. Staff attended a meeting from February 25-26, of the U.S./Egyptian Joint Consultative Committee (JCC) to the U.S. Agency for International Development (AID) on their Applied Science and Technology Project with the Egyptian Academy for Scientific Research and Technology (ASRT). At this meeting a proposal to AID was discussed for the funding of an NBS assistance program for Egyptian standards institutions, namely the National Institute for Standards (NIS) and the Egyptian Organization for Standardization (EOS). The proposed project had been discussed at meetings of the JCC held during the previous one and one half years.

b. Prior and subsequent to the February JCC meeting, Egyptian visitors were accommodated for two weeks each from both NIS (February 1980) and EOS (March 1980). The visitors toured the NBS laboratories in both Gaithersburg and Boulder and focused on possible specific areas of cooperation.

c. In May 1980, the staff participated in a visit to Egyptian institutions to sharpen a specific program for assistance to Egypt in standardization. The result was a specific proposal to AID in June 1980 and the identification of possible cooperative-assistance projects with EOS and NIS.

d. An NBS project with ASRT has been reviewed by AID and is expected to be approved shortly. The total level of support is expected to be about $\$ 1.6 \mathrm{M}$ for three years. From $3-10$ projects will be carried out each year and equally divided between NIS and EOS. More specifics will be worked out by the staff and other NBS visits to Egypt before the beginning of the program in about January 1981. 


\subsubsection{Meetings in Support of Bilateral Science and Technology Agreements}

Joint U.S./Yugosiav Board Meeting

Joint U.S./Yugosiav Board Meeting
Dec. 3-6, 1979

Apr. $8-11,1980$
Belgrade, Yugoslavia Washington, D.C.

\subsubsection{Meetings in Support of Technical Assistance Programs}

Joint U.S./Egyptian Consultative Committee on Applied Science and Technology Research Program

Meeting with Officials of Egyptian National Institute for Standards and Egyptian Organization for Standardization and Quality Control
Feb. 25-26, 1980 Washington, D.C.

May 15-26, 1980 Cairo, Egypt

\subsubsection{Special Publications}

Sixth International Conference of Legal Metrology, June 16-20, 1980, Washington, D.C. - General Information, May 1980, French and English.

Report to the Advisory Committee for International Legal Metrology on the 17 th Meeting of the International Committee of Legal Metrology on the 6th International Conference of Legal Metrology Sponsored by the International Organization of Legal Metrology, August 1980.

Report of the United States Delegation to the Sixth International Conference of Legal Metrology, June 16-20, 1980, July 1980.

\subsubsection{Invited Talks}

October 1979 "Prospects for a Model Program for Realization of Traceability in Low-Level Radioactivity Measurements" - International Committee on Radionuclide Measurements Meeting - Braunschweig, FRG.

October 1979 "MTN Standards Code and OIML" - Health Industries Manufacturers Association Meeting - Washington, D.C.

November 1979 "International Standards - Their Increased Importance to the U.S." - 6th Annual AAMI/FDA Conference on Medical Device Regulation - Washington, D.C.

March $1980 \quad$ "MTN Standards Code and Trade Agreements Act of 1979" - Annual Meeting of the National Committee for Clinical Laboratory Standards - Cherry Hill, NJ.

Apri 11980

September 1980 "Implications of United States Participation in the InternationaI Organization of Legal Metrology (OIML)" - Annual Meeting of the National Conference of Standards Laboratories - Washington, D.C. 


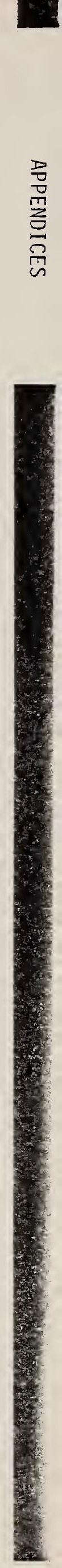




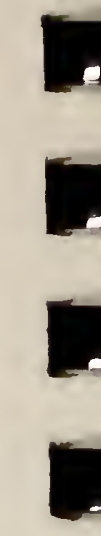


APPENDIX 1

\author{
DRAFT PLAN \\ for \\ TRAINING AND EDUCATION \\ PROGRAMS \\ in
}

MEASUREMENT SCIENCE

Updated: February 22, 1980

July 8,1980

August 29, 1980

7.1 
Measurement practice today must be a professional service, for it requires quality training as an essential to acquiring and maintaining the specialized skills of those engaged in this most demanding occupation . . training programs must be expanded in line with authority in the various laws and regulations and the challenges and opportunities derived from science and technology.

Albert $D$. Tholen

Chief, Office of Weights and Measures 


\section{CONTENTS}

Part I, General I

Background 1

Objectives 1

Scope 2

Potential Subjects 3

Part II, On-The-Job Training 4

Part III, National Training Program 5

History 6

Objectives 6

Implementation 7

Related Tásks 8

Training Manuals 8

Certification 9

Existing Regional Groups 9

Proposed Regional Groups

Conclusion 10

Part IV, University Based Programs $\quad 11$

General ․ 12

Approach 12

Prerequisites 12

Procedure $\quad 12$

Tasks 14

Related Activities 18

Publicity 19

Draft Schedules 23

Technical Training Program in Measurement Practice 26

Higher Education Program in Measurement Science 24

Part V, Environmenta? 32

Part VI, Health and Safety 33

Part VII, Industrial Metrology 34

Part VIII, Engineering Metrology 35 


\section{BACKGROUNO}

\section{Genera 1}

This paper is the proposed plan designed to result in the development and implementation of training and education programs in measurement science. Several organizations are addressing the perceived need for improved competence and proficiency in the measurement sciences as applied to research, government, and industry at the professional and technical levels.

The measurement practitioner (whether a scientist, engineer, technician, or manager) is faced with a technical environment growing more complex and interdisciplinary.

As a result of this perceived need, the Directorate of Measurement Services explored the potential benefits, feasibility, and implementation problems in the use of university capabilities to extend State metrology services. $\mathrm{Mr}$. Albert Tholen was assigned as the DMS staff person to explore this subject. An investigation of methods to upgrade the skills and knowledge of the State personnel (which would not likely exist unless new programs were developed and used) was undertaken.

Initial explorations were directed to State laboratories. It was soon realized that private and other governmental laboratories were concerned about the same subject. At this time, and as reflected in this Plan, the need for new training and educational programs are being pursued across a broad range of measurement science needs in government and industry focused by such groups as the National Conference of Standards Laboratories (NCSL), the National Conference on Weights and Measures

(NCWM), and the American Society for Quality Control (ASQC).

\section{OBJECTIVES OF TRAINING AND EDUCATIONAL PROGRAMS}

A. Enhance the quality and quantity of personnel skills in measurement sciences relative to:
(1) Lega 1 metrology
(2) Technical metrology
(3) Quality assurance
(4) Standardization
(5) Research and Development 
B. Improve the functional level and image of the measurement science.

C. Generate benefits through:

(1) Reduced inflation (cost of measurement, efficiency of enforcement, reduction of scrappage, increased productivity)

(2) Conservation of energy

(3) Improvement of customer protection

(4) Expedite commercial transactions in international trade

D. A curriculum with multidiscipline foundation to prepare students for:

(1) Functioning in a productive role based on state-of-the-art technology

(2) Developing and/or utilizing tomorrow's technology

SCOPE OF PROGRAM

Currently, organizations surveyed depend on a variety of methods for training and education which include:

a. Internal Training Programs

b. On-the-job Training

c. National Bureau of Standards 1

d. Professional Society Short Courses 2

e. Books/Magazines, Literature

f. Professional Society Conferences

g. University/colleges

h. Government Seminars

i. Self-study Courses

j. Manufacturer Training

k. Technical schools 4

1. Consultants

This plan addresses $c, d, g$, and $k$ primarily.

The program is intended for:

a. Administrators;

b. Inspectors;

c. Servicemen;

d. Metrologists; and

c. Business men, who are working for:

a. State and local governments;

b. Industry and business;

c. Federal Government; and

d. Foreign government, and

Office of Weights and Measures (Commercial Trade)

2Institute for Weights and Measures

3 University of Texas at Dallas (future possibility)

${ }^{4}$ Texas Engineering Extension Service (future possibility) 
involving:

a. Legal Metroiogy commercial trade, environmental, and health and safety;

b. Industrial Metrology; and

c. Engineering Metrology.

\section{POTENTIAL}

Subjects:

Fundamentals

Base and Derived Units

Statistics, Sampling

Quality Assurance

Inspection

Basics, Accuracy, Precision

Specifications, Codes

Requi rements

Devices

Commodities

Variable Frequency

Laws and Regulations

Equity

Uniformity

Fraud

Inforcement

Prosecution

Organization

Goals, Objectives

Program Evaluation (justification)

Budgeting, Financial Management

Records

Technical

Mass and Density

Volume and capacity

Length, Angle, Form

Electrical

Time and Frequency

Temperature

Pressure

Radiation

Weighing Devices

Measuring Devices 
PART II

ON-THE-JOB-TRAINING

[not addressed in this plan at this time]

1.7 
PART II I

NATIONAL TRAINING PROGRAM

Training for a new weights and measures inspector resembles the training formerly given a new police officer -- next to none --

The inspector is given a book of local laws, Handbook 44, a set of field weights, and sent out to do his job.

Albert Tholen

Chief, Office of Weights and Measures 


\section{HISTORY}

The United States is the only country in the world in which weights and measures enforcement is not a Federal function but a State and local responsibility. With this system, the need for central coordination and direction is obvious. The National Bureau of Standards (NBS), through the Office of Weights and Measures (OWM), serves State and local weights and measures officials much as a trade association serves its membership. Weights and measures officials must rely on the NBS to furnish needed interpretations and explanations of National Conference Laws and Regulations which serve as the basis for uniform control throughout the U.S. The OWM staff members serve as staff assistants to the various standing committees of the Conference and consequently this information is not available elsewhere. The control of new technology in the form of electronics, digital indicators, and computers facing the weights and measures officials today make assistance from the National Bureau of Standards essential.

Each State today has a weights and measures law, most of which are patterned after the Model Weights and Measures Law developed by the National Conference. Mississippi was the last State to enact their law in 1966. The enactment of uniform laws and regulations are the direct result of the Office of Weights and Measures training effort. The training program serves as a catalyst for adoption of uniform laws and procedures and has been cited as an outstanding example of Federal-State cooperation in a vital area of commerce.

The benefactors of the program in addition to the more than 3,000 weights and measures officials include manufacturers, service personnel, users, and consumers as a result of a fair and equitable marketplace.

In recent efforts to broaden the impact of the program and to spread our limited resources further, industry service personnel have been invited to participate in our seminars, both as instructors and students. An effort is also being made to group adjoining States together where possible to form regional training groups. Four such regional groups exist today in the Northeast, Southeast, Northwest, and Southwest. Under this plan, a different State in each group hosts the seminar each year with all of their field staff participating and as many officials as possible from the other States in the region. Industry officials with national responsibility have been willing to participate in assigned specific areas as instructors in our regional seminars.

\section{OBJECTIVES}

1. To develop and conduct a nationwide training program that will offer OWM training on a completely equitable basis to all of the State and local jurisdictions. In the past OWM training has been conducted on an "as requested" basis with some of the jurisdictions receiving training each year and others receiving little or no training. This type of program is not considered to be making the best use of our resources and has not produced the desired results on a nationwide basis. 
2. To seek the help and support of the National Conference Committee on Education, Administration, and Consumer Affairs in implementing and gaining Conference endorsement of this program.

The OWM training program is of vital interest and concern to the committee and has been discussed at length during recent Committee meetings. All involved agree that OWM can spread their resources further by grouping States together into regional groups for the purpose of training and including local scale and meter service personnel as participants. The Committee has also endorsed the practice of including industry officials as instructors in certain specific areas.

3. Seek the help and support of the four regional conference committees on education on a continuing basis to implement and improve the program. Each of the regional committees (Northeast, Southern, Northwest, and Western) will be asked to develop as a continuing program the implementation of this program.

4. Promote a much closer working relationship between the National Conference Committee on Education and the four regional conference committees in all areas of mutual interest such as the National Training Program, Weights and Measures Program Evaluation, and National Weights and Measures Week.

The regional committees can provide a valuable and necessary servica to their respective memberships and assist in promoting uniformity nationally by working closely with the National Conference in these important areas.

\section{IMPLEMENTATION}

Beginning in 1979, Mr. R. N. Smith, Manager of OWM Training and Staff Assistant to the National Conference Committee on Education, Administration, and Consumer Affairs will attend each of the four regional conferences for the purpose of outlining the program and asking for assistance in the following areas.

1. Ask each State in the region to name a State Training Officer or other person to act as coordinator of training in the State and be the OWM and Conference contact on all matters related to training. This person would also manage continuing in-house training for State and local officials in the State.

2. Assist OWM in forming regional State groups in those areas where they do not already exist. See the following list of existing and proposed groups. Under this plan, one State in the regional group agrees to host the training school each year on a rotating basis, affording the opportunity for all of the host State officials to attend and supervisory personnel from the other states in the group. This plan will guarantee the opportunity for all officials in each State in the group to attend periodically depending on the size of the group. 


\section{Existing Regional Groups}

1. Maine, New Hampshire, Vermont

2. Alabama, Tennessee, Mississippi, Georgia, Florida

3. Kansas, Missouri, Nebraska, Colorado

4. Montana, Wyoming, North Dakota, South Dakota

5. Utah, Arizona, New Mexico

6. Washington, Oregon, Idaho, Alaska

Proposed Regional Groups

7. Massachusetts, Connecticut, Rhode Island

8. Pennsylvania, New York, Ohio

9. Maryland, Virginia, West Virginia

10. North Carolina, South Carolina

11. Michigan, Indiana, Kentucky

12. Minnesota, Wisconsin, Iowa, I1linois

13. Texas, Oklahoma, Arkansas, Louisiana

14. Hawai, California, Nevada

15. Puerto Rico, Virgin Islands

16. New Jersey, Delaware, District of Columbia

3. Assist OWM in developing State "Profi les" for each State in the regional conference. These "Profi les" would contain information regarding number of inspectors, level of enforcement activity, testing standards and equipment, program areas, needs, and level of training. This phase of the program wi 11, of necessity, be conducted on a continuing basis.

5. Work with OWM and the National Conference in developing uniform "in-house" training programs for both new and experienced officials.

\section{RELATED TASKS}

Within this perspective, the following related tasks will be undertaken by OWM/NBS:

1. Ascertain individual State training needs by formalizing a dossier on each State containing:

a. organization and administration of State weights and measures program

b. current needs and problems

c. training given by OWM

d. training available, exclusive of OWM

e. functional job description of weights and measures personne 1

f. turnover rate for weights and measures personnel 
2. Develop detailed course outline for a 11 training programs and make available to individual States and localities.
a. course content
b. visual aids
c. textual resources

3. Produce a complementary/explanatory document to accompany Handbook 44.

4. Review a 17 NBS published weights and measures material and recommend retention, revision, or elimination.

5. Encourage States to develop incentive programs to motivate weights and measures inspectors to seek training.

6. Develop and promote an examination (given through the NCWM) for certification of weights and measures inspectors.

TRAINING MANUALS

Prepare three comprehensive training manuals to be used for: (a) an eight-week intensive inspector training program; (b) a four-week intensive metrologists training program; (c) a two-week intensive administrators training program. A training manual consists of a detailed course syllabus and a textbook. Its preparation would be facilitated by referring to the comparable training manual used by other Federal agencies such as the FBI, FDA, and OSHA. More useful would be the syllabi and textbooks already prepared at some of the weights and measures jurisdictions. Some of them are quite exceptional. (It should be remarked that the need for a training manual applies with equal urgency to the ongoing OWM training programs, especially for the metrologist and administrator training.)

\section{CERTIFICATION}

Work out an NBS certification program for new inspectors similar to that for new metrologists.

There is no legal basis at present for the NCWM to formally certify an inspector; nevertheless, the prestige of the NCWM can be put to good use by the inauguration of a certification program. It would give the NCWM some measure of influence on the hiring policy of new inspectors by the State and local jurisdictions. This, in turn, could tend to insure the maintenance of some minimum qualification level for the new recruits since jurisdictions may not wish to be identified as those having uncertified or uncertifiable inspectors.

What is more desirable is eventually to confer some legal sanction to the certification of inspectors. One way to achieve this end would be the adoption of a model code by the National Conference on Weights and Mea sures. 


\section{CONCLUSION}

The total program, with expected cooperation from all involved, will be completely operational by 1985 and should do much to upgrade and standardize commercial weights and measures activity in the U.S. With rapidly changing new technology and merchandising methods, ever changing and expanded legal requirements, and the fact that we have over 700 independent weights and measures jurisdictions in this country, makes it imperative to develop a uniform level of training for all officials. 
PART IV

UNIVERSITY BASED PROGRAMS

GENERAL 
This part of the Plan describes, first, the establishment of two programs based in university or university related training organizations initiated by NBS:

1. Technical training program in measurement ${ }^{1}$ practice, and

2. Higher education program in measurement science ${ }^{2}$

Second, it describes programs being explored and developed primarily through the efforts of individuals and groups other than NBS.

\section{PROGRAMS INITIATED BY NBS}

\section{APPROACH}

This part of the Plan proposes a four task program:

$$
\begin{aligned}
& \text { Task I - Planning } \\
& \text { Task II - Decision } \\
& \text { Task III - Preparation } \\
& \text { Task IV - Imp lementation }
\end{aligned}
$$

The first three tasks extend from the second half of FY 1979 through the third quarter of FY 1982. Assuming successful completion of Tasks I through III; the first on-campus course work will commence in the fal1 of $\mathrm{CY} 1982$.

\section{PREREQUISITES}

The development of a Measurement Science Educational Program should have the following prerequisites:

1. Establish that there is a need for a quality education program and a sufficient number of potential students to support the program.

2. There should be a sincere desire on the part of decision makers to provide a continuing program of education and training that will offer career development opportunities for all personnel interested in measurement science and related fields.

3. Industry must provide leadership for the program. (Assume that educators are not aware of the technical requirements and skill levels required. Stress the fact that measurement science is a set of specialized disciplines in present day manufacturing, service, and regulatory organizations.)

4. Encourage and enlist aid from other local technical societies in related fields.

\section{PROCEDURE TO ESTABLISH A COLLEGE PROGRAM}

After the prerequisites have been considered, the following specific procedures are planned to assure a well established educational program:

1. Conduct surveys to obtain data on local and national industry needs for specific measurement science educational needs.

1 Texas Engineering Extension Service

2 University of Texas at Dallas 
2. Prepare educational program package papers for presentation to college officials. Ensure that these presentations demonstrate the following:
a) The expected annual student enroliment.
b) Student sources.
c) Local industry management support.
d) Source of qualified instructors.
e) Program compatibility with college standards and facilities.
f) The present and future scope of the educational program.

3. Arrange initial meetings with top college officials such as the heads of departments for the first presentations of the educational program package. Sell the idea at the top. Obtain approval to make follow up presentations to the department staff. Staff approval is necessary.

4. Make department staff presentations. Thoroughly explain program goals and technical requirements.

5. Arrange and conduct field trips for the school staff. Show them just what people do in measurement science, and how industry will support your program.

6. Prepare course proposals using college proposal forms and procedures. Ensure the backing of a specific college staff member appointed by the department head.

7. Utilize local college vocational coordinators in assisting qualified instructors in credential applications and establishment of course schedules.

8. After instructors are approved by the Credential Board, the Advisory Council assists in the testbook(s) selection and course outline preparation.

9. Submit all course outlines to the Coordinator of Measurement Science Program for review by the State and local representatives.

10. Monitor each class with guidance from the school coordinator and Advisory Council to ensure effective course material and instruction.

11. Periodically review and update course requirements to ensure current measurement science needs are being fulfilled.

Toward the end of Task II, this Plan proposes the establishment of a committee to guide its development. Its objectives will be:

1. To recognize educational needs and requirements for existing and potential employees in the fields of measurement science.

2. To coordinate with management in local industry and government agencies to determine the scope and depth of educational programs. 
3. To coordinate with local colleges and universities in establishing educational programs that support industry's and government's needs for personnel trained in the latest concepts and techniques.

4. To provide support to local secondary and middle schools in guidance and career awareness activities.

5. To provide support to local colleges and universities by selecting courses, preparing or improving curriculum, selecting textbooks, and recommending qualified instructors.

6. To work with the faculty and administration to insure proper identification of the courses within the college bul letin and identification and credit of these courses within other but related occupational fields.

7. To cooperate with the NCWM, NCSL, ASQC, and other associated professional societies to promote professional development.

8. To communicate educational concepts through a program of public relations and promotion.

TASKS (see attached schedule) 


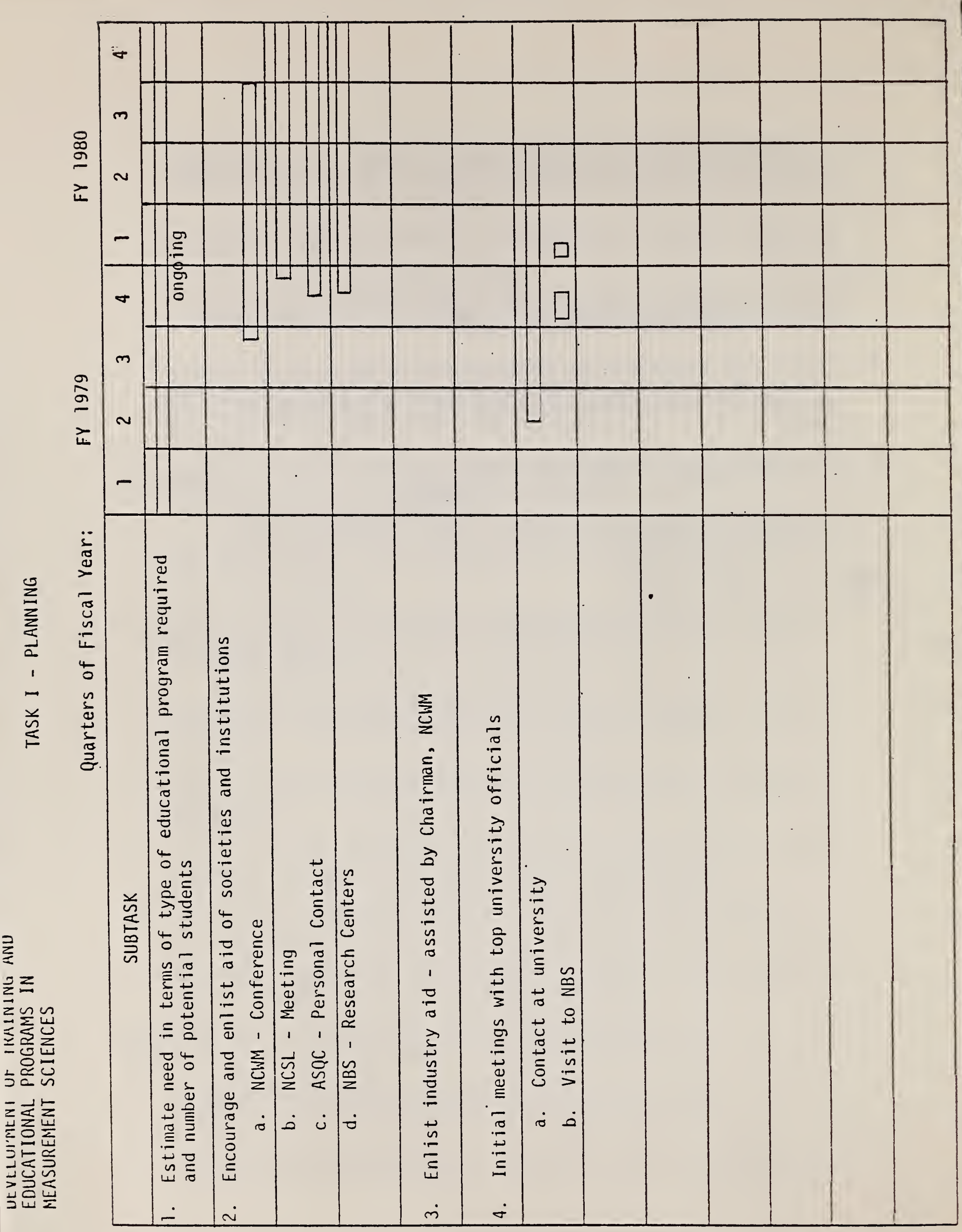




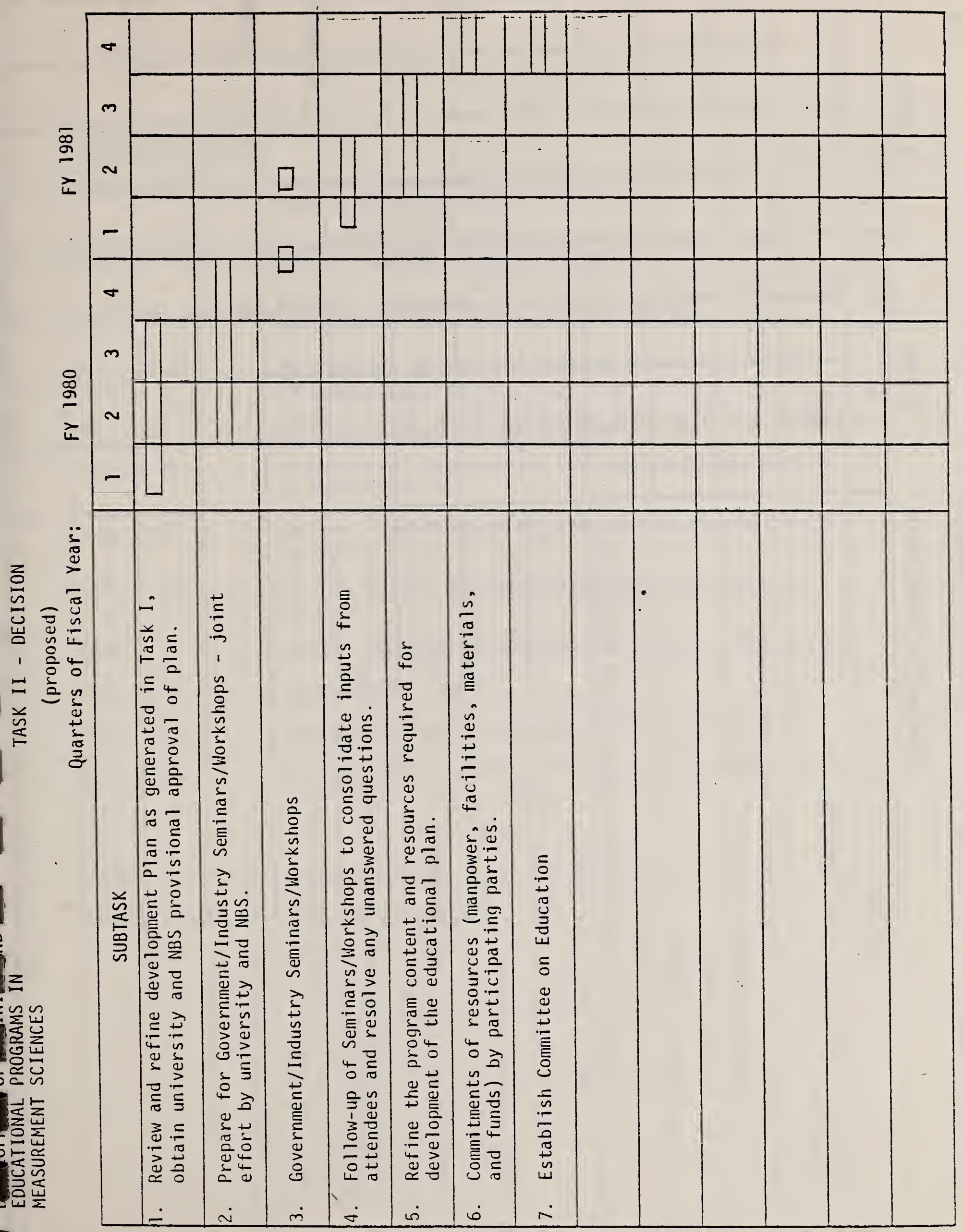


RELATED ACTIVITIES

March 3-5

- Northwestern Weights and Measures Association meeting in Minneapolis.

March 17-31 - Tho len visits to European countries to learn their training and education practices.

April 23 - National Conference of Standards Laboratories Education and Training Committee Meeting - Las Vegas.

Apri 128-30 - Northeastern Weights and Measures Association meeting Springfield, Illinois.

May 19-23 - National Scale Men's Association meeting in San Francisco.

June 16-20 - International Organization for Legal Metrology meeting in Washington, D.C.

June 23-27 - National Conference on Weights and Measures meeting in Washington, D.C.

Sept. 7-12 - Western Weights and Measures Association meeting in Alaska.

Sept. - - National Association of State Departments of Agriculture.

Sept. 22-25 - NCSL meeting - NBS.

Sept. 30-Oct. 1 - Seminar/Workshop, University of Texas, Dallas.

Oct. 20-24 - Southern Weights and Measures Association meeting in

$$
-1981-
$$

January 12-14 - Seminar/Workshop, Texas A\&M, College Station.

January 19-24 - NCWM Interim Meetings - NBS. 


\section{PUBLICITY}

For Dimensions Magazine

September 30 - October 1, 1980

Seminar/Workshop on Education Programs in Measurement Science, University of Texas at Da17as; sponsored by NBS and UT/D; contact Albert Tholen, B363 Physics Building, 301/921-3301.

January $12-14,1981$

Seminar/Workshop on Technical Training Programs in Measurement Practice, Texas A\&M University, College Station, Texas; sponsored by NBS and A\&M; contact Albert Tholen, B363 Physics Building, 301/921-3301

\section{Announcing Seminars/Workshops}

1. Higher Education Programs in Measurement Science

Mail first flyer - March 14, 1980

Mai1 tentative program - July 25, 1980

Mail program - August 30,1980

Hold Seminar/Workshop - September 30/October 1, 1980

2. Technical Training Programs in Measurement Practice

Mai1 first flyer - August 1, 1980

Mail tentative program - September 26, 1980

Mai 1 program - November 28, 1980

Hold Seminar/Workshop - January 12-14, 1981

\section{Draft Flyers}




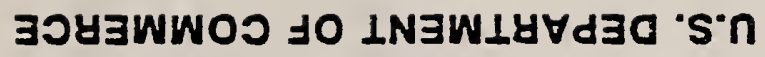

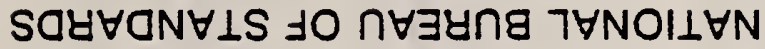

$\exists H \perp$ aN $\forall$

$S \forall 77 \forall \square \perp \forall S \forall X \exists \perp\rfloor O \lambda \perp I S \forall \exists \wedge I N \cap \exists H \perp$

18 वヨUOSNOdS $\forall \forall N I W \exists S \forall$

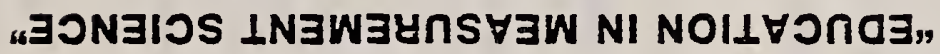

פNIONกONN 

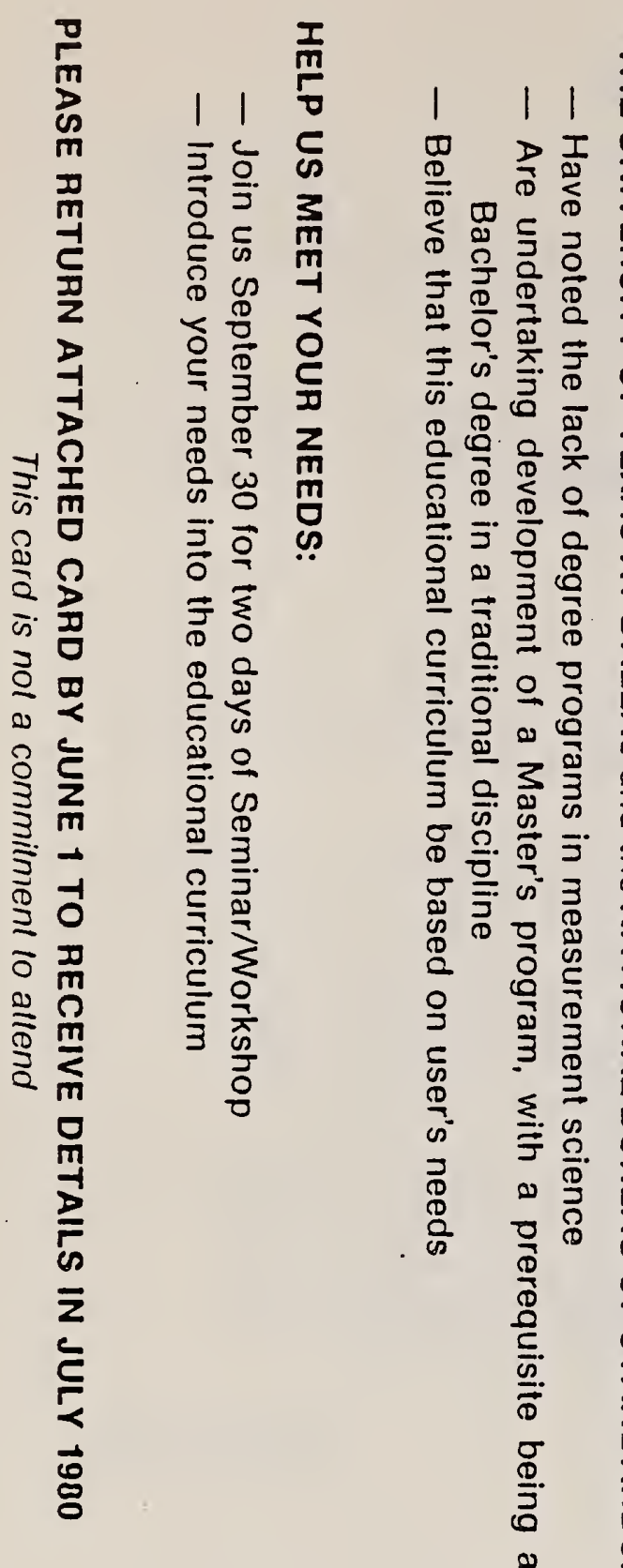

UTD/NBS SEMINAR: EDUCATION IN MEASUREMENT SCIENCE; SEPTEMBER 30/OCTOBER 1,198

Name

Address

City

State Zip

Employer

Position

Phone: Area Code
No.
( ) I am interested in attending the Seminar. Ple send me preliminary program information $i \mathrm{~L}$ 1980, along with registration and accommodatic particulars. (This is not a commitment to aties

( ) I do not plan to attend, but please put me on yo future mailing list.

( ) I have questions and desire to be contacted program coordinator.

(or phone 214/690-2204 for information)

PLEASE RETURN THIS CARD BY JUNE 1,198 

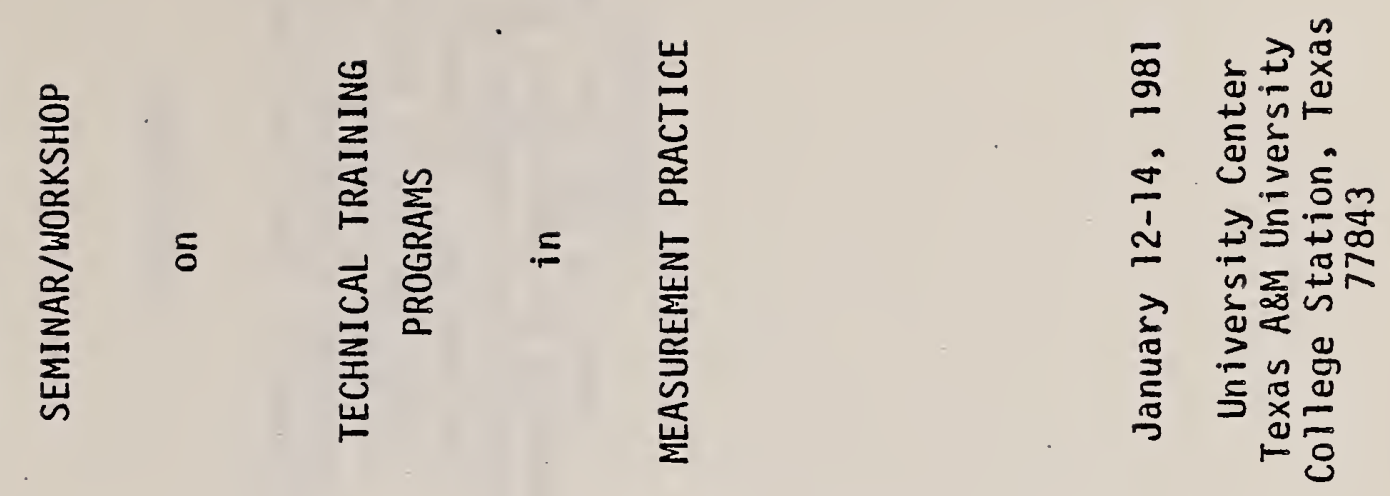

Place

Stamp

Here

THE UNIVERSITY CENTER

TEXAS A\&M UNIVERSITY

COLLEGE STATION, TX 77843 
PROGRAMS 
September 30 -October 1,1980

UT-Dallas Conference Center

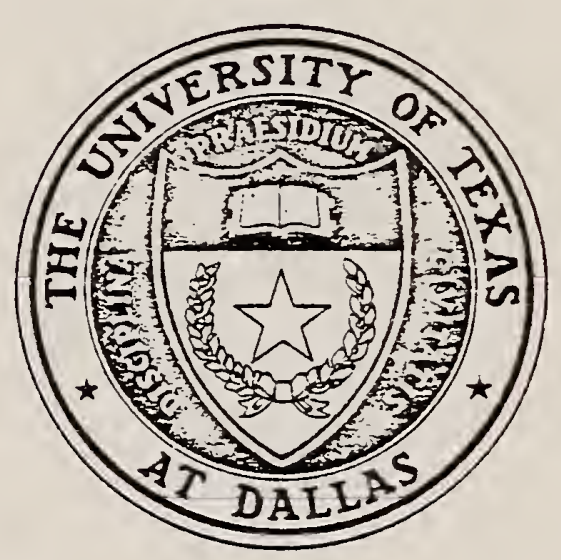

The University of Texas at Dallas Center for Continuing Education

National Bureau of Standards 


\title{
MEASUREMENT SCIENCE EDUCATION
}

MEASUREMENT SCIENCE brings together many technical disciplines and specialized personnel to develop new technology for application to modern operations.

MEASUREMENT of physical quantities is essential to:

- Control of operations

- Conduct of commercial trade

- Consumer protection

- Management decisions

MEASUREMENT TECHNOLOGY has changed in the last generation from simple mechanical and electrical devices to sophisticated computerized systems.
EDUCATION is urgently needed on a continuing basis.

NO DEGREE-GRANTING PROGRAM currently exists in the field of measurement science.

The University of Texas at Dallas, in cooperation with the National Bureau of Standards, is conducting a seminar/workshop designed to assess the educationa! needs in the area of measurement science.

September 30, 1980

\section{PROGRAM}

\author{
9:00 REGISTRATION-UTD CONFERENCE CENTER \\ 9:15 Introduction \\ Janet Harris \\ Director, Continuing Education \\ The University of Texas at Dallas \\ 9:30 Keynote Address: \\ A UNIVERSITY LOOKS AT MEASUREMENT SCIENCE \\ Bryce Jordan \\ President \\ The University of Texas at Dallas \\ 10:00 Moderator: Alexander L. Cläk \\ Vice President, Academic Affairs \\ The University of Texas at Dallas \\ RESEARCHING AND DEVELOPING \\ NEW MEASUREMENT TECHNOLOGY \\ Cary Gravatt \\ Deputy Director, Nationat Measurement Laboratory \\ National Bureau of Standards \\ 10:30 COFFEE \\ 11:00 DEVELOPMENT OF STANDARD METHODS \\ FOR MEASUREMENT SCIENCE \\ Bryant Mather \\ Chief, Concrete Laboratory \\ U.S. Army Engineers \\ Waterways Experiment Station
}


APPLYING NEW MEASUREMENT TECHNOLOGY

S. H. Raskin

President

S. H. Raskin Corporation

$12: 00$

LUNCH - UTD Conference Center

Address: FAR OUT MEASUREMENTS

John $\mathrm{H}$. Hoffman

Head, Physics Programs

The University of Texas at Dallas

MEASUREMENT SCIENCE-ANTICIPATED NEEDS

AND CAREER OPPORTUNITIES

Moderator:

Charles Vincent

Director

Department of Consumer Affairs

City of Dallas

Panel:

\section{ELECTRONIC HARDWARE}

Graydon Larrabee

Manager, Materials Science Branch

Texas Instruments

STEELMAKING

Donald Leckie

Assistant Director for Research

Republic Steel Research Center

2:30 COFFEE

2:45 AEROSPACE

Winton Howelt

Supervisor of Metrology

Bell Helicopter Textron

MEDICAL/BIOLOGICAL RESEARCH

Robert Putnam

Professor of Pathology

Department of Pathology

The University of Texas Health Science Center-Dallas

3:45 INTRODUCTION TO PROGRAM FOR DEVELOPING GUIDELINES

Alexander L. Clark

Vice President

Academic Affairs

The University of Texas at Dallas

4:00

THE WORKSHOP PROGRAM

Introduction to Group Leaders

Formation of Groups

Distribution of Materials

John Van Ness

Dean of School of Natural Sciences and Mathematics (Acting)

The University of Texas at Dallas

4:30 ADJOURNMENT

7:00 RECEPTION AND DINNER-UTD Conference Center 
October 1, 1980

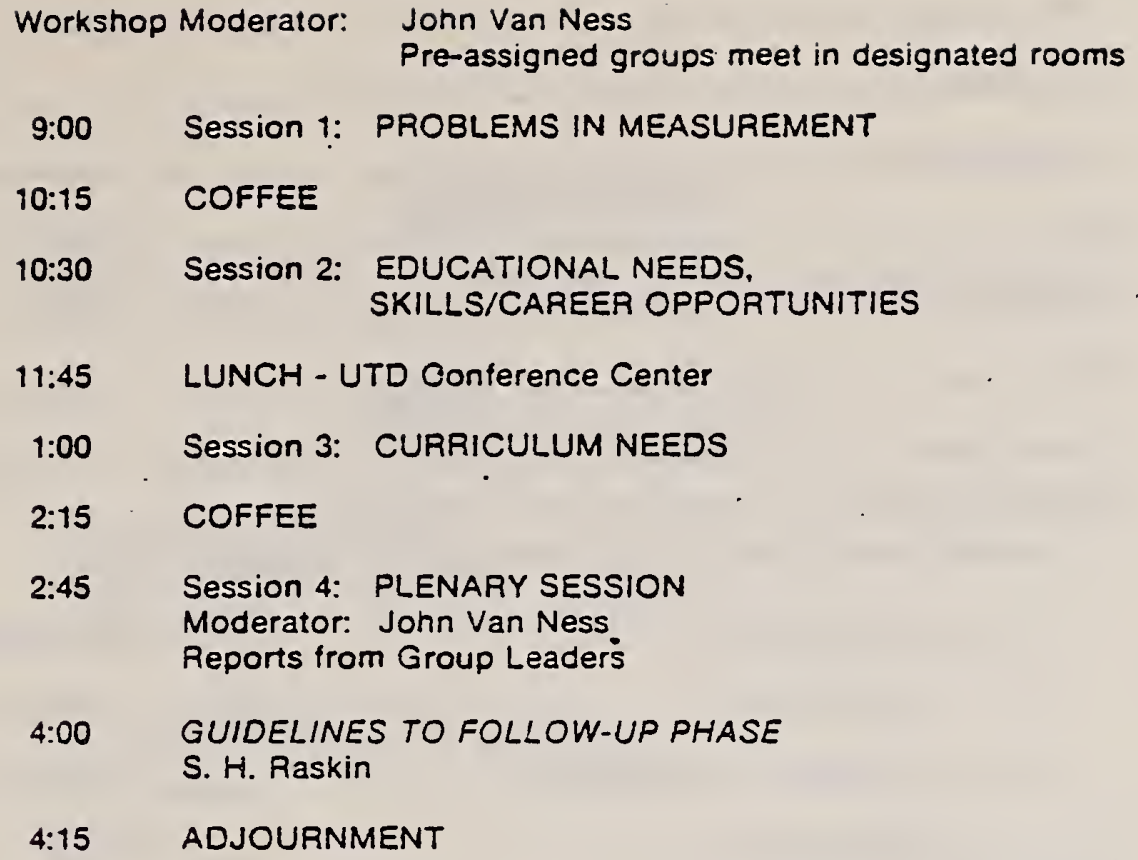

\section{REGISTRATION INFORMATION}

Registration Fee: $\$ 75$ (includes coffee, lunches, reception, and dinner) To register, fill out the form on the back of this page and mail with fee or billing instructions to the Center for Continuing Education. No acknowledgment of fees received will be made. Receipts, if required, may be requested on the day the seminar meets. For additional information, call the UT-Dallas Center for Continuing Education at 214/690-2204.

\section{Location: UTD Conference Center}

The University of Texas at Dallas is located at the intersection of Floyd and Campbell Roads in Richardson. Campbell Road is Exit 26 off North Central Expressway. The Center is on the western edge of the campus. Participants in Conference Center programs may park free of charge in spaces designated for visitors in the lot west of the Center. The most direct access to the Center is from Campbell Road on Waterview Drive.

\section{Hotel Accommodations:}

Seminar participants should reserve rooms directly with hotels of their choice. For convenience, a block of rooms will be held at the following hotels near the UTD campus: Holiday Inn (214/239-7211). Best Western Inn (214/234-2431), and La Quinta Inn - Richardson (214/234-1016). When making reservations at one of these hotels, please specify attendance at the seminar on Measurement Science Education. 
Name

Title

Firm Name

Business Address

City

State

Zip

HomeAddress

City

State

Zip

Home Phone

Business Phone

Please check all of the items that apply to your work:

A. YOUR FUNCTIONAL ROLE WITHIN YOUR ORGANIZATION Management Manufacturing Marketing Finance

Research \& Development Administration Engineering Other:

B. TYPE OF ORGANIZATION (please describe)

Business:

Industry:

Government:

Educaţion:

Other:

C. AREA OF MEASUREMENT INTEREST

Development of New Measurement Technology Application of New Measurement Technology Operation of Measurement Devices and Systems Service/Maintenance of Measurement Hardware Regulation of Measurement Functions Other:

Make checks payable to The University of Texas at Dallas and return with registration form to the Center for Continuing Education, Box 688, Richardson, TX 75080.

(For OHlce Use)

Registration Fee \$

Date

Recelved by 


\title{
SEMINAR/WORKSHOP
}

\section{Technical Training Proorams in Measurement Practice}

\author{
January $12-14,1981$
}

$\begin{array}{ll}\text { Place: } & \begin{array}{l}\text { University Center } \\ \text { Texas A\&M University } \\ \text { College Station, Texas } 77843\end{array} \\ \text { Sponsor: } & \begin{array}{l}\text { Texas A\&M University and } \\ \text { National Bureau of Standards } \\ \text { \$40.00 }\end{array} \\ \text { Fee: } & \text { WCHEDULE } \\ \text { Monday (January 12) } \\ \text { 9:00 a.m. } & \text { Welcome / Introduction to Seminar/Workshop } \\ \text { 9:15 a.m. } & \text { Keynote Speaker } \\ \text { 9:45 a.m. } & \text { Invited Speakers } \\ \text { 12:00 noon } & \text { Lunch } \\ \text { 1:30 p.m. } & \text { Invited Speakers } \\ \text { 6:00 p.m. } & \text { Reception - Cash Bar } \\ \text { 7:00 p.m. } & \text { Dinner in Center } \\ \text { Tuesday (January 13) }\end{array}$

Workshops

Wednesday (January 14)

9:00 a.m. Workshops (summary sessions)

12:00 noon Luncheon Buffet

1:30 p.m. Plenary Session

3:00 p.m. End of Seminar/Workshop 


\section{PUBLICITY}

See "Related Activities"

Mailings:

August 1 - "Alert" mailing including letter from Chief OWM plus two flyers (one for a general perspective andoone for A\&M Seminar)

September 26 - Tentative program and logistics information

Movember 28 - Seminar/Workshop Program

Suggested Speakers:

Reagan Brown

Syd Andrews

Ambler

McCoubrey

Stabler

Workshop Leaders:

Federal - Jensen

Service Industry - Fuller

State - Delfino

FDA

Development of Agenda:
A.D. Tholen
R.N. Smith
S.H. Raskin
T.M. Stabler
O.K. Warnlof
L.H. DeGrange
D. Tonini
F. A. Gerk 
[To be developed as result of Seminar/Horkshop] 
Possible candidates for subjects for training sessions include (for weights and measures inspectors):

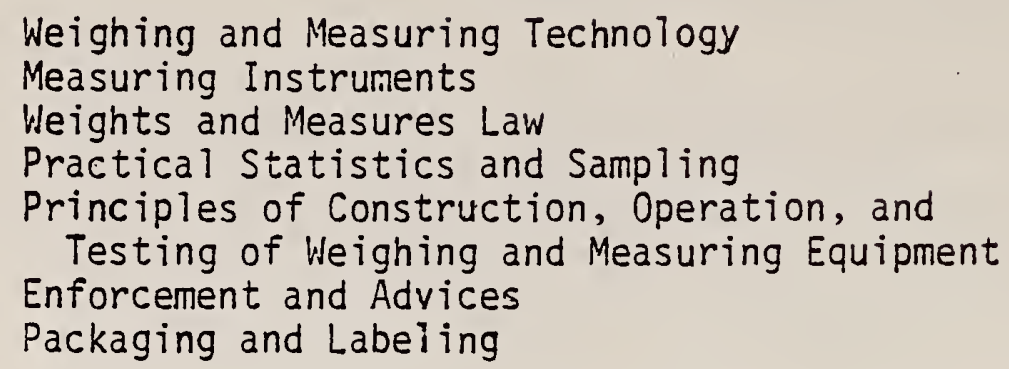

(for metrologists):

History and Theory of Measurement

Basic Metrology

Standards Lab Practice

Precision and Accuracy

Digital Theory and Practice

Automatic Control

Selected Electrical, Physical, and Chemical Courses

Instrumentation 
HIGHER EDUCATION PROGRAM IN MEASUREMENT SCIENCE

[To be developed as result of Seminar/Workshop] 


\section{PROGRAMS INITIATED BY OTHERS}

The Office of Weights and Measures is attempting to integrate into its overall plan the development of continuing education courses, seminars, and related training developed by other groups.

The Great Lakes Division of the National Scale Men's Association has established the Institute for Weights and Measures to work with the Continuing Education Department of Ohio State University in establishing and conducting short courses and seminars. Mr. A. Tholen is on the Executive Committee of the Board of Directors.

Several other schools have visited or contacted Mr. Tholen expressing their interest in developing programs in metrology. Most notably have been Harrisburg Community College (Harrisburg, Pennsylvania) and Butler Community College (Butler, Pennsylvania).

Possible curricula for Continuing Education will permit a student to enhance knowledge on a selective bases and might include:

Graphical Communication

Logic and Method in Analys is

Mathematics and Statistics in Science

Fundamentals of Measurement Science

Introduction Physics

Introductory Analytical Mechanics

General Chemistry

Introductory Transducers and Instrumentation

Mathematics for Engineers and Physicists

General Physics

Possible curricula for the Masters Program:

General Metrology

Probability and Statistics of Metrology

Measurements Laboratory

Transducers and Instrumentation

Calculus

Selected Management, Business, and Technical Courses 
PART $V$

ENVIRONMENTAL

[To be developed based on results of NBS

"Measurement Needs Study" scheduled for completion by the summer of 1981] 
PART VI

HEALTH AND SAFETY

[To be developed based on results of NBS

"Measurement Needs Study" scheduled for

completion by the summer of CY 1981] 
PART VII

INDUSTRIAL METROLOGY

[To be developed separately in cooperation with private industry and the NCSL] 
PART VII

INDUSTRIAL METROLOGY

[To be developed separately in cooperation with private industry and the NCSL] 


\section{PART VIII}

\section{ENGINEERING METROLOGY}

[To be developed separately in cooperation with private industry and the NCSL] 

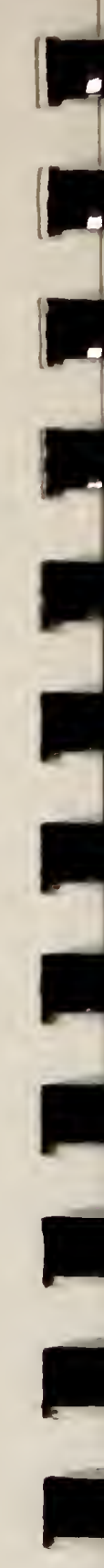
Plon 


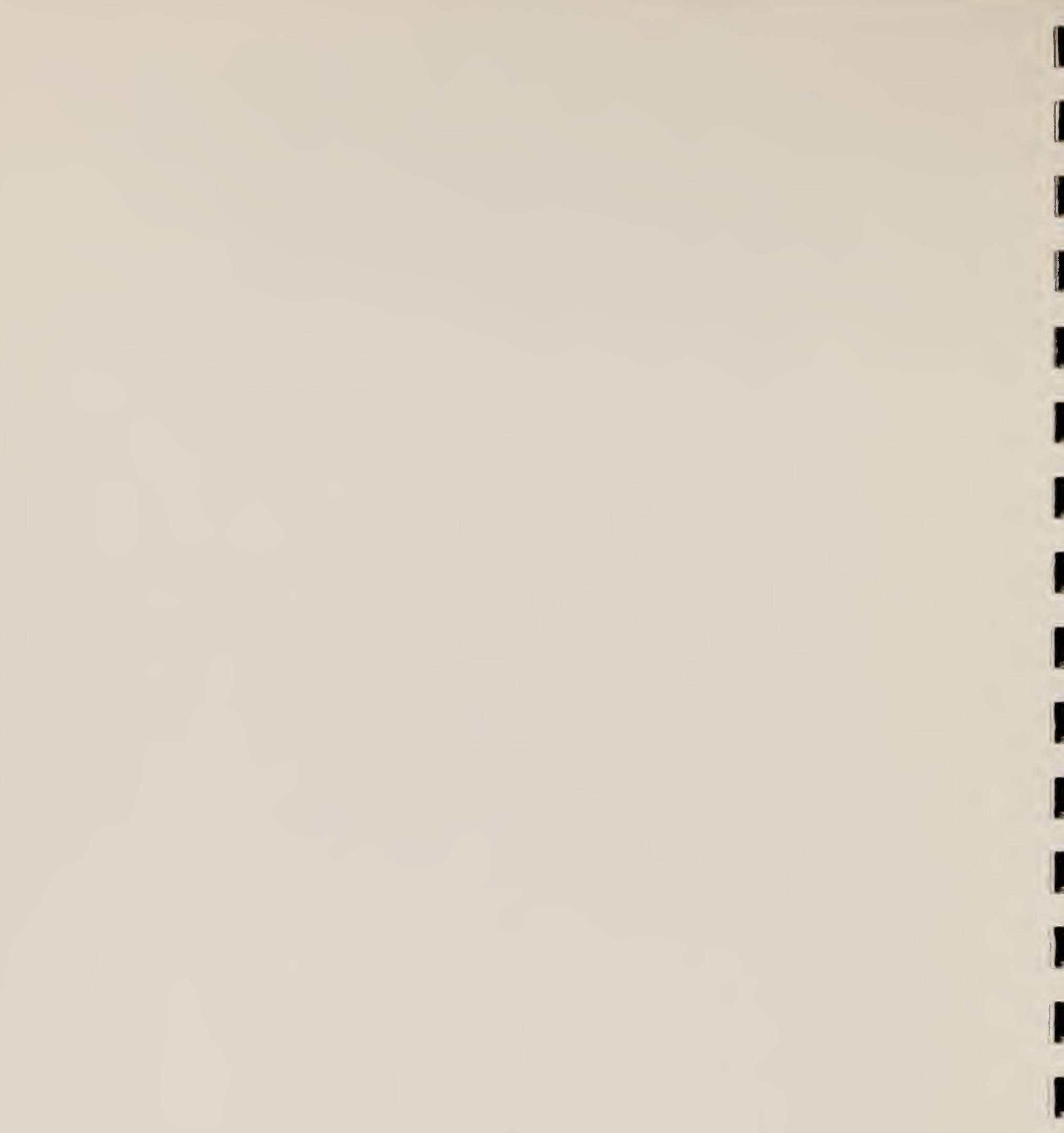


Subject: PMTE Project Background

During May and June 1977, the U.S. General Accounting Office (GAO) issued two comprehensive reports on Federal Government precision measuring and test equipment (PMTE) activities. The first report, titled: "A Centralized Manager is Needed to Coordinate the Military Diagnostic and Calibration Program" (GAO Report \#LCD-427), complimented the Department of Defense for having an advanced PMTE Program, with a sophisticated system for coordination among the many elements of DOD, but was critical of DOD's slow progress toward consolidating its dupl icative facilities and foot-dragging on its other efforts to standardize among the military departments.

The second GAO report, titled: "Centralized Direction Needed for Calibration Program", (GAO Report \#LCD-426), was aimed at the civil agencies of the Government and charged that those agencies have failed to conduct their PMTE activities in an efficient and economical manner. From these two reports, the GAO concluded that improvements could be achieved and significant savings realized through improved coordination of the Government's management and use of PMTE.

In a June 13, 1977, letter to the Director, U.S. Office of Management and Budget (OMB), the GAO recommended that OMB "(1) provide for central program direction and coordination of civil agencies' calibration systems, and (2) require closer coordination with the Department of Defense for standardization and consolidation of the total Federal calibration program".

On August 17, 1977, the Director, OMB, asked the Secretary of Commerce to have the National Bureau of Standards (NBS) take the following actions relative to the Government's use of precision measurement and test equipment (PMTE):

- Assume the lead for coordinating improvements in the management and use of such equipment.

- Assist agencies as necessary to identify areas for improvement.

- Recommend to OMB such actions as are needed to improve the management and use of such equipment.

Within NBS, the Office of Measurement Services (OMS) was given responsibility for preparing and implementing an NBS action plan to respond to the OMB directive. The plan was completed by OMS on Apri1 5, 1978, and approved by OMB on May 24, 1978.

As a first step toward implementing the approved plan, OMS established the "PMTE Project" consisting of a project manager, two technical coordinators, and administrative aides. Staffing of the PMTE Project was completed on November 5, 1978. 




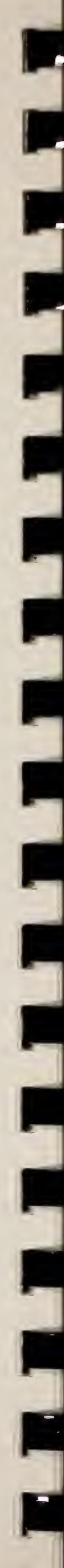


PRECISION

MEASURING AND TEST

EQUIPMENT

U.S. DEPARTMENT OF

COMMERCE

National Bureau of

Standards

December 1979

Vol. 1 , No. 3

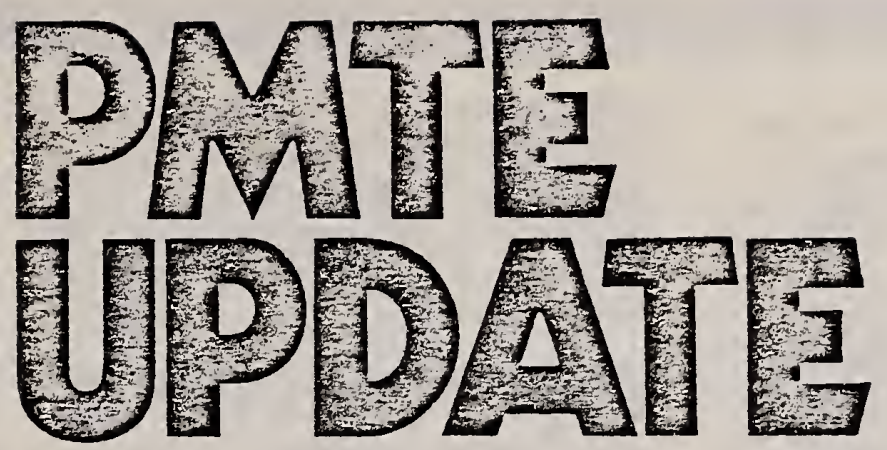

\section{PMTE Project Awards Study}

On September 5, 1979, the NBS Precision Measuring and Test Equipment (PMTE) Project awarded a $\$ 117,523$ contract to the Raytheon Service Company, Burlington, Massachusetts, to study the following two issues:

1. Feasibility and cost-effectiveness of increasing the use of in-situ calibrations, calibration checks, measurement assurance programs or other alternatives to out-of-service equipment calibrations for measurement quality assurance and control in the Federal government.

2. Cosi-effectiveness of optimizing calibration recall intervals and algorithms for PMTE.

In the first study Raytheon will identify and evaluate successful alternatives to out-of-service equipment calibrations to determine the cost and/or benefits of Federal-wide adoption. Both cost savings and improvements to measurement quality will be quantified to the extent possible. This study is scheduled for completion July 1980.

The second study will examine situations where adjustment of calibration recall intervals for different types of PMTE has improved measurement quality. or reduced costs without degrading measurement quality, and will also examine the advantages of Federal-wide guidlines for setting and acjusting PMTE calibration intervals. This study will be completed March 1980.

In the periormance of these studies, Raytheon will distribute questionnaires and visit approximately 20 Federal calibration facilities to gather technical Coninued Center Page

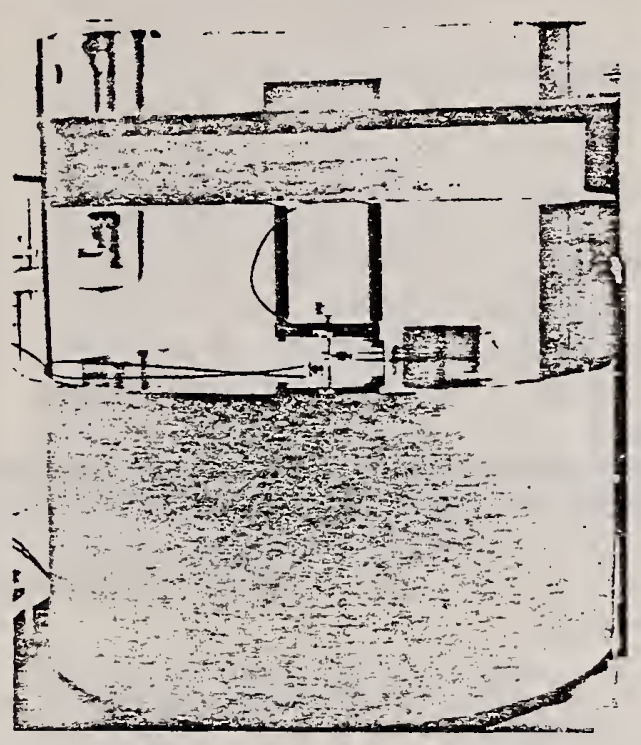

Steel transfer block used for acoustic emission sensor calibration.

\section{Ultrasonic Nondestructive Evaluation \\ By Donald G. Eitzen}

Acoustic emission and pulse/echo ultrasonic techniques offer great potential for detecting and evaluating materials defects nondestructively. However, these methods are sensitive to measurement system characteristics and to the condition of the reference artifacts used. An effort to improve the reliability and diminish the uncertainty of these techniques is underway at the National Bureau of Standards. Part of this effort has focused on the development of measurement services for transducers and reference blocks. The measurement services now available from NBS are described below:

1. Ultrasonic Transducer Power Output Versus Frequency. By using a modulated radiation pressure technique, the absolute total power output of ultrasonic transducers versus frequency is measured over any part of a range from about $1-20 \mathrm{MHz}$. The uncertainty is frequency dependent but is nominally about \pm 5 percent.

2. Ultrasonic Transducer and System Power Output by Calorimetry. By using a twin, series flow ulirasonic calorimetric comparator, the time-averaged total absolute power output of a transducer or sytem is measured for any voltage input waveform in the range of $1-15 \mathrm{MHz}$. The uncertainty is approximately \pm 7 percent.

3. Ultrasonic Reference Block Calibration. Sets of ASTME-127 type ultrasonic reference blocks are compared with an interim aluminum reference block and associated model by using a well-characterized measurement system. The service provides a mechanism for comparing sets of aluminum blocks with the NBS data base and with other reference blocks through the NBS ultrasonic system. This measurement service has recently been expanded to include steel reference blocks.

4. Loaner Services for Transducers and Reference Blocks. By arrangement, carefully characterized ultrasonic source transducers and aluminum reference blocks can be made available for loan. These can provioe on-site calibration of blocks or power and frequency measurement apparatus with the user's system.

An expansion of the NBS artifact system for ultrasonic reference olocks to titanium is also being developec. Also under consideration are materialindependent reference blocks maoe o: amorphous, low-attenuation material: these could replace much of the present multıplicity of reierence artifacts.

A calibration capability has also deer developed ior acoustic emission i $\dot{\sim}$ E 


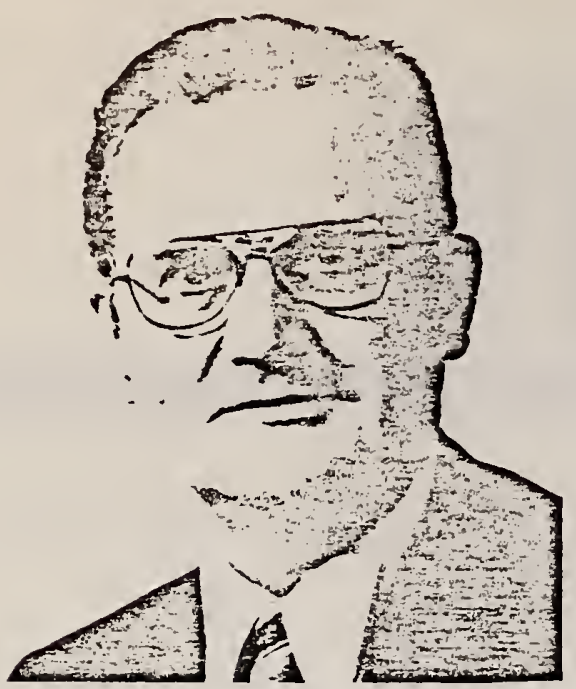

Melvin L. "Dutch" Fruechtenicht, retired Chief of the Metrology Development and Engineering Division, U.S. Army Metrology and Calibration Center, Redstone Arsenal.

\section{Fruechtenicht Retires}

After more than 38 years of Government service, Melvin L. "Dutch" Fruechtenicht has retired from the US Army Metrology and Calibration Center which he founded. Starting his Government career in the early 1940's with the Army Ordnance Corps in Washington, DC, it was not long before he found himself in Army uniform at Frankford Arsenal, Philadelphia. At the end of World War II it was only natural that he would remain as a civilian at Frankford in the Army's Gage Laboratory.

During the next two decades, there were many changes in the calibration requirements of the Army, changes that were necessary to support complex weapon and missile systems. Consequently, in 1962, the US Army Metrology and Calibration Center was established at Franktord Arsenal to develop and provide calibration standards for the field Army. The core of the new Center was the Army Gage Laboratory and the top civilian helmsman was its Technical Director, Dutch.

After five years, the Center was relocated at Redstone Arsenal. Alabama, where Dutch became Chief of the Metrology Development and Engineering Division. With only 13 civilians and 4 military people transterrino irom Franikiord to Redstone. re- establishment of the facility was a challenge. Dutch has played down his own role in the rebuilding of the Center at Redstone, but insiders know that because of his guidance the Center has prospered.

Dutch's guidance at the Center will be missed, but fortunately there was a well-qualified candidate to take his place, Fred Seeley, the new Chief of the Metrology Development and Engineering Division. Fred has worked in the Army's metrology program at Redstone Arsenal since 1967. Prior to that, he worked for the Calibration Laboratory at White Sands Missile Range, New Mexico. In the early 1970's, Fred was active in initiating the Army's program for automated calibration systems and calibration support of ATE systems. He is perhaps best known for his work in developing and advancing technology for selfcalibration of automated systems. He also has extensive experience in the field of precision infrared, electrooptical, and basic electrical measurements.

in his new position, Fred Seeley will manage the Army's development and engineering efforts in metrology and calibration. The development, design and acquisition of calibration and repair equipment and facilities for an expanded Army test equipment calibration and repair program makes the job a great challenge.

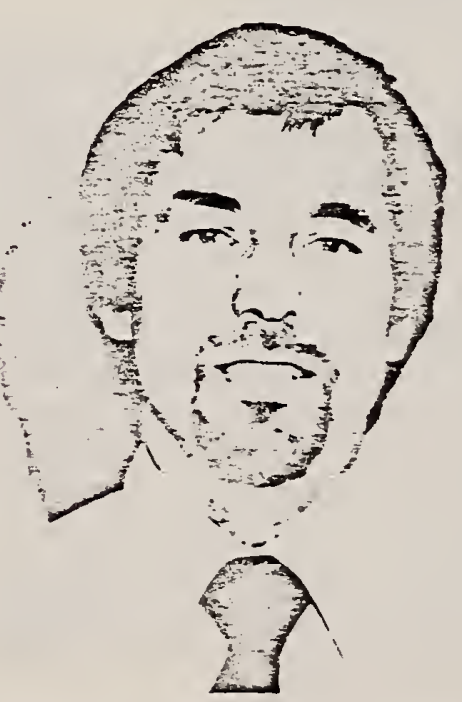

Fred Seely, newily appointed Chief of the Metrology. Development and Engineering Division. U.S. Army Metrology and Calioration Center. Redstone Arsenal.

\section{New Publications}

"Field-Instrument Calibration Moves Ahead in Navy's MECCA", George Sideris, Electronic Design, Vol. 27, No. 15 , p. 36, July $19,1979$.

"PATEC--An Air Force Approach to ATE Calibration", Joseph Santo. Proceedings of AUTOTESTCON '79, p. 242 , Sept. 1979 :

"Metrology Course Register", prepared by the Education and Training Committee of the National Conference of Standards Laboratories, Sept. 1979. Contact: Bryan Werner, Westinghouse R\&D Center, 1310 Beulah Road. Pittsburgh, PA 15235

"Automatic Test Equipment--A Challenge from the Designers". Thomas Keller, Workshop and Symposium of the National Conterence of Standards Laboratories, Oct. 15-17, 1979.

"NBS Interagency Transducer Project 1951-1979--An Overview", Paul S Lederer, NBS Tech Note 1110, issued August 1979.

"Didymium Glass Filters for Calibrating the Wavelength Scale of Spectrophotometers--SRM 2009, 2010. 2013. and 2014". William H. Venable. Jr., and Kenneth L. Eckerle. NBS Specia! Publication 260-66, issued Ociober 1979

NBS publications are available from Joanne Marshall.

\section{Mailing List}

If you want to regularly receive PMTE UPDATE, let us put your name on our mailing list. Call or write Joanne Marshall.
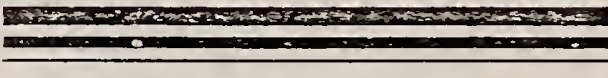

PMTE HPQAT

Publishec by the PMTE Proec: Oitice c: ':eas urement Services. Naticnal Vieasuremen: Laboratory. National Bureau of Stancarcs. US Depariment of Commerce.

Editor: Kainryn Leedy

Production: Joanne Marshall

For additional iniormation. cail (301) $921-2805$. ci write

Ctfice of Measurement Services Nailonal Bureau oi Stancaras Wasning:on DC 20234 


\section{GIDEP - One Way to Save Those Hard To Get Resources}

Does your organization write calibration procedures, design systems, and/or components, need failure experience data, or have an interest in exchanging metrology information with other organizations? If your answer to any of the above is yes, then you need to know about the GovernmentIndustry Data Exchange Program (GIDEP).

The GIDEP is a cooperative activity between Government and Industry participants seeking to reduce or eliminate expenditures of time and money by making maximum use of existing knowledge. The program provides a means to exchange certain types of technical data essential in the research, design, development, production, calibration, and other operational phases of the life cycle of systems and equipment.

The program is centrally managed and funded by the Government. Its participating organizations include most Federal agencies, the Canadian Department of Defence, and hundreds of industrial organizations.

Participants in GIDEP have access to four major data banks:

- Metrology Data Bank

- Engineering Data Bank

- Reliability-Maintainability Data Bank

- Failure Experience Data Bank

The proper utilization of these data banks can assist in the improvement of

\section{Meeting Ammouncements}

ATE Seminar/Exhibit, Janúary 7-10, 1980, Pasadena, CA. Contact: Kate Fitzgerald, 1050 Commonwealth Ave., Bcston, MA 02215, (617) 232-5470.

Precision Thermometry Seminar, March 10-14,1980, and September 8-12, 1980 , NBS, Washington, DC 20234. Contact: Nancye E. MCBryde or James F. Schooley, Temperature Measurements and Standards Division, (301) 921-3315 or 3316 .

American Society for Nondestructive Testing, Conference/Display, March 2427, 1980, Philadelphia Marriott, Philadelphia, PA. Contact: Conference Department, ASNT, 3200 Riverside Drive, P. O. Box 5642, Columbus, OH 43221, (614) 488-7921.

Micromeasurements on Integrated-Circuit Silicon Wafers, July 15-18, 1980 , NBS, Washington, DC 20234. Contact: Elaine C. Cohen or John M. Jerke, Electron Devices Division, (301) 921-3786 or 3621.

Electrical Measurements at High Voltage Levels, April 1-3, 1980, NBS, Washington, DC 20234. Contact: F. Ralph Kotter, Electrosystems Division, (301) $921-3121$

Metrology of Modern Electronic Instrumentation, May 13-15, 1980, NBS, Washington, DC 20234. Contact: Barry A. Bell, Electrosystems Division, (301) $921-2727$

Traceability for Ionizing Radiation Measurements. May 8-9, 1980. NBS, Washington, DC 20234. Contact:H. T. Heaton, II, Building 245, C229, (301) 921 2551.

Time and Frequency User's Seminar, Spring and Fall, 1980. NBS. Bovider, CO 80303. Contact: George Kamas, Time and Frequency Division (303) 499-1000 $\times 3378$.

Introduction to Vibration and Shock Survivability, Measurement, Analysis, Calibratıon, and Testing. 5-day course given on various dates in various cities. Contact: TLstin Institute of Technoiogy. 22 E. Los Olivos St.. Santa Barbara, CA 93105,1805 ) $682-7171$.

quality and reliability and reduce costs in the development, manufacture, and support of complex systems and equipment:

The Metrology Data Bank (MDB) contains related metrology engineering data on test systems, calibration systems, and measurement technology and test equipment calibration procedures, and has been designated as a data repository for the National Bureau of Standards (NBS) metrology related data.

GIDEP also provides three special services: the ALERT system, in which the participant is notified of problem areas, the Urgent Data Request (UDR) system, in which a GIDEP participant may query all other GIDEP participants on specific problems and the Metrology Information Services (MIS) which provides rapid response to GIDEP participants on queries related to test equipment and measurement services. The MIS system also includes an extensive research capability which is available to participants on a fee basis.

GIDEP participants are not subiect to any fees or assessments. However. each participating organization must provide an internal program operation to include at least one Representative, a microfilm reader-printer, and adequate working area within its facility.

Participation requirements or additional information about GIDEP may be obtained by contacting the Director. GIDEP Operations Center, Corona, California 91720. (714) 736-4677, or Autovon 933-4677

\section{PMTE (continued)}

and cost data related to the government's management and use of PMTE. Members of the PMTE Project staff will accompany Raytheon on many of these visits and will monitor the company's performance throughout the contract.

The results of these siudies are expected to point the way towards significant improvements and cost reductions in the manage ment and use of PMTE throughout the Federa! government.

Contact: Jack Vogt (301) $921-2805$ 


\section{Standards} Information Service

The National Bureau of Standards maintains the Standards Information Service (SIS) to provide up-to-date information on standards and standardization activities. The core of this function is the maintenance of a reference collection of engineering and related standards, which includes over 240,000 standards, specifications, test methods, codes, and recommended practices issued by:

- U.S. technical societies, professional organizations, and trade associations

- State purchasing offices

- U.S. Government agencies

- Foreign national and international standardizing bodies

The staff of SIS is prepared to respond to inquiries from government, industry or private individuals on the existence, source, and availability of standards, standardization activities and related activities. They also prepare lists and bibliographies of standards and publish general and special indexes of standards. In many cases, they have information on historical versions of standards as well as the current standard.

In order to use the services of the SIS, which are available at no cost, contact them directly at the address below. Requests should be as specific as possible. Include all terms necessary to locate the standards of interest (e.g." $x$-ray machines rather than medical electronic equipment). Their response will be a list of the appropriate standards together with information on where copies of the standards can be obtained.

Standards Information Service

Room B-162, Building 225

National Bureau of Standards

Washington, DC 20234

(301) 921-2587 Telex: 89-8493

\section{Video Tape Facility}

By E. P. Williams

The US Army Metrology and Calibration Center (USAMCC), Redstone Arsenal, Alabama, has established its own Video Tape Program. A video tape capability and library were established for providing tapes to aid calibration technicians and repairmen of test. measuring and diagnostic equipment in the proper operation, maintenance and calibration of US Army calibration standards. In addition to video tapes on calibration standards, tapes are also available on general subjects such as "Why Calibrate," "What's a db," "Practical Transistors," and "Digital IC Troubleshooting." If you have problems with the maintenance of a calibration standard, understanding the latest state-of-the-art in techniques, or just need retresher training, the USAMCC Video Tape Library may have a tape to solve your problem. These tapes are available for loan to government calibration and repair facilities worldwide. Contact: Commander

US Army Missile Command ATTN: DRSMI-MFTT

Redstone Arsenal, AL 35809

(205) 876-2984 AV: $746-2984 / 7661$

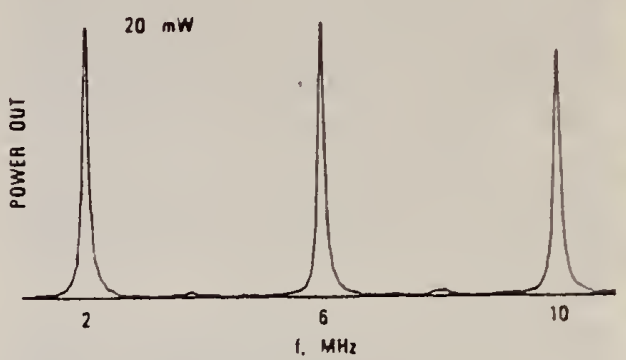

Transducer frequency response as determined by the modulated radiation pressure, shown for one of the NBS transducers avallable for loan.

\section{Ultrasonic (continued)}

transducers and will shortly be offered as a measurement service. This activity is partially supported by a larger EPRI/NBS Acoustic Emission Program and by the Office of Naval Research. The objective is to celermine the sensitivity versus frequency of $A E$ transducers over the approximate range of 100 to $1000 \mathrm{KHz}$. This is accomplished by obtaining time histories from the transcucer uncer test and the NBS standard transducer both mounted on a large $(2200 \mathrm{~kg})$ steel transfer block. The input is a simulated source on the same suriace of the block as the transducers.

Contact: D. G. Eitzen (301) 921-3646

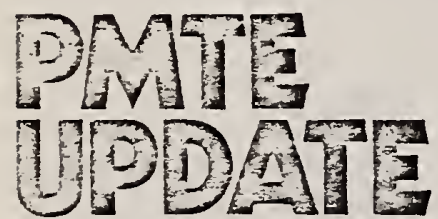

- Standards Information Service

- GIDEP

- Nondestructive Evaluation

- PMTE Study

- Video Tape Facility

- Publications

- ivieetings
U.S. Department of Commerce

National Bureau of Stancards

Washington, D.C. 20234

512

Official Busıness
Postage and Fees Paic

US. Department

of Commerce

COM 215

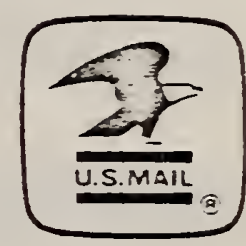

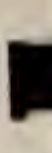


U.S. DEPARTMENT OF

COMMERCE

National Bureau of

Standards

June 1980

Vol. 2, No. 1
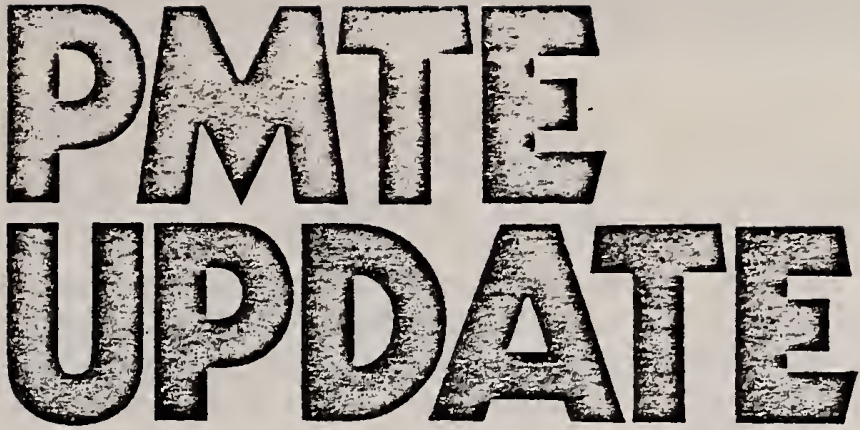

\section{PMTE Notes}

\section{By Jack Vogt}

In our May 1979 issue, I described the PMTE Project and its principal objectives. Since we have now completed our first full year of operation, I want to describe some of the things we have been doing over the past year, as well was our thoughts for the future.

Most of our first year efforts have been directed toward three of our major objectives; improving communications and exchange of information among agencies, assisting other agencies in identifying areas for improvement, and identifying particularly effective practices for broader adoption.

Some of the things we have done are:

- Publication of this newsletter, the PMTE UPDATE, and publication of the first edition of SP 546, "Catalog of Federal Metrology and Calibration Capabilities". As an indication of the acceptance of UPDATE, we are pleased to say that more than $70 \%$ of the articles in our first four issues have come from you, our readers. The trend in circulation is upward--from an initial distribution of 600 for the first issue to more than 2100 for this issue. I think these facts are a real tribute to all of you who have contributed, and to our editor, Kathryn Leedy, for the fine job she has cione in putting it all together.

- Provide assistance to the NASA Headquarters staff in a comprehensive survey of quality and reliability assurance programs at the Johnson Space Center. Through assuming principal responsibility for the metrology and calibration part of the survey. we were able to significantly improve our own knowledge of NASA PMTE policies and operations. including severai particulariy eitectue practices. while at Coninued on sage 6

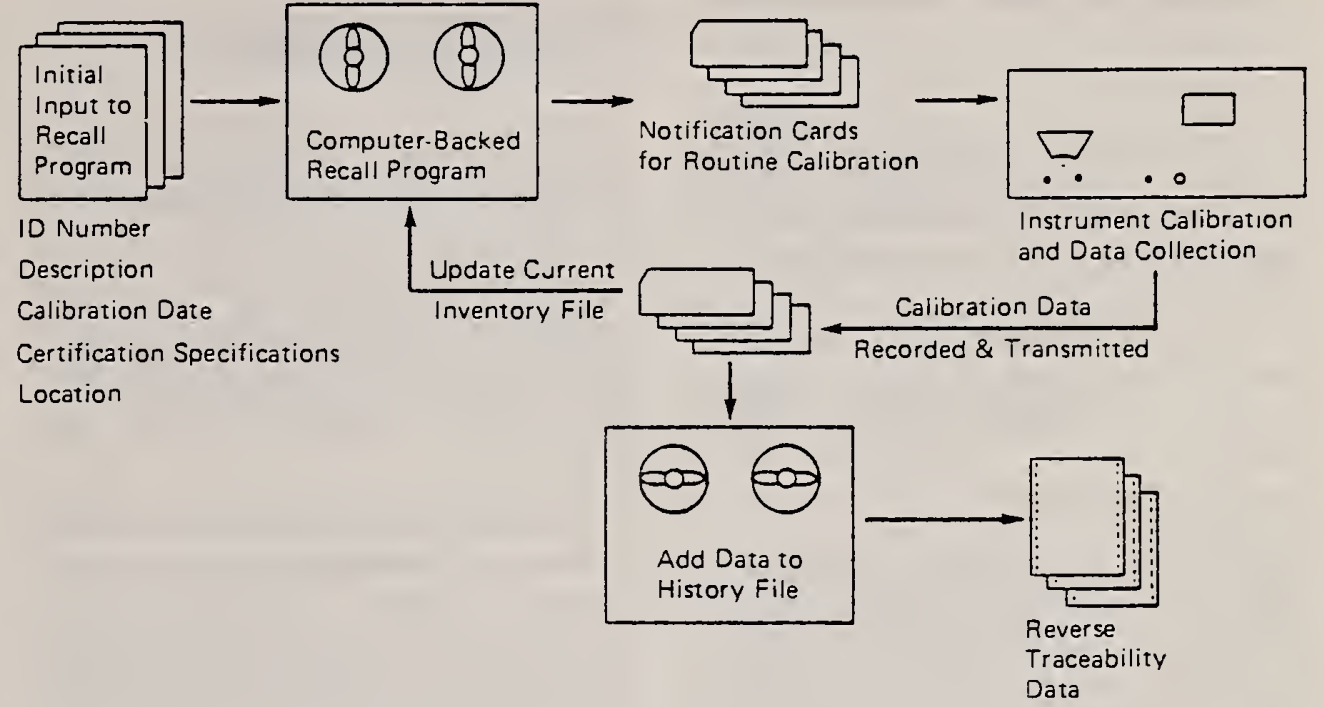

Reverse traceability system at the Department of Energy's Oak Ridge facility.

\section{Reverse}

\section{Traceability}

By Paul W. Pless

Reverse Traceability--what is it? Why do we need it? It is the ability to determine which instruments were calibrated with a given standard during a specified time interval. When a standard is recalibrated and found to be out-of-tolerance, reverse traceability is a valuable tool for eliminating or minimizing costly product retest where instrument calibration is suspect, especially when two or more similar standards are available for calibration work.

Prerequisites for a reverse traceability system are a computer-backed recall program and an indivicual identificaiton number for each instrument and standard. The computer-backed recall program must provide a history file ano a current inventory (working) file. Required data for the current inventory file are identification number, description. caliuration date, certification specifications, and location of each instrument and standard. We use a card form for Computer Services to generate a "notification of scheduled calibration" for each instrument or standard. We print on this card the data required ior the current inventory file. These data, plus the new calibration date, the identification number of the standard(s) used for the calibration, and the condition in which the instrument was found at calibration. are required data for the history file. The card is used to transmit these data to the computer dala base for updating the current inventory file and adding traceability data to the history file.

If a large error is found durıng the calibration of a stanciard. then the validity' of measurements made with this staridard, and with instruments calibrated with this standard are quesionable ior the period since the previous calioration of the standard. In the event this occurs. we use our reverse iraceability program to identify all ins: uments calibrated with this stancaro curnng this period. The orintout wilt ist all of the calibratıons of each. ins:rumeni curing 


\section{Technician Training}

In the past several years, members of the National Conference of Standards Laboratories (NCSL) have identified a growing need for training programs for calibration technicians. The Education and Training Committee of NCSL has addressed this problem in several ways including publication of a register of training courses and maintenance of a lending library of training courses on video tape.

A new and enthusiastically received project is the development of adjunct training courses for presentation at the same time and in the same place as the NCSL regional meetings. The courses are designed to be one day in length, so that as the NCSL member attends the regular meeting, technicians from his organization attend the training session.

The first adjunct training course was held in NCSL Region II at the Lockheed Electronics Company in Plainfield. NJ. under the direction of Stanley Hale of Bendix Corporation. The subject was basic metrology which included information on mass, length, temperature, voltage, resistance, and time and frequency. It was presented to 21 attendees from a wide variety of government, industrial, and commercial laboratories at a cost of only $\$ 10$ per attendee. The entire course was prepared and presented by NCSL members on a voluntary basis. The response of the students was enthuslastic. indicating they would like similar courses on each of the parameters introduced.

Sased on the success of Region II. several other NCSL Regions plan to hold adjunct courses in the coming year for more information, contact Bryan Werner, 401-5X40. Westinghouse Electric R\&D Center, Beulah Road, Pittsburgh, PA 15235 (412) 2563420 .

\section{Editors Notes}

- It has been suggested that each copy "PMTE UPDATE" have holes ched in the maroin so that it can be ored in a three-rino binder. Would this neloful io you? Lel me know your ierence.
- Notices of meetings and announcements of new publications are difficult to locate. I need your help. Please send me your information

- If you would like to receive your own copy of "PMTE UPDATE" regularly, contact Joanne Marshall to get on the mailing list.

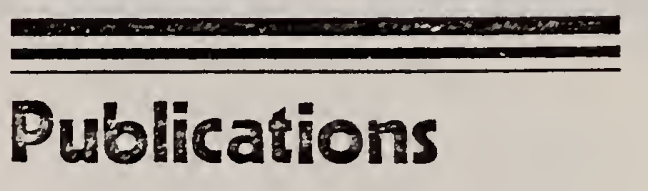

"Training Index," GIDEP, Nov. 1979. Available from GIDEP Operations Center, Corona, CA 91720.

"NVLAP Glossary of Terms for Laboratory Accreditation. Product Certification and Standardization." D.B. Thomas, NBSIR 79-1956, Jan. 1980.

"A Practical Test of the Air Density Equation in Standards Laboratories at Differing Altitude." R.M. Schoonover, et.al., Journal of Research of the NBS. Vol. 85, No. 1, p. 27, Jan-Feo 1980.

"Industry/Joint Services Automatic Test Project--Final Report." F. McGinnis, Project Chairman. Dec. 79. Copies available from Project Executive Secretary R.D. Wothen, Aerospace Industries Assoc., 1725 Desales Street, NW, Washington. DC 20036, (202) $347-2315$.

"Didymium Glass Filters for Calibrating the Wavelength Scale of Spectrophotometers--SRM 2009, 2010. 2013. and 2014," W.H. Venable, Jr. and K.L. Eckerle, NBS Spec. Pub. 260-66. Oct. 1979.

"Nondestructive Tests Used to Insure the Integrity of Semiconductor Devices. With Emphasis on Acoustic Emission Techniques." G.G. Harman. NBS Spec. Pub. 400-59. Sept. 1979

"Accurate Linewidth Measurements on Integrated-Circuit Photomasks." J.M. Jerke. NBS Spec. Pub. 400-43. Feb. 1980.

"A Reference Method for the Determination of Chloride in Serum." R.A Velapoldi, et.al.. NBS Spec. Pub. 260-67, Nov. 1979.

'Large Scale Integration Digital Testıng--Annoiated Bibliography.
1969-1978," T.F. Leedy, NBS Tech Note 1102. Aug. 1979

"Classification of Industrial lonizing Radiation Gauging Devices," by ANSI Subcommittee N43-3.2, NBS Handbook 129, Oct. 1979.

"A 20 Bit + Sign, Relay Switched D/A Converter," T.M. Souders and D.R. Flach, NBS Tech Note 1105. Oct. 1979.

"Measuring Aerosol Particles." D. Bright and I. Chabay, et.al., Chemtech. Nov. 1979. Contact: D. Bright, A208 Chemstry BIdg., NBS Wasnington. DC 20234

"SPEED2. A Computer Program for Reduction of Data from Automatic Data Acquisition Systems." R.D. Peacock and J.M. Smith, NBS Tech Note 1108. Sept. 1979.

"Design of Reflection Apparatus for Laser Beam Profile Miesurements." E.G. Johnson, Jr., NBS Tech Nore 1015. July 1979.

\section{Free Publications}

The following publications are available free to qualified readers.

"It's About Time," a newsletter written for the time and frequency community by Frequency and Time Sysiems. Inc.. 182 Conant Street, Danvers, MA 01923.

"Technology Transier Fact Shee!." a publication which is part of the Navys efforts to encourage lechnology transfer to a broad auoience. Contac: Gary Wagner, Code E411. Naval Suriace Weapons Center. Danlgren. VA 22448

"Test Trends," a newsletter about micro control published by the Vilcro Control Company, 7950 Main Stree: NE, Minneapolis, MN 55432 .

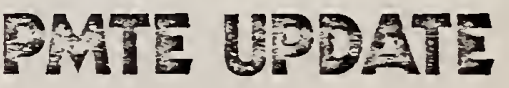

Published bv the PMTE Prolesi. Oifice of Measuremeni Services. Naicnal $\because$ isurement Laboratory. National Bureau c: Sia-Ja:cS US Decartment of Commerce.

Editor: Katnryn Leeoy

Production: Joanne Marsna!

For acditional information.

call (301) $92 i-2805$. or witie

Otfice of kiseasurement Sar.:a

Nalional Bureau c: Sianza: =s

Wias?ingion D.C 20234 


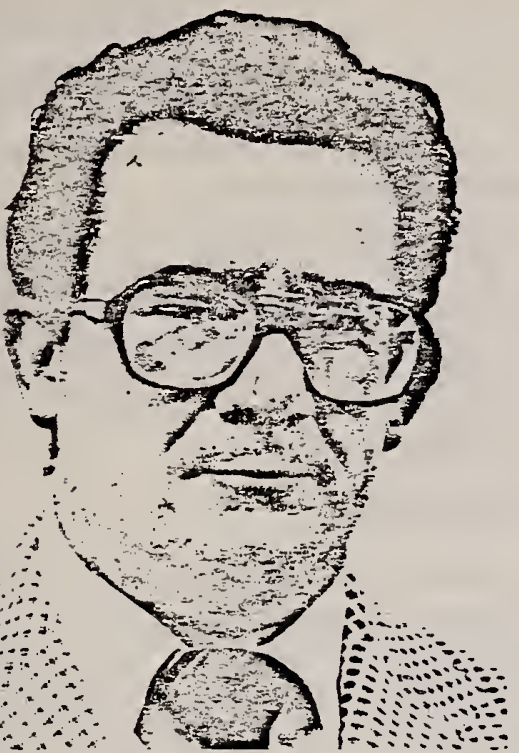

Fred Kern, Vice Chairman of the NASA Metrology and Calibration Workshop. Kern is head of the Optical and Pressure Measurements Section at NASA's Langley Research Center.

\section{NASA Workshop}

The National Aeronautics and Space Administration held its third annual Metrology and Calibration Workshop in Estes Park, Colorado. Representatives from all the NASA Centers and NASA Headquarters, NBS, U.S. Army and several NASA support contractors attended the conference. The workshop was established to provide for a centralized agency-wide standardization and coordination of metrology and calibration activities. The program included assessment of current NASA metrology and calibration activities; an update by Jack Vogt on the NBS PMTE Project; a review of the U.S. Army Metrology and Calibration System for Calibration Interval Analysis and Adjustment by Frank Westmoreland and Jack Bradford; plans for improvements in agency-wide equipment management; a review of the use of GIDEP services; current and planned MAP activities at each center; use of agency-wide calibration and standards decals; status of each center's calibration activities and use of automatic calibration equipment; NASA's calibration capabilities catalog; and development of the group's goals and objectives.

Future directions of the group include; development of coordinated procedures for determining recalibration intervals for the NASA Reference, Transfer, and Working standards; development of agency-wide system for using video tape metrology, calibration and maintenance training films; development of a coordinated program for development and use of ATE; and continued coordination of NASA activities with NBS's PMTE project. This group is presently evaluating the requirements for improvements in the techniques and standards for calibrating radiometric sensors, a problem area identified during a recent Flight Technology Improvement Workshop at the University of Maryland. Finally, the workshop format was evaluated to improve the effectiveness of group activities and future workshops.

Contact: Fred Kern, (804) 827-3234.

\section{Welcome ISA}

We would like to welcome our new readers from the Instrument Society of America. We appreciate the efforts of Ted Plum at ISA Headquarters in handling the distribution. We stress to our ISA readers that PMTE UPDATE is intended to be a medium for information exchange between people interested in calibration and metrology. We urge you to participate in this exchange by submitting articles. or ideas for articles, about your own PMTE experiences.

\section{NCSL Conference}

ATE Seminar/Exhibit, June 16-19, John B. Hynes Veterans Auditorium, Boston, MA. Contact: Benwill Publishing Corp., (617) 232-5470.

National Conference on Weights and Measures, June 22-27, ShorehamAmericana, Washington, DC. Contact: H. Wollin, (301) $921-3677$.

Micromeasurements on Integrated-Circuit Silicon Waters, July 15-18, NBS, Gaithersburg, MD. Contact: E. Cohen, (301) 921-3786.

NCSL 1980 Workshop and Symposium, September 22-25, NBS, Gaithersburg. MD. Contact: B. Belanger, (301) 921-2805.

Autotestcon '80, November 3-5, Sheraton Washington Hotel, Washington, DC Contact: T. Dankworth, (703) 521-5956.

Cherry Hill 1980 Test Conference, November 10-13. Cherry Hill. NJ. Contact: $K$. Anderson, (609) 424-2856.

Second International Symposium on Flow: Its Measurement and Control in Science and Industry, April 6-10, 1981. Marriott's Pavilion Hotel, St. Louis, MO. Contact: G. Mattingly, (301) 921-3681.

Second International Conference on Precision Measurement and Fundamental Cor.stants. June 8-12, 1981. NBS. Gaithersburg. MD. Contact: B. Taylor, (301) $921-2701$
The National Conference of Standards Laboratories (NCSL) has announced that their 1980 Workshop and Symposium will be held September 22-25, 1980, at the National Bureau of Standards in Gaithersburg. Maryland. Dennis Gallagher, Leeds \& Nortinup. and Brian Belanger, NBS, will co-chair the conierence.

The theme of the 1980 meeting will be "Management's Role in Measurement Quality." Technical sessions will address ATE, NBS Measurement Assurance Services, instrumentation inventory control. NDE, standard reference materials, and quality assurance.

Contact: Brian Belanger. NBS. Physics B362. Washington. DC 20234 301 $921-2805$ 


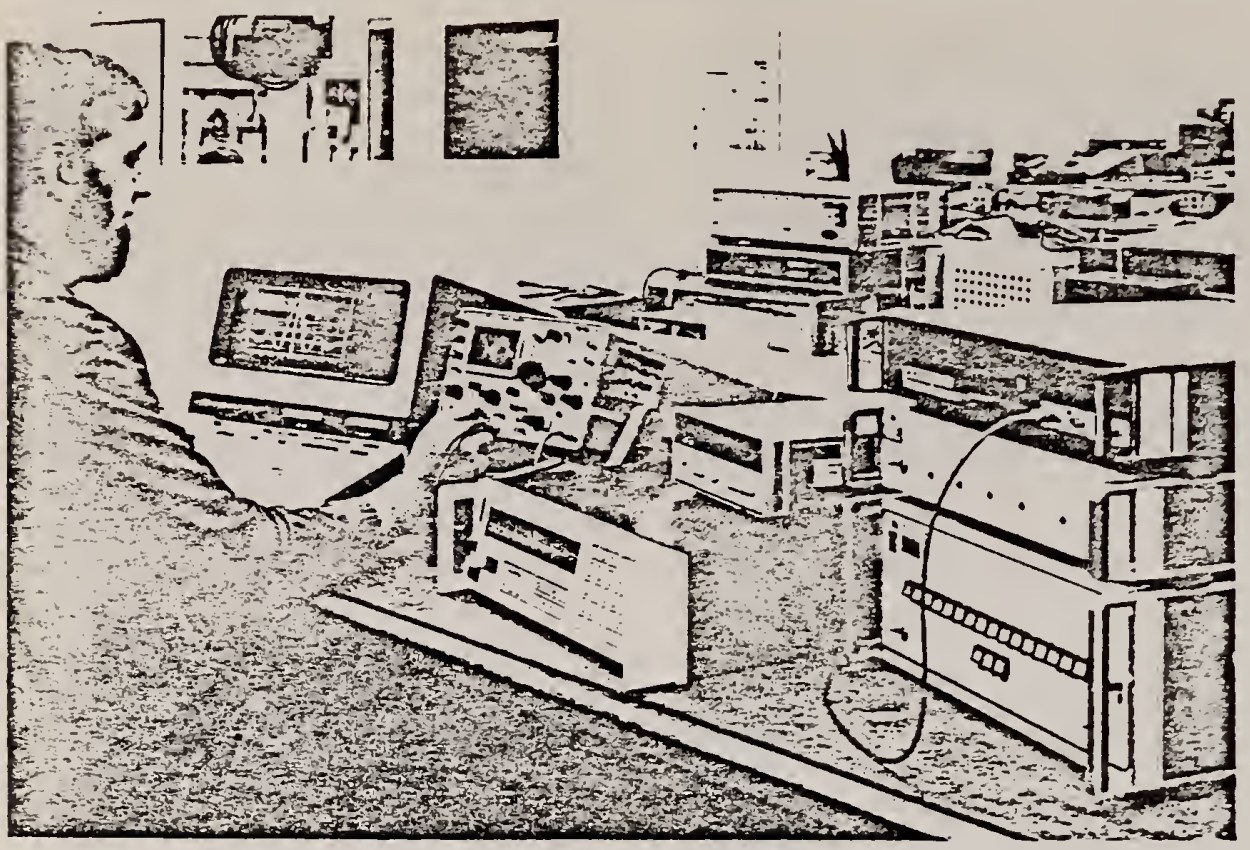

Measurement of $A C$ waveforms, an activity which relies heavily on the calibration soltware. (Naval A vionics Metrology Laboratory)

\section{Software Management}

Automated measurements offer an exciting and productive future for the metrology laboratory, but also provide new and significant challenges. Computer software, as an integral part of measurement systems, must have development, quality assurance, and utilization control. Software "certification" can be as important as hardware "calibration" in assuring the quality of automated measurements.

The Metrology Division of the Naval Avionics Center (NAC) has studied the problem and has developed a system for software management and control. The system is designed to maintain quality control. schedule control, and cost control.

Even though the system at NAC is used for software control for automated calibration on the HewlettPackard System 1000, it is anticipated that many of the principles and methods employed will have wider application and may be utilized wherever automated measurements are made.

A complete description of the system is avaliable in an NAC report entitled System 1000 Calibration Software Aerraçement and Control System." omas A Pearson. Direcior.
Metrology Div. 430, Naval Avionics Center, 6000 East 21 st Street, Indianapolis, Indiana 46218, (317) 353-3931

\section{Reverse Traceability (continued)}

the period, even if the calibration was performed using another similar standard. This is valuable information when coupled with the data showing the condition in which the instrument was found at the time of calibration. If the reverse traceability printout shows that subsequently calibrated with another similar standard. and the instrument was found to be in tolerance at the time of the later calibration, then we have reasonable assurance that the error found in the questionable standard was not reflected in that instrument. This knowledge restores our confidence in the measurements made by that instrument and thus eliminates costly product retesting. As a matter of interest. We find that subsequent recalibration with another similar siancard occurs frequently because the calibration interval for the typical instrument is shorter than that for the standard.

Our next step is to recalibrate those instruments identified by the reverse a questionable instrument was traceability printout as being last calibrated using the questionable standard. Then, we retest only the product which was originally tested with instruments found out-of-tolerance at this special recalibration.

Contact: Paul W. Pless, Oak Ridge $Y$ 12 Plant, Oak Ridge, TN 37830, (615) 574-2558. (This facility is operated for the Dept of Energy by Union Carbide Corp.--Nuclear Div. Under Contract W-7405 eng26).

\section{Editor's Note:}

"Reverse traceability" as described by Mr. Pless in this article should not be confused with the term "traceability" which refers to the ability to show that measurements are accurate relative to NBS or some other reference base. See for example "The Evolving Concept of Traceability" by Z. C Belanger, PMTE UPDATE, Vol. 2, No. 2 , September 1979.

\section{Conference}

The National Bureau of Standards will host the Second International Conference on Precision Measurement and Fundamental Constants in Gaithersburg, Maryland, from June 812, 1981

Conference organizers hope io provide an international forum for scientists engaged in experimental and theoretical research on precision measurements relating to the iundamental physical constants and to ihe testing of related theory. The last such comprehensive international meeting was held at NBS in August of 1970.

One goal of the 1981 Conference will be to gather additional cata ior the 1981 adjustment of the values of the fundamental constants recommenced for iniernational use. Proposals for papers for the conierence are now being solicited.

Contact: Dr. B. Taylor, Bldg. 220, Room. B258. NBS. Washingion. DC 20234.

\section{New Standard}

A modulation factor stancard ras ween developed to support the Feceral Aviation Acministration s recurrements for a measurement cavazility ior the ILS and VOR navigalion sysiems Tre ConunLec on rege 


\section{Laboratory Automation}

The Automatic Test and Calibration Systems Committee of the National Conference of Standards Laboratories (NCSL) has recently produced a directory of automatic calibration system users and a listing of calculator program tapes available for exchange.

The directory of calibration organizations who are utilizing some degree of automation in their calibration processes is designed to:

1. provide a means whereby users of similar automatic calibration systems could share common and unique problems, solutions and experiences, and to

2. serve as a useful source of contacts for those organizations wishing to evaluate the benefits and trade-offs prior to system/instrument acquisition.

The directory is divided into three sections. Section (A) contains the users of major commercial systems. and Section (B) lists the users of inhouse designed systems. Section (C) was developed to identify semiautomatic systems, and any areas wherein sequential data collection or machine data reduction was being utilized. The information for the directory was obtained from several surveys and questionnaires mailed to the NCSL membership during 1977 and 1978 by the Automatic Test and Calibration Systems Committee.

The listing of the desk-top calculator program tapes contains orograms which were developed by NCSL member organizations and are used in conjucrion with desk-top calculators or small controlling computers to perform metrology related tasks such as data reduction. table generation, and in some instances, actual calibration iasks when used with peripheral equipment and/or standards.

Ar exchange program has been ceveloped by the Automatic Test and Calibration Systems Committee to provide for the exchange of tape orograms between interested NCSL memioer organizations. The listing isentifies each tape with a control uncer. itle ine calculatcr used and a zriat sescriation ot inat ine program

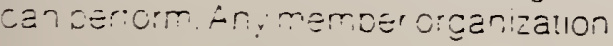

may participate as a REQUESTOR or SUBMITTOR by properly filing a release form with the Committee and following the written procedure for exchange. The information for the listing was obtained voluntarily from a direct mailing to alt NCSL member delegates in 1978. As new programs are developed and offered by member organizations, the Committee will release revisions to the listing to all NCSL organizations who have a signed Release Form on file with the Committee.

Contact: R.B. "Pete" England, General Dynamics Pomona, P.O. Box 2507. MZ4-32, Pomona, CA 91766, (714) 629-5111, ext. $4312 / 3945$

\section{NBS Services}

\section{Acoustic Measurements}

Three new services are available for pressure and iree-field calibration of "half-inch" diameter condenser microphones: pressure calibrations periormed in couplers by comparison with NBS standard microphones; freefield calibration performed at normal incidence in an anechoic chamber using reciprocity methods; free-field calibration of certaın other microphone types.

\section{Acoustic Emission Sensors}

The new calibration service will provide the frequency response of a transducer to surface waves in the solid to which it is attached. The response is absolute, the units being volts output per unit of surface displacement. The measurement is made possible by a technique for generating an accurate step function force, an exact elastic solution for the ensuing motion of the surface, and a precise capacitive motion sensor. A two ton sieel block with optically colished faces is used as the eiastic medium.

\section{Length \& Diameter}

Replacing the linewidth calibration service. N8S will supply through its Standard Reference Materials program a series of artifacts intended for calibratıng optical microscopes used to measure linewidths in the 0.5- to $10, \mu \mathrm{m}$ regime. The first arifiact in this serles. Which wil be announced as
SRM 474, is specifically designed for the measurement of opaque lines and clear spaces on integrated-circuit photomasks in transmitted illumination. This SRM consists of lines and spaces in an anti-reflective chromium film on a glass. substrate. It is designed for use with all commonly used types of linewidth measurement systems, including filar, image shearing, and video micrometer.

\section{Reduction of Little Used Services}

Several services for which there is little or no demand have been discontinued.

- Photographic edge calibrations (NBS furnished)

- Photographic edge calibrations (customer furnished)

- Photographic sinusoid calibrations

- 4-terminal ac resistors up to $10 \mathrm{kHz}$

- Current transformer, ratio and phase angle--1 range at 1 freq., 1 burden. primary current 8,000 to $12,000 \mathrm{~A}$

- Current transformer, ratio and phase angle, at 1 secondary current on additional combination of range, freq., and burden, primary current 8,000 to $12,000 \mathrm{~A}$

- Watthour meters, special high accuracy test--2 determinations of percentage registration

- Coaxial and waveguide pulse power meters

- Irradiance of $253.7 \mathrm{~nm}$ line of $\mathrm{Hg}$ from low pressure mercury lamp

Contact: Lee Kieffer, NBS, (301) 921 2805.

\section{New Standard (continued)}

standard consists of both a orecision modulation meter and a stable amplitude-modulated signal source. Although designed primarily for iLS and VOR signals, it has general purpose capabilities within an ri range of $10 \mathrm{MHz}$ to $500 \mathrm{MHz}$ and an af range of $20 \mathrm{~Hz}$ to $20 \mathrm{kHz}$. Measuremen: uncertainty is less than 0.11 percen: modulation below 90 percent modulaion for ILSIVOR tones of $90 \mathrm{~Hz}$ anc above, and is somewhat greater at 30 $\mathrm{Hz}$. Details of this work are published in "A Stancard for RF Modulation Factor." MG. Arthur and G.R. Reeve. NBS Tecnnical Note 1016. Septembe. 1979.

Contact: M G. Artnur. 1303, 490 . 3603 


\section{PMTE (continued)}

the same time offer suggestions for improvement.

- Provide assistance to the US Air Force Logistics Command Inspector General's Otfice in its inspection of the Aerospace Guidance and Metrology Center (AGMC). Again, this effort was mutually beneficial, as it afforded us an opportunity to learn more about particularly effective Air Force PMTE concepts, and resulted in management improvement suggestions for the AGMC.

- Award of a contract to the Raytheon Service Company to study the feasibility and cost-effectiveness of (1) increasing use of alternatives to outof-service equipment calibrations, and (2) optimizing calibration recall intervals and algorithms. This contract, which was described in greater detail in the December 1979 UPDATE, will be completed this summer and is expected to point the way towards improvements and cost reductions in Federal management and use of PMTE.

During the course of the past year, we have identified. specific opportunities for improvement in PMTE management and use. Some of these are:

CALIBRATION PRODUCTIVITY--OUR observations noted a low of 100 actions per person per year to a high of 1300 actions per person per year at facilities having sımilar although not identical mixes of workload.

AVERAGE CALIBRATION TIME--we saw a range of 0.5 hour to more than 7 hours for the same mechanical item in one case and 0.5 hour to 15 hours in another case involving an electronics item, with less pronounced variations in many more cases.

TERMS AND DEFINITIONS --the PMTE terms we are all familiar with just don't mean the same thing to everyone.

CALIBRATION PROCEDURES.differences between procedures for the same item appear to be more philosophical than technical in nature.

CALIBRATION INTERVALS--rariging from 90 days to 2 years for the same model PMTE item.

TRACEABILITY FOR AUTOMATIC TEST EQUIPMENT (ATE)--the current concepts for estabilishing measurement traceability are somewhat questionable.

\section{About the Future}

While continuıng our regular activities. we will emphasize projects which are specifically directed toward the opportunities we have identified. For example, we have gathered considerable information on average calibration times from several representative facilities, and are now irying to understand the reasons for large variations in both calibration tıme and productivity--in the hope that both productivity and quality can be improved.

We are reviewing multiple calibratıon procedures to assess the technical and economic differences and to determine the costs/benefits of standardization. We are preparing a publication of PMTE terms and definitions.

Our plans also include more involvement in ATE traceability, completion/ implementation of the cost-effectiveness studies contract, gradual expansion of the Interagency PMTE Group to include other agencies. and preparation of special hanabocks/ reports aimed at assisting managers and users of PMTE. These plans, however, will be changed as necessary to contorm to the priorities identified over the next several months. This is where your input and assistance can ve most valuable--let us have your cancid comments on boin our ongoing projects and the direction of our future plans. We are vitally interested in your opinions and suggestions as to now we can best utilize our limitec resources to coordinate and provide assisiance in improving PMTE opera- tions at botn the national and local leveis

Senc me your suggesions or call me at (301) $921-2805$

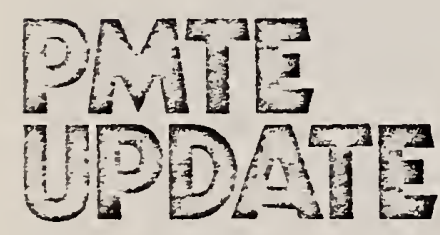

- Reverse Traceability

- Laboratory Automation

- NASA Workshop

- Soítware Mianagement

- Tecnnician Training

- NCSL Conference
U.S. Department of Commerce

Natıonal Bureau of Standards

Washington. D.C 20234

512

Official Business
Posiage and Fees Palc

US Dedarment

of Commerce

CON 215

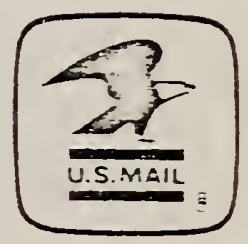





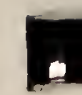




\author{
COST-EFFECTIVENESS \\ STUDY TO DETERMINE AITERNATIVES TO \\ OUT-OF-SERVICE CAIIBRATION OF \\ PMTE WITHIN THE FEDERAL GOVERNMENT
}

12 August 1980

NBS CONTRACT: NB79SBCA0061

\begin{abstract}
Prepared for
The Precision Measuring and Test Equipment (PMTE) Project

Office of Measurement Services National lieasurement Laboratory U.S. National Bureau of Standards Washington, D.C. 20234
\end{abstract}

\author{
Prepared by \\ RAYTHEON SERVICE COMPANY \\ 2 Wayside Road \\ Burlington, Massachusetts 01803
}


EXECUTIVE BRIEF

\section{Background}

Federal agencies use Precision Measuring and Test Equipment (PMTE) valued in excess of $\$ 2.7$ billion. Total Federal expenditures for calibrations of instruments are estimated to be more than $\$ 200$ million per year. A General Accounting office (GAO) report to the Office of Management and Budget (OMB) has criticized some Government agencies for not having well-coordinated and managed agency-wide programs for calibration of their PMTE. The OMB believes there are potential cost savings in more effective use of PMTE and has asked the National Bureau of Standards (NBS) to coordinate a program within the Federal Government to improve the management and use of PMTE.

In performing this coordination, NBS established the Precision Measuring and Test Equipment (PMTE) Project and developed a PMTE Program Plan which was approved by both $O M B$ and GAO. The direction, as outlined by the OMB, is as follows:

- Assume the lead for coordinating improvement in the management and use of such equipment.

- Assist agencies as necessary to identify areas for improvement.

- Recommend to OMB such actions as are needed to improve the management and use of such equipment.

As part of these tasks, the PMTE Project on September 5, 1979, awarded a contract to the Raytheon Service Company (RSC) to study two areas (1) alternatives to PMTE out-of-service calibration, and (2) optimization of calibration recall intervals and algorithms. This report contains the findings and recommendations of Study Number 1, Alternatives to PMTE Out-of-Service Calibration. 


\section{Introduction}

Precision measuring and test equipment must be accurate and precise; that is, calibrated to produce readings comparable to readings from devices traceable to the U.S. National Legal Measurement Standards. There is a degradation with time in the characteristics of PMTE so that, in order to establish confidence that it has retained the ability to make accurate and repeatable measurements, PMTE must be recalibrated periodically. In most cases today, PMTE throughout the Federal Goverment is removed from service and transported to a calibration laboratory or facility for recalibration. Depending upon the nature and reliability of the PMTE, it may be removed from service for recalihration as often as three or more times per year, and for several days each time. Since many applications demand constant availability of PMTE, the result has often been procurement of duplicative PMTE for use while similar items are out-ofservice for recalibration. In view of the generally high acquisition cost of PMTE, and the additional cost of recalibrating duplicative items, this is not generally regarded as an acceptable solution to the problem. Some agencies are known to have developed and implemented a variety of alternatives to this. conventional out-of-service calibration concept. For example, one agency uses mobile truck/van laboratories to take the calibration capability to installations remote from the central laboratory. The same agency, and other agencies have also permanently relocated calibration capabilities, as satellite units, to remote locations with large workloads. A number of facilities have reportedly implemented other types of measures allowing calibration to be done on-site, or even in situ to greatly minimize out-of-service time. The identification of such altematives, determination of the extent and success of their use today, and feasibility and desirability of their broader use throughout the Federal Government is the subject of this report.

\section{Methodology}

The study was begun on September 5, 1979. The Raytheon Service Company, in close coordination with the PMTE Project staff, selected 23 different calibration activities for site visits by RSC personnel, with an additional fifty-two 
activities selected for completion of a questionnaire. Both site and questionnaire locations were chosen to be representative of agencies, both military and civilian, throughout the Federal Government and with a wide range of workload. For comparison, some private industry facilities were included. Data gathered represents information available between September 1979 and March 1980 .

A major purpose of this study was to identify, explain, and define alternatives to out-of-service equipment calibrations; that is, methods of performing calibration without removing the PMTE item being calibrated from service during the calibration process.

Only one application of an absolute alternative to out-of-service calibration was observed at the twenty-three sites visited, and it was in use on a limited basis and only in one parameter (mass). However, several other partial or less absolute alternative methods of delivering calibration services were observed, all of which significantly shorten the out-of-service period. For the purpose of this study, all of these methods are referred to and treated as "alternatives to out-of-service equipment calibration."

\section{Alternatives Identified}

The methods currently used as alternatives to out-of-service calibration are:

1. Satellite Laboratories - Elements of a central laboratory relocated to installations or heavy workload sites on an installation. Takes the calibration capability nearer to the workload.

2. Mobile Truck/Van Laboratories - Similar to satellite laboratories, but mobile to allow one such laboratory to service PMTE at several instailations or sites with smaller workloads. Takes the calibration capability even nearer to the workload, but may cost more due to travel and per diem expenses. 
3. Calibration Carts - Mobile carts equipped with selected calibration standards and rolled to and from workload points within an installation or building on an installation. May be used to calibrate PMTE in situ.

4. Portable Standards - Selected calibration standards which may be hand carried or otherwise easily transported to and from workload points and offer the same benefits as calibration carts.

5. Measurement Assurance Programs (MAP) - Use of externally certified standards to verify local measurement systems (standards, techniques, operators, environment, etc.). Often accomplished in situ.

6. Operator Calibration - Accomplished by the owner/operator using a simple reference standard furnished by a central laboratory.

7. Wire Transmission - Dissemination of standard or reference signals from a central laboratory to satellite laboratories, production lines, etc.

\section{Other Factors}

Several other factors which affect the frequency or length of the outof-service period were also identified. Examples of such factors are turnaround time, pick-up and delivery services, loan crib/exchange pools, and variations to calibration requirements, e.g., no periodic calibration required (NPCR), calibrate before use (CBU), calibrate only upon repair, and limited calibration. All of these factors were reviewed as a part of this study and are discussed in this report. 


\section{Findings and Recommendations}

\section{(1) Finding}

Only one true example of in situ calibration was identified. It is an excellent example of a successful application of in situ and in-service calibration, and there is every reason to believe that other cases exist where good results can be obtained.

\section{Recommendation}

Encourage increased use of in situ and in-service calibration. Perform research and development to facilitate increased use.

\section{(2) Finding}

Out-of-service time for PMTE calibration in a central laboratory is excessive (16-17 days). At some facilities, centralized pick-up and delivery services have shortened out-of-service time to 7-8 days, on-site calibration has shortened it to 3-4 days, and in situ calibration has shortened it to one day or less.

\section{Recommendations}

Encourage increased use of on-site and in situ calibration at all Government facilities.

Encourage use of centralized pick-up and delivery services. 


\section{(3) Finding}

PMTE is often underutilized. Central loan pools have improved utilization.

\section{Recommendation}

Central loan pools be established.

\section{(4) Finding}

Many facilities under or overcalibrate PMTE as a result of a suboptimum calibration interval program and/or routine acceptance of manufacturer's specifications as tolerance limits, regardless of the actual use of the instrument.

\section{Recommendations}

Consider adoption of calibration interval programs recomended in NBS Study, "Optimizing Calibration Recall Intervals and Algorithms".

Review actual instrument use to establish realistic tolerance limits.

Broaden tolerance limits and limit calibration. Calibration need only be done to the extent necessary to meet user requirements.

\section{(5) Finding}

Some facilities periodically calibrate PMTE which does not require or warrant periodic calibration. 
Recommendations

Designate instruments which are not used to make quantitative measurements as "No Periodic Calibration Required (NPCR)" and remove them from the recall system.

Place seldom used instruments in a "Calibrate Before Use" only status.

\section{(6) Finding}

Calibration program management information is limited, lacks uniformity and in some cases is non-existent. Facilities cannot exchange such data, and facilities without such data cannot effectively assess or manage their calibration programs.

\section{$\underline{\text { Recommendation }}$}

Develop a uniform calibration program management information system for Federal Agency use.

\section{(7) Finding}

There is confusion created by the lack of common understanding of the meaning of various metrology and calibration terms.

\section{$\underline{\text { Recommendation }}$}

Develop and disseminate standard terminology. 



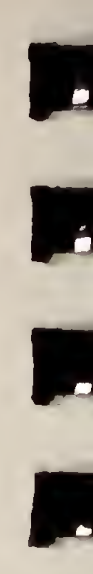




\author{
COST-EFFECTIVENESS \\ STUDY TO DETERMINE METHODS FOR \\ OPTIMIZING CALIBRATION INTERVALS FOR \\ PMTE WITHIN THE FEDERAL GOVERNMENT
}

12 August 1980

NBS CONTRACT: NB79SBCA0061

\begin{abstract}
Prepared for
The Precision Measuring and Test Equipment (PMTE) Project

Office of Measurement Services National Measurement Laboratory U.S. National Bureau of Standards Washington, D.C. 20234
\end{abstract}

Prepared by

RAYTHEON SERVICE COMPANY

2 Wayside Road

Burlington, Massachusetts 01803 
Background

Federal agencies use Precision Measuring and Test Equipment (PMTE) valued in excess of $\$ 2.7$ billion. Total Federal expenditures for calibrations of instruments are estimated to be more than $\$ 200$ million per year. A General Accounting Office (GAO) report to the Office of Management and Budget (OMB) has criticized some fovernment agencies for not having well-coordinated and managed agency-wide programs for calibration of their PMTE. The OMB believes there are potential cost savings in more effective use of PMTE and has asked the National Bureau of Standards (NBS) to coordinate a program within the Federal Government to improve the management and use of PMTE.

In performing this coordination, NBS established the Precision Measuring and Test Equipment (PMTE) Project and developed a PMTE Program Plan which was approved by both OMB and GAO. The direction, as outlined by OMB, is as follows:

- Assume the lead for coordinating improvement in the management and use of such equipment.

- Assist agencies as necessary to identify areas for improvement.

- Recommend to OMB such actions as are needed to improve the management and use of such equipment.

As part of these tasks, the PMTE Project on September 5, 1979, awarded a contract to the Raytheon Service Company (RSC) to study the optimization of calibration recall intervals and algorithms. This report contains the findings and recommendations of RSC. 


\section{Introduction}

Precision measuring and test equipment must be accurate and precise, that is, it must be calibrated to produce repeatable readings comparable to readings from other devices whose accuracy is traceable to the National Legal Measurement Standards. There is a degradation with time in the characteristics of PMTE so that, in order to establish confidence that it has retained the ability to make accurate and repeatable measurements, PMTE must be calibrated periodically. The more often that recalibration occurs, the greater the assurance that an instrument is capable of accurate and repeatable measurements, and the greater the cost of the calibration program. The determination of the optimum method for establishing/adjusting the frequency of recalibration, i.e., calibration interval, is the subject of this report.

\section{Methodology}

The study was begun on September 5, 1979. The Raytheon Service Company, in close coordination with the PMTE Project staff, selected 23 different calibration activities for site visits by RSC personnel, with an additional 52 activities for completion of a questionnaire. Site visit locations and mailed questionnaire recipients were chosen to be representative of agencies, both military and civilian, throughout the Federal Government and with a wide range in workload. For comparison, some private industry facilities were included. Data gathered represent information available between September 1979 and March 1980. 


\section{Alternatives Identified}

The methods currently used for establishing calibration intervals are:

1. Adjustment by Instrument Seriạl Number--takes into account individual characteristics of an instrument; decision is made with the most recent although perhaps limited statistical information.

2. Adjustment by Manufacturer's Model Number--based on statistical analysis of all instruments of a given model number; does not consider individual instrument performance.

3. Adjustment by Instrument Class--broad assignment of intervals; difficult to group different model instruments into classes.

4. Adjustment for the Entire Instrument Population--simplifies calibration scheduling; results in over- or under-calibration.

5. Arbitrary Intervals--flexible; lacks systematic approach.

6. No Periodic Intervals--useful as "calibrate before use" for instruments seldom used, in storage, or requiring verification immediately before each use.

7. No Calibration--useful as "calibration not required" for instruments which do not perform quantitative measurements. 


\section{Findings and Recommendations}

\section{(1) Finding}

A calibration program which utilizes a systematic method of setting intervals based on accumulation of performance data for each individual instrument provides the best means for assuring instrument quality for minimum cost.

\section{$\underline{\text { Recommendations }}$}

The following should be discouraged:

- Setting the same interval for the entire instrument inventory.

- Adjusting intervals based on an instrument class, e.g., oscilloscopes or meters.

- Adjusting intervals by outside, e.g., user, evaluation.

- Arbitrary interval alteration in response to fiscal constraints.

\section{(2) Finding}

It was found that there are many successful calibration programs in existence which implement interval adjustment based on instrument model number or serial number. The details of the algorithms vary somewhat, but all consist of collection and analysis of data by serial number and subsequent interval adjustment based on serial number or based on the accumulation of data for all instruments of a given model number. This allows the implementation of trend analysis for individual instrument performance and the ability to identify problem instruments. 


\section{Recommendations}

- Collection and retention of instrument performance data should be organized on a serial number basis.

- Using the data collected, intervals should be adjusted on either a serial number or a model number basis, depending on the needs and requirements of the enacting facility. Factors to be considered in establishing a program include: reliability requirements, quality level of applications supported by PMTE, size of the calibration program, availability of calibration support and availability of administrative support.

- Consistent with program objectives, interval adjustment procedures should be as flexible as possible in the establishment of intervals. If all intervals are set in multiples of a given number, that number should be as small as practical.

\section{(3) Finding}

The three military services publish listings of calibration intervals for a very large variety of PMTE. The listings, organized by model number, are based on the individual military services' analysis of instrument performance of PMTE in their inventories.

\section{Recommendation}

If a facility has a limited statistical basis for setting an interval for a particular instrument, or if the facility is not well equipped to develop an interval adjustment program, the intervals established by one of the military services should be utilized. These intervals would also be convenient to use as initial intervals in a program of interval adjustment by serial number. If more than one interval is listed, the interval most closely associated in application should be selected. 


\section{(4) Finding}

During the site surveys, it was not clear that, in all cases, each agency or facility had a sound basis for calibration interval adjustment. If criteria are not carefully set, instrument quality will be inadequate or the calibration program will be unduly costly.

\section{Recommendation}

Methods for assessing optimum quality-level criteria should be developed and disseminated.

\section{(5) Finding}

It was found that considerable variation exists in the manner in which calibration program management information is accumulated and retained. In some cases such information is non-existent. Most facilities deal with the same kind of data (scheduled requirements, accomplishments, instrument intolerance data, cost data, etc.) but handle it in different ways so that it is difficult for one Federal facility to benefit from the experience of another. More importantly, facilities which do not accumulate such information cannot effectively assess or manage the effectiveness of their calibration program.

\section{Recommendation}

A uniform calibration program management information system be developed and implemented for use in Federal agencies. 
(6) Finding

Most interval adjustment pragrams are based on the historical collection of in-or out-of-tolerance data for an instrument; the broader the tolerance limits, the longer the intervals. Most frequently, the tolerance limits are taken to be the manufacturer's specifications, regardless of the actual use of the instrument.

\section{Recommendation}

The use of broad tolerance limits and limited calibration should be strongly encouraged. Calibration need only be done to the extent necessary to meet the user's requirements.

\section{(7) Finding}

There is confusion created by the lack of common understanding of the meaning of various technical and management terms related to calibration and metrology.

\section{Recommendation}

Standard calibration términology should be developed and disseminated for use throughout the Federal Government. Terms relating to calibration program management should be included. 
(8) Finding

From the questionnaire survey, it was found that there is a wide variation in the intervals that are currently being assigned for the same model instruments.

$\underline{\text { Recommendation }}$

Further study should be undertaken to determine why there is such a wide variation in intervals assigned. Factors to be considered include interval assignment method and instrument application.

5.9 
.

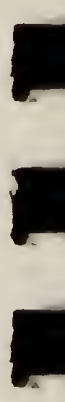

.
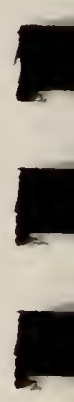

.

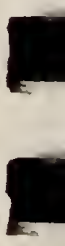

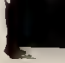

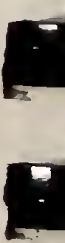





\title{
OFFICE OF MANAGEMENT AND BUDGET Federal Participation in Voluntary Standards
}

\begin{abstract}
The Office of Management and Budget circular printed below. issued in its final form on 17 January 1980, lays out government poilicy for federal participutzon in the cievelopment and application of voluntary standards: The text of the circular is reprinted from the Federal Register of 21 January.
\end{abstract}

\section{OFFICE OF MANAGEMENT AND BUDGET}

\section{Office of Federal Procurement Polfcy}

Federal Participation in the Deyelopment and Use of Voluntary Standards; Final Issuance

AGENGY: Office of Management and Budget. Office of Federal Procurement Policy.

ACtion: Final Issuance of OMB Circular No. A-119.

SUHAARY: OMB Circular No. A-119 was approved and issued by the Director of OMB on January 17, 1980. Developed during the last three years, the Circular provides policy guidance to Executive

Departments and Aģencies in participating in the development of voluntary standards and in their subsequent use. Specifically, the Circular encourages Federal participation in. and support oi. voluntary standards-deveioping activities when those activities are conducted in accordance with specified rules assuring due process. The Circular also encourages Federal use of adequate voluntary standarcs for procurement purposes. The Circular assigrs to the Department of Commerce an administrative and coordinating role for executive branch implementation of those policies. the Circular is set forth belosv, in its entirery.

FOR FUATHER IMFORIATAION COATACT.

Mr. David F. Baker. Deputy Assistant Adninistrator for Logistics. teleprione 202i395-i207.

James D. Currie.

Acring Administrotor.

[Circular No. A-119]

Fedural Participation in the

Development and Use of Voluntary

-Sicaciards

as:usry 17. 1980.

1. Purpose. This Circular establishes oolicy to be followed by executive brarch agencies in working with organizations which plan. develop. produce. and coordinate voluntary stardards for muterials, products. systems. services. processes, and practices. It also establishes policy to be followed by executive branch agencies in adopting and using such standards in procurement activities.

2. Background. The Federal Govermment performs many functions which involve the use of products and services that depend upon reliable standards. Many standards tor such products and services, appropriate or adaptable for the Government's purposes. are developed and are available from certain privat? organizations, known as vollintary standards bodies. Federal participation in the standards-related activities of these voluntary bodies provides incentives and opportunities to establish standards that serve national reeds. In addition. Federal use of voluntary standards, whenever practicable and appropriate, reduces the cost of developing and using standards and. thereby, serves the public interest. Federal adoption of suci standards. moreover. is consistent with, and in furtherance of, the Federal Govermment's general policy of relying upon the private sector to supply Govemment needs for goods and services, as enunciated in OMB Circular No. $A-76$.

3. Coverage. This Circular applies to ail executive branch agency participation in voluntary standards activities, both domestic and international, except as roted in paragraph 6. but does not apply to United States participation in muitinational standards activities pursuant to treaties.

4. Dejintitions. As used in this Circular:

a. Executive agency (hereinaiter referred to as "agency") meens an executive department. independent commission, board, bureau. oitica agency, Government-owned or controlled corporation or other estabiishment of the the Federal Government, inciuding regulatory commission or board. and also the municipal govermment of the District of Colurbia. It does not include the legislative or judicial brancines of the Federal Government.

b. Sicndara' means a prescribed set of rules, conditions, or requirements concerned with the definition of terms: classification of components: delineation of procedures: speciñcation of materials, performance, design. or operations: or measurement of çuality and quantity in describing materials. products, systems. services. or pracices.

c. Voluntary stondaras are established generally by private sector bodies and are available tor use by any person or organization. private or governmental. The term includes wist are commonly referred to as "incustry standards" as well as "consensus standards" but does not inciuce professional standarcs of personal conduct. private standards of individual firms, or standards manciated by law. such as those contained in the United States Pharmaccpeia and the Nacional Formulary, as referenced in 21 U.S.C. 351.

d. Govemment standarcis include inhouse and agency standarcis and specifications as weil as Fecieral and .ilitary standards and specifications.

e. Voluntary siandards bodies are nongovemmental bodies which are broadly based. muiti-member. comestic and multinational organizations inciuding. for example. nonprofit organizations, indusiry association, and professional technical societies which develop. establish. or coordinate voluntary standards.

f. Slandards-developing groups are committees, boards. or any other principal subdivisions of voluntary standards bodies, estab!ished by such bodies for the purpose ui developing. revising, or reviewing standarcis and which are bound by the procecures of those bodies.

g. Secretcry means the Secretary of Commerce or that Secretary's designee.

5. Policy. It is the general policy ot the Federal Government :o:

a. Re!y on voluntary standards both domestic and intemacionai with respect to Federai procurement. ivinenever feasible and consistent with luw and regulation pursuant to isw:

b. Participate in voluntury standarcs bodies when such particieation is is the puclic interest and is compatibie with agencies' missions, authorsties. priorities, and budset limitations. Such participation. horvever, is limited to those voluntury bodies that conduc: 
their standards activities in accordance with the criteria listed in paragraph $6 c$. unless such participation is required by law; and

c. Coordinate agency participation in voluntary standards bodies so that (1) the most effective use is made of Fecieral agency representatives; and (2) the views expressed by such representatives are in the public interest and as a minimum, do not conflict with the interests and established views of Fecieral agencies.

6. Policy Guidelines. In implementing the policy established by this Circular, agencies should recogrize the positive contribution of stanciardization and related activities. When properly conducted, standardization can increase procuctivity and efficiency in industry, exparid opportunities for international tade, conserve resources, and improve health and safety. It aiso must be recognized, however, that these activities, if improperly conducted. could suppress free and fair competition. impede innovation and technical progress, exclide safer and less expensive products, or otherwise adversely affect trade, commerce. health, or safety. Full account shall be taken of the impact on the economy, applicable Federal laws, policies, and national objectives including, for example, laws and regulations relating to antitrust, naticnal security, small business, product safety, environment. and conflicts of interest. In light of these considerations, the following policy guidelines are established to assist and govern implementation of the policy exunciated in paragraph 5 . except that the provisions of paragraph $6 c$ are not applicable to Federal participation in multinational organizations which develop and issue voluntary international standards. It should also be noted that the provisions of this Circular are not istended to create delay in the administrative process or provide new grounds for judicial review.

\section{c. Reljonce on Voluntary Standaris in} Federal Procurement.

(1) Voluntary standards that will serve the agencies' purposes and are consistent with applicable laws and regulations should be adopted. in whole or in part. and used by Federal agencies in the interests of greater economy and efficiency. While it is recognized that. acceptable voluntary standards are more likely to result when developed in accordance with the due process and otrer basic criteria listed in paragraph 6.c. it is also recognized that suitable voluntary standarc's have resulted and will result from other developmental processes. Consequently. it would not be in the public interest for these guidelines to be interpreted as prohibiting the use of suitable voluntary standards merely because they were not developed in accordance with the criteria contained in paragraph 6.c. Federal agencies may, therefore, adopt and use such standards unless specifically prohibited by law from doing so. Voluntary standards will be given preference over in-house standards in the absence of mandatory Government standards unless use of such voluntary standards would result in impaired functional performance. unnecessary cost to the Government or the Nation, anticompetitive effects or other significant disadvantages.

Agencies responsible for developing Government standards will periodically review their existing standards and cancel those for which an adequate and appropriate voluntary standard can be substituted.

(2) Voluntary standards which are adopted by Federal agencies will be cited. along with their dates of issuance and source of availability, in appropriate publications, regulatory orders, and related in-house documents.

(3) Agencies will not be inhibited, if within their statutory authorities, from developing and using in-house standards in the event that voluntary standards bodies cannot or do not develop a standard needed by, and acceptable to. these agencies or do not do so in a timely fashion. Nor sinall the policies contained in this Circular be construed to commit any agency to the use of a voluntary standard which, after due consideration, is. in its opinion, inadequate, does not meet statutory criteria, or is otherwise inappropriate for the agency concerned.

\section{b. Participation in Voluntary} Standards Bodies.

(1) Participation by knowledgeable Federal employees in the standards activities of voluntary standarcis bodies and standards-developing groups should be actively encouraged and promoted by Federal agency oifficials when such participation is consistent with the provisions of paragraphs $5 \mathrm{~b}$ and $6 \mathrm{c}$.

(2) Federal employees who, at Govermment expense, participate in standards activities of voluntary standards bodies and standarisdeveloping groups will do so as Federal agency representatives and, as such. must be authorized to participate by appropriate agency officials.

(3) Federal agency participation in voluntary standards bocies and standards-developing groups will not, of itself, connote agency agreement with. or endorsement of. decisions reached by such bodies and groups or of standards approved and published by voluntary standards bodies.

(4) For procurement applications in which Federal requirements are consistent with those of the private sector, participation by Federal azency representative should be aimed at contributing to the development of voluntary standards which will eliminate the necessity for in-house development of Federal standarcis for use in the procurement process.

(5) Federal agency representatives serving as members of standardsdeveloping groups should participate actively in the standards actuvities of those groups but in doing so, snould not seek to dominate such groups. Active participation is intenced to include full involvement in discussions and technical debates, registering of opinions and. if selected. serving as chairpersons or in other oificial capacities on such groups. Federal agency representatives may vote at each stage of standards development unless specifically prohibited from coing so by the head of the agency or that oificial's designee.

(6) The number of individual Federal agency participants in a given voluntary standards activity shall be kept to the minimum required for efiective presentation of the various program. tecinnical, or other concerms of Federal agencies.

(7) The granting of Federal support to a voluntary stanciarcis activity sisall be limited to that which is clearly in furtherance of an agency's mission and responsibility. Normally. the total amount of Federal support given shall be no greater than that of all nonFecieral participants in that activity except where it is in the direct anc predominant interest of the Fecieral Government to develop a seecied standard or revision therelo and suci development appears unlike!y to ocsur in the absence of such Fecieral support. The form of agency support. subject to legal and budetary authority. may extend to:

(a) Direct financial suppor: e.g.. grants, sustaining membersnips, and contracts:

(b) Administrative support: e.g. travel costs, hosting of meetıngs. and secretarial functions;

(c) Technical supoort: e.g. cooperative testing for standards evaluation and participation of agency personnel in the activities of standards-deveioping groups; and

(d) Joint planning with voluatary standards bocies to facilitate a coordinated effort in resclving priority standardization problems.

(8) Participation by Federal asency representatives in the policymaking process oi voluntary standards bodies is encouraged-particularly ir maliers such as establishing p:iorities. developing procedures for preparing. 
ceviewing, and approving standards. d creating standards-developing oups. In order to maintain the private. nongovernmental nature of such bodies. bowever, Federal agency

presentatives should refrain from cisionmaking involvement in the nternal day-to-day management of such bodies (e.g.. selection of salaried officers d employees, establishment of staff laries).

c. Identification of Voluntory Standards Bodies for Federal

rticipation. As further described in ragraph $7 \mathrm{a}(2)$, the Secretary will Jrepare and maintain a list of voluntary standards bodies which wish to have

nderal participation in their standards tivities and which conduct their Ictivities in accordance with the due Jrocess and other basic criteria untained in this paragraph. Voluntary andards bodies must be listed as a Frecondition to Federal participation dritess sich participation is required by

w. The due process and other basic

teria to be adhered to by listed

roluntary standards bodies are as ollows:

(1) That public notice of meetings and her standards activities is provided in in appropriate and timaly fashion: and. o invite broadly-based representation.

hrougn media which are designed to ach those persons reasonably xpected to have an interest in the iubject. Interested persons may include. or example, consumers; small ousiness ncerns: manufacturers: labor: poliers: distributors; industrial. nstitutional and other users:

anvironmental and conservation groups: d State and local procurement and de officials. Such notices should nclude a c!ear and meaningiul

tescription of the purpose of the meeting other proposed activity;

(2) That public notice is given in an appropriate and timely lasnion of the initiation. final review, and adoption or proval of new and revised voluntary incards. and the proposed withdrawal of suci standards. througn media characterized in paragraph 6c(1). Such tice must clearly describe the purpose d scope of the relevant standards:

(3) That meetings are open and that participation in standards activities is lailable to interested persons.

areascnable restrictions on nembership in standards-developing roups by means of protessional or hrical qualifications, trade uvirements. unreasonable iees. or ther such restrictions must be avoided; (4) That decisions reached by - luatary standurcis bodies in their ndards activities represent suostantial agreement. diter a concerted effor: to resolve objections, and that bach agreements are reached by the participants in accordance with the published procedures of the voluntary standards body and the judgment of the official(s) duly appointed by the voluntary standards body. Such agreements imply more than a simple majority but not necessarily unanimity:

(5) That prompt consideration is given to the expressed views and concerns of all interested parties including proposals made for new or revised standards:

(6) That adequate and impartial mechanisms for handling suostantive and procedural complaints and appeals are in force for use by interested parties:

(7) That appropriate records, sufficient to review and understand what transpired. are maintained of formal discussions, decisions, standardis drafts, technical or other rationale for critical requirements of standards. complaints/ appeals and their resolution, meeting minutes and balloting results: and that such records are retained in accordance with published procedures and are readily accessible to all interested persons on a timely and reasonable basis:

(8) That either a one-time written policy statement is maintained in the official procedures of the body or that standards literature published by the voluntary standards body specifically state that participation by Federal agency representatives in that body does not constitute Government endorsement of that body or the standards which it develoos. A voluntary standard which includes a list of its develupers and identifies Federal agency representation must include this disclaimer:

(9) That voluntary standards bodies publish their official procedures and make them available to interested. parties on a reasonable basis:

(10) That voluntary standards are periodically reviewed and revised. as necessary, and that participation in the review process is granted to all interested persons:

(11) That preference is given to the use of performance criteria in standards development when such criteria may reasonabiy be used in lieu of design. materials, or construction criteria.

$i$. Responsibilities. a. The Secretary will:

(1) Coordinate and promote executive branch implementation of the policy in paragraph 5, in accordance with the policy guidelines in paragraph 6 . The Secretary will establish within nine months of the date of this Circular:

(a) Written procedures, developed in such a manner as to allow for the participation of all interested parties, to implement the provisions of this Circular; and

(b) An Interagency Committee on Standards Policy which the Secretary may call upon when needed to assist in implementing the policy contained herein. All executive branch agencies having substantial standardization involvement will be represented on that Committee and will cooperate with the Secretary, as requested, in carrying out tasks assigned to the Committee.

(2) Develop and maintain current a list of voluntary standards bodies which indicate a desire to be listed and which certify to the Secretary that they are in compliance with the due process and other basic criteria cited in paragraph $6 \mathrm{c}$ and which provide published evidence of such compliance. The list will be published in the Federal Register and will include the names of voluntary standards bodies and those relevant standards-developing groups in which Federal participation is authorized. The listing will not, however, inclucte names of units subordinate to standardsdeveloping groups. Úpon receipt of a specific challenge regarding nonadherence to the due process and other basic criteria. the Secretary will take appropriate steps to determine whether a voluntary standards body or standards-developing group is. in fact. conducting its activities in accordance with the aforecited criteria. the Secretary may call upon the Department of Justice and the Federal Trade Commission for assistance in establisning specific provisions for the due process and other basic criteria in paragraph oc and in evaluating adherence oy voluntary standards bodies to those provisions:

(3) Establish procedures by which the listing of a voiuntary standards body or standards-developing group can be challenged by interested persons. For purposes of this paragraph. each standards-developing group may be considered separately. Removal irom the list of a group does not automatically call for the removal from the list of all groups of the parent body. or of the parent body itself. The Secretary will establish procedures by which:

(a) Such bodies and groups can be removed from the list if a determination is made by the Secretary that they are operating, and after appropriate notice continue to so operate. without benefic of the due process and other basic criterua cited in paragrạn dòc.:

(b) Federal agencies will be notified of such removal for the purpose of cedsing their participation in the standards activities of such bodies and grouos:

(c) Public notice will be provicted ui actions taken. Such proceciures shall ensure that the rights of the vouy or group which is the subject ot the challenge are comparable to those granted to challengers: and 
(d) Voluntary standards bodies which have been delisted or have had one or more siandards-developing groups delisted by the Secretary may reapply for listing for themselves or for their standards-developing groups.

(4) Establish and maintain current. with the cooperation of Federal agencies, a central public register of all voluntary standards activities in which Federal agencies participate:

(5) Establish and maintain current, a comprehensive and consolidated listing. cross-referenced by subject. of standards developed by voluntary standards bodies and by Federal agencies. Such listing of standards developed by bodies other than Federal agencies shall not necessarily constitute Government endorsement thereof:

(6) Establish a program which shall make available a department-sponsored voluntary dispute resolution service for the rapid handiing of procedural complaints by interested parties against listed voluntary standards bodies. As a precondition to invoking that service, a complainant must seek relief from. and have exhausted al! available sources of remedy within. the affected voluntary standards body. Such a service shall have. among its requirements, the agreemeni of both complainant and respondent to use the service and their consent to accept the determinations of the serrice as the sole and final administrative review by the executive branch:

(7) Report annually to the Office of Management and Budget concerning agency impiementation of this Circular.

b. The heads of executive agericies concerned with standards and standardization activities will:

(1) Implemen: the policy in paragraph 5 of this Circular in accordance with the policy guidelines in paragraph 6 and the procedures to be establisined by the Secretary within 120 days of the issuance of those procedures:
(2) Establish appropriate procedures to ensure that:

(a) Agency representatives refrain from participatiang in the standards activities of voluntary standards bodies and standards-developing groups which are not listed by the Secretary of Commerce as conducting themselves in accordance with the due process and other basic criteria cited in paragraph 6c. unless such participation is specifically mandated by la w;

(b) Agency representatives on voluntary standards bodies are familiar with the due process and other basic criteria contuined in paragraph $6 c$. and that agency representatives $u$ ho learn of an apparent infringement of the aforecited criteria by a listed voluntary standards body or standards-developing group register their questions and concerns with that body or group and with their agencies: and

(c) The Secretary is notified of such incidents of apparent noncompliance with the aforecited due process and other basic criteria by a listed voluntary standards body:

(3) Establish appropriate procedures by which agency representatives participating in voluntary standards bodies and standards-developing groups will. to the extent possible. ascertain the views of the agency on matters of paramount interest and will, as a minimum, express views which are not inconsistent or in conflict with established agency views:

(4) Endeavor. when two or more agencies participate in a given voluntary stanciards body or standards-deveioping group. to coordinate the views of their respective agencies on matters of paramount importance so as to present a single. unified position rellective of the public interest. In instances where agreement is not reached by the affected agencies. such agencies will notify the Secretary who shall designate a lead agency. The lead agency will be responsible for developing a unified position on the important matter at issue. In so doing. that designated lcad agency will consider carefuliv the views of the other participating Federal agencies:

(5) Provide for participation in the Interagency Committee on Standards Policy to be established by the Secretary and cooperate with the Secretary. as requested, in carrying out the mission of that Committee:

(6) Consult with the Secretary in the development and issuance of agency reguiations implementing this Circular. and submit. in response to the request of the Secretary, reports on the status of agency interaction with voluntary standards bodies.

8. Reporting Requirements. One vear from the date of issuance of this Circular, and each year thereafter. the Secretary will submit to the Office of Management and Budget a report on the status of Federal interaction with voluntary standards bodies. As a minimum. the report will include the following information:

a. The nature and exient of Federal dgency participation in. and support of. voluntary standards bodies:

b. A summary of the nature of procedural compiants against lisied voluntary standards bodies in accordance with the program to oe developed. and a summary of the disposition of such complaints: and

c. An evaluation of the efiectiveness of the policy promulgated in this Circular and recommendations for change or modification. as appropriate.

9. Inquiries. For iniormation concerning this Circuiar. contact tie Office of Management and Bucget. Office of Federal Procurement Policy. telephone 202/395-i20:.

James T. McIntyre. Js..

Direcior.

[FR DœC BQ-i815 Filed 1-i8-60: 8:45 am] BHLING COOE 3110-01-W 



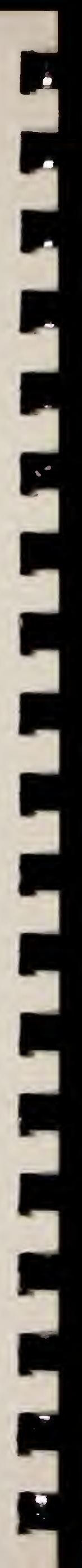



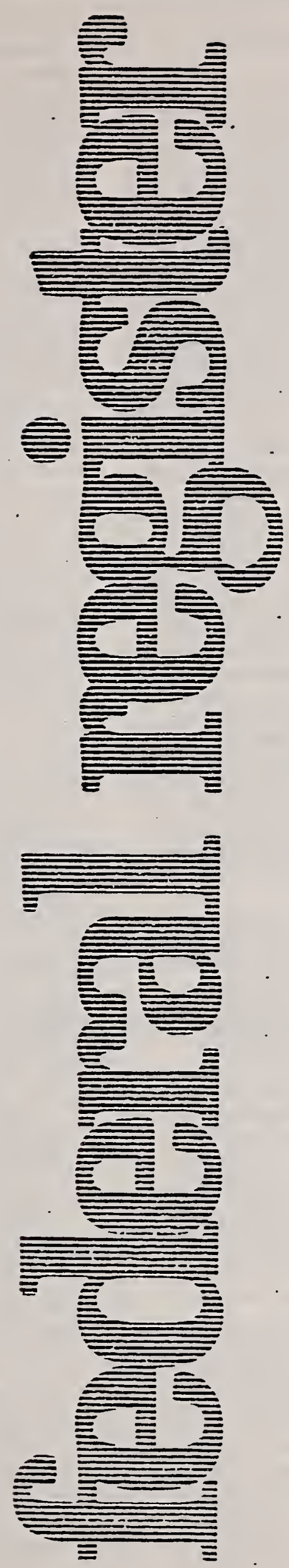

Monday

June 2, 1980
Part III

\section{Department of Commerce}

\section{Office of the Secretary}

Implementation of Federai Voluntary Standards Policy; Proposed Procedures for Listing Voluntary Standards Bodies Eligible for Federal Agency Support and Participation, and for a Department Sponsored Voluntary Dispute Resolution Service for Procedural Complaints Against Listed Voluntary Standards Bodies 


\section{DEPARTMENT OF COMMERCE}

Office of the Secretary

\section{CFR Part 19}

Implementation of Federal Voluntary Standards Policy; Proposed

Procedures for Listing Voluntary Standards Bodies Eligible for Federal Agency Support and Participation, and for a Department Sponsored Voluntary Dispute Resolution Service for Procedural Complaints Against Listed Voluntary Standards Bodies

AGENCY: Assistant Secretary for Productivity. Technology and Innovation, Commerce.

ACTION: Proposed procedures.

SUMMARY: Under the provisions of Circular A-119 issued by the Office of Management and Budget on January 17. 1930, entitled. "Federal Participation in the Development and Use of Voluntary Standards." the Department is proposing procedures required by the Circular to implement the policy relating to Federal agency participation in and support of voluntary standards organizations. The Secretary. through this notice, is requesting comments on the proposed procedures for listing and delisting voluntary standards bodies and their standards-developing groups and on the proposed procedures for a voluntary dispute resolution service for the rapid handling of procedural complaints by interested parties against voluntary standards bodies listed by the Department.

DATES: Written comments are due on or before August 1. 1980. All comments should be submitted in four copies.

ADORESS: Comments should be mailed to Dr. Jordan J. Baruch, Assistant Secretary for Productivity, Technology and Innovation. Room 3864. U.S.

Department of Commerce. Washington. D.C. 20230: or delivered to Room 3864.

Mlain Commerce Building. 14th Street between Constitution and Pennsylvania Avenues. N.W.. between 8:30 and 5:00 p.m.

FOR FURTHER INFORMATION CONTACT: Dr. Howard l. Forman. Deputy Assistant Secretary for Product Standards Policy. Room 3876. U.S. Department of

Commerce. Washington. D.C. 20230. telephone (2021 37T-3221: or Mr. Donald R. Mackay. Office of Product Standards Policy. Room 3876. U.S. Department of Commerce. W'ashington. D.C. 20230. telephone (202) 3T -4562 .

\section{SUPPLEMENTARY INFORMATION:}

Background

The Office of Management and Budget issued Circular $A-119$ on January 17. 1980, entitled "Federal Purticipation in the Development and Use of Vuluntary Standards" (45 F.R. 4326. Jünuary 21. 1980). This Circular establishes policy guidance governing executive brunch participation in voluntary standards activities and encourages the use of acceptable voluntary standards in the Federal procurement process. The Circular encourages Federal agencies to support and paticipate in the activitics of those standards bodies which adhere to specified due process and other basic criteria.

The OMB Circular assigns to the Department of Commerce responsibility for the administration of specified provisions of the Circular and the responsibility for coordinating the executive branch implementation of the policies established by the Circular. In particular, the Circular, in subsections $7 \mathrm{a}(1)(\mathrm{b})$ and $7 \mathrm{a}(2)$ and (3). provides for the establishment of procedures for the listing of voluntary standards bodies which comply with the due process and other basic criteria cited in the Circular. The Circular. in subsections $7 \mathrm{a}(1)(b)$ and $7 a(6)$. also provides for the

establishment of procedures for a department-sponsored voluntary dispute resolution service for the handling of procedural complaints against a listed voluntary standards body.

\section{Policy}

The OMB Circular emphasizes Federal policy of relying on voluntary standards with respect to Federal procurement whenever feasible and consistent with law and regulatiori. The $O M B$ Circular establishes a policy encouraging the participation of Federal agencies and their representatives in voluntary standards bodies which conduct their standards activities in accordance with specified due process and other critieria and which are listed by the Department of Commerce after certifying that they comply with all of the due process and other criticra established in the Circular.

\section{The Proposed Procedures}

Subpart A of Part 19 is proposed to establish procedures by which voluntary standards bodies and their standardsdeveloping groups can be listed by the Secretary of Commerce. This subpart 1) describes the steps to be taken by the standards bodies and groups in applying for listing. 2) identifies the due process and other criteria which such bodies and groups must follow, 3) describes the steps to be taken by the Department of
Commerec in processing requests for ligting. 4) establishes procedures for delisting organizutions which are sulsequently found. upon specific chillenge. not to be complying with all of the specified criteria. and 5) provides for the reapplication for listing of bodies or groups which have been delisted.

The procedures proposed by the Department of Commerce allow a voluntary standards body to apply for listing for itsclf and all of its standardsdeveloping groups or to apply forlisting either alone or in conjunction with some of its standards-developing groups provided that the body and the identified standards-developing groups comply with the prescribed due process and other basic criteria. A voluntary standards body has to be listed in order to have its standards-developing groups listed. If the standards body is not listed. Federal agencies will be prohibited from participating in the activities of any of its boards. councils, committees, or standards-developing groups, and will be prohibited from providing any type of financial. administrative. technical, or other support to that body or its groups.

The proposed Subpart $A$ also provides for the voluntary as well as the involuntary termination of listing by a voluntary standards body or of any of its groups. The removal of the name of any body or group will automatically terminate the involvement of Federal agency representatives in the standards activities of those bodies or groups and. further, will terminate any Federal support being provided to those bodies or groups.

Subpart B of Part 19 proposes procedures for a voluntary dispute resolution service for the timely settlement of complaints pertaining to the procedural aspects of actions or lack of actions on standards by listed voluntary standards bodies.

The proposed procedures require as a precondition to invoking the service. that a complainant must have exhausted all available sources of remedy from within the voluntary standards body. Also, both the complainant and the respondent must agree to use the service and to accept the determinations by the service as the sole and final

administrative revies by the executive branch of the Federal Government.

Under the proposed dispute resolution service. the Department will: (1) consider the processing pursuant to these procedures of all bona fide procedural complain!s against listed voluntary standards bouies which are reccived from interested parties and which. in the opinion of the department. appcar to be capable of resolution in the public interest under these procedures: 
(2) provide in the first instance for informal conciliation efforts wherein all parties agree to discuss the compluint together with a representative of the department. seek to identify and clarify the specific issues under disagreement. and discuss those issues openly in an altempt informally to arrive at a mutually acceptable resolution: (3) provide for mediation services. in cases where conciliation fails: (4) publicize the facts and results of appropriate cases processed under these procedures; and (5) monitor any follow-up action taken. by the complainant and/or the respondent voluntary standards body pursuant to these procedures, for the primary purpose of assessing the effectiveness of the senice.

The Department will accept complaints only against voluntary standards bodies or standardsdeveloping groups thereof which are listed by the Secretary under the Department of Commerce's "Procedures for Listing and Delisting Voluntary Standards Bodies and Their StandardsDeveloping Groups" (15 CFR Part 19, Subpart A).

\section{Additional Information}

In preparing these proposed procedures, discussions were held with representatives of the following organizations (listed alphabetically):

Aerospace Industries Association: Air-Conditioning and Refrigeretion Institute; American Chemical Society; American Gas Association: American Gear Manufacturers Association: American Institute of Aeronautics and Astronautics; American National Standards Institute: Anerican Nuclear Society; American Petroleum Institute: American Public Health Association; American Society for Testing and Materials: American Society of Agricultural Engineers: American Society of Heating. Refrigerating, and Air-Conditioning Engineers: American Society of Mechanical Engineers: American WVater Worlis Association: Association for the Adrancement of Medical Insirumentation: Association of Home Appliance Marufacturers: Composite Can and Tube Institute: Computer and Business Equipment Manufacturers Association: Consumers Union: Electronic Indestries Association: Gus Appliance Manufacturers Association: Industrial Heating Equipment Association: Institute of Electrical and Electronics Engineers: International Brotherhood of Electrica! Worhers: National Consumers Leaguc: National Council on Fuir Standards: Nituonal Elcctrical Mianufucturers Association: National Fire Protection Associstion; Orfice of the
Special Assistant to the President for Consumer Affuirs: Production Systems for Architects and Engineers ( $\Lambda \mathrm{I}$ ): Rubber Mlaqufucturers Association: Society of Automotive Engineers: Society of the Plastics Industry; Steel Joist Institute: Underwriters Laboratories: and Vacuum Cleaner Manufacturers Association.

As the representatives of the organizations identified above were advised at the informal meetings. their participation in those meetings was not to be construed as any form of endorsement of the proposed procedures by the individuals involved or by the organizations they represented.

The Department has chosen to publish these proposed procedures for the purpose of soliciting public comment and is allowing sixty $(60)$ days from the date of this publication for the submission of those comments. A public docket will be available for examination by interested persons at the Central Reference and Records Inspection Facility, Room 5317, U.S. Department of Commerce.

Dated: May 27, 1980.

Jordan ]. Baruch,

Assistant Secretary for Productivity,

Technology, Innovation.

It is proposed to amend Subtitle $A$ of Title 15. Code of Federal Regulations, by adding Part 19 as follows:

\section{PART 19-FEDERAL INTERACTION WITH VOLUNTARY STANDARDS BODIES}

Subpart A-Procedures for Listing and Delisting Voluntary Standards Bocies and Their Standards-Developing Groups

Sec

19.1 Purpose

19.2 Goal of Procedures

19.3 Coverage

19.4 Definitions

19.5 Elfective Date

19.6 Listing Requirements

19.7 Listing Process

19.8 Delisting Process

19.9 Voluntary Temination of Listing

19.10 Reapplication

19.11-19.20 [Reserved]

Subpart B-Procedures for a Voluntary Dispute Resolution Service for the Rapid Handling of Procedural Complaints by Interested Parties Against Voluntary Standards Bodies Lusted by the Department of Commeres

19.21 Purpose

19.22 Objective of Procedures

19.23 Definution

19.24 Precondition to Submitting Complaint

19.25 Umulation

19.20 Submulling a Compluint

19.27 Action Upon Receipl of Complaint sec.

19.28 Responsibility of Complainant and Respondent if a Complaint is Arcepted by the Department

19.29 Investigation/Conciliation

19.30 Mediation

19.31 - Publications and Records

19.32 Technicul Referee Service

19.33-19.40 [Rescrved]

Autbority: Section 7 of the Office of Management and Budget Circular A-119. issued pursuant to Section 6 of Pub. L 93-400 (41 U.S.C. 405).

Subpart A-Procedures for Listing and Delisting Voluntary Standards Bodies and Their Standards-Deyeloping Groups

\section{$\$ 19.1$ Purpose.}

(a) The purpose of this subpart is to establish procedures for the Development and maintenance by the Secretary of Commerce of a list of voluntary standards bodies in which Federal executive agencies may participate and provide support. To be considered for listing. and to remain listed, voluntary standards bodies and their standards-developing groups must adhere to certain due process and other basic criteria. These criteria are specified in Section $6 c$ of the Office of Management and Budget Circular A-119 of January 17,1980 , entitled. "Federal Participation in the Development and Use of Voluntary Standards" ( 15 FR 4326, January 21, 1980). These criteria are a!so described in \$ 19.6(b).

(b) Nothing in these procedures shall be interpreted as providing any party with an opportunity to unreasonably delay, inhibit, or otherwise interfere with the normal and lawful process of voluntary standardization, or any action available under the law with respect to any matter involving the establishment or use of voluntary standards.

\section{$\$ 19.2$ Goal of procedures.}

The Secretary has been directed by paragraphs 7a (2) and (3) of Circular A119 to prepare and implement these procedures. The goal of these procedures is to strengthen the private sector voluntary standards system by providing Federal agency participation in and support of voluntary standards programs and by encouraging Federal agency reliance on the standards developed by that system.

\section{$\$ 19.3$ Coverage.}

As specified in Section 3 of Circular A-119. the proceulures of this subpart apply to all executive agency participation in U.S. domestic voluntary standards activities including the development of U.S. pusitions relating to international voluntury stundards activities. The procedures do not apply to direct participation in multinational 
orgonizations. including regional and international organizations. which develop and issue internitionisl standirds, in arcordance with Section 6 of Circular A-119. (For the purposes of these procedures, building code organizations are not considered to be voluntary standards bodies if either of the following criteria is met: (1) the voting membership of the building code organization is composed entirely of govemment officials; or (2) the building code organization references or adopts voluntary standards developed and issued by other organizations and does not itself develop standards.)

\section{$\$ 19.4$ Definitions.}

As used in this subpart:

(a) Executive agency (hereinafter referred to as "agency" or "Federal agency") means an executive department. independent commission. board. bureau, office, agency. Government-owned or controlled corporation or other establishment of the Federal Government. including a regulatory commission or board. and also the municipal govermment of the District of Columbia. It does not include the legislative or judicial branches of the Federal Government.

(b) Standard means a prescribed set of rules, conditions, or requirements concerned with: the definition of terms; classification of components:

delineation of procedures; specification of materials. performance, design, or operations; or measurement of quality and quantity in describing materials. products. systems. services. or practices.

(c) Voluntary standards are established generally by private sector bodies and are available for use by any person or organization, private or governmental. The term includes what are commonly referted to as "industry standards" as well as "consensus standards" but does not include professional standards of personal conduct. private standards of individual firms. or standards mandated by law. such as those contained in the United States Pharmacopeia and the National Formulary, as referenced in 21 U.S.C. 351.

(d) Valuntary standards bodies are nongovernmental bodies which are broadly based. multi-membered organizations including. for example. nonprofit organizations. industry ossociations. and professional and/or technical socictics which develop. establish. or coordinate voluntary standards.

(e) Siundord's-developins sroups are committees. boards. or any other principal subdivisions of voluntary standards bodies. established by such bodies for the purpose of developing. revising. or reviewing standards and which are bound by the procedurcs of those bodies. (In the case of a voluntary standards organization that is completely autonomous, operates under its own procedures. and accepts responsibility for enforcing compliance with its procedural requirements as well as the responsibility for assuring the technical adequacy of its standards. such an organization, will be considered as both a voluntary standards body and a standards-developing group, at the request of the organization. For the purpose of these procedures, such organizations will meet all of the due process and other criteria established herein.)

(f) Department means the Department of Commerce.

(a) Secretary means the Secretary of Commerce of the Secretary's designee.

(h) Federal agency participation in . listed voluntary standards bodies means the direct and formal involvement in the standards development process and the provision for support to that process in terms of: (1) direct financial support such as grants, sustaining membership. and contracts: (2) administrative support such as travel costs, hosting of meetings. and secretarial functions; (3) technicall support such as cooperative testing for standards evaluation and participation of agency personnel in the activities of standards-developing groups: and (4) joint planning with voluntary standards bodies to facilitate a coordinated effort in resolving priority standardization problems.

(i) Consumer means a user of the products or services for which a standard is developed who is not currently engaged in the manufacture or distribution of the same, or involved in the development. issuance, or enforcement of government regulations related to the same.

(j) Person means associations. companies. corporations. institutions. partnerships. societies. firms. government agencies at the Federal. State, and local level, and individuals.

\section{\$ 19.5 Effective date.}

This subpart shall become effective thirty (30) days after the date of publication of the final procedures in the Federal Register. The Secretary will publish the first Fedoral Registor notlce of listed bodies and their listed groups within four months after the effective date of this subpart. Federal agencies will not participate in or otherwise support (as deñned in $19.4($ h) above) any voluntary standards body or standardsdeveloping group which is not listed (unless such porticipation is atherwise opecifically mandated by law). beginning nincty $(30)$ days after the Sccretary publishes the first Federal Register notice which identifies listed voluntary standards bodies and their listed standards-developing groups, and as prescribed by Section $7(b)(2)(a)$ of Circular A-119. A voluntary standards body which submits its application and certification within sixty (60) days immediately following the effective date of these procedures will be considered for inclusion in the first list issued by the Secretary.

\section{.\$ 19.6 Usting requirements.}

(a) Any voluntary standards body which wishes to be listed must apply for listing and certify in writing to the Secretary that it complies with all of the due process and other basic criteria identified in paragraph (b) of this section. This certification must contain a statement that the standards body conducts its standards activities entirely in accordance with its published procedures. Requests to be listed, and accompanying certiñcations, shall be signed by a person who. in the normal course of the requestor's business, has the authority to make binding statements on the requestor's benalf. Requests shall be addressed to the Secretary of Commerce. U.S.

Department of Commerce. Washington. D.C. 20230.

(1) Calegory A. Listing. For this category. all of the voluntary standardsdeveloping groups of a volurtary standards body must meet the due process and other basic criteria identified in paragraph (b) of this section. In applying for Category $A$ listing the voluntary siandards body must. if it has standards-deve!oping groups, state that all of those groups comply with such criteria, and must provide a list of all such groups. New standards-developing groups formed after the initial listing (under Category A) of a voluntary standards body by the Department must be reported to the Department by the standards body concerned as complying with the criteria in paragraph (b) of this section. In a Category A listing. the voluntary standards body and all of its standardsdeveloping groups (if any) will be listed.

Voluntary standards bodies lisied in Category A will be eligible for the types of Federal support described in paragraph (h) of $\$ 19.4$. Federal agency representatives $w i l l$ be able 10 participate in the activities of the committees. boards and councils of those voluntary standards bodies listed in Category $A$ as well as in the activitics 
of the standards-developing aroups of those bodies.

(2) Cotegory B. Listing. This category allows for situations in which a voluntary standards body wishes to have only some of its voluntury standards-developing groups listed. Since not all of the groups are listed, the voluntary standards body itself cannot be listed except in conjunction with a particular standards-developing group thereof. In Category $B$ listing. the name of the voluntary standards body and the name of the standards-developing groups to be listed are identified together. For example, if the "Acme Standards-Developing Body" has five standards-developing groups, but wishes that only the groups on 'widgets' and 'gidgets' should be listed. that body would apply for listing as follows:

(i) Acme Standards Body/StandardsDeveloping Group on 'Widgets'

(ii) Acme Standards Body/StandardsDeveloping Group on 'Gidgets'

An effect of this type of listing is that while Federal agencies may participate in and otherwise render support to the two listed groups (on 'widgets' and 'gidgets'). they may participate in and render support to the Acme Standards Body itself oniy insofar as that participation and support relate to the standards activities of the two groups. Accordingly. Federal agencies may not participate, for example. on the Board of Directors (or similar governing or advisory unit) of the Acme Voluntary Standards Body itself, since some of its standards-developing groups are not listed. In such cases. Federal agencies should endeavor to provide financial and other support directly to the listed groups. If for procedural or administrative reasons this is not possible. Federal agencies should only provide support to the standards body with the understanding that such contributions are to be expended directly on matters related to these two listed groups.

(b) The following due process and other basic criteria shall be adhered to by listed voluntary standards bodies and the listed standurds-developing groups of those bodies:

(1) Voluntary standards budies shall provide adequate public notice of standards meetings and other standards activities (e.g. regional conferences) sponsored or conducted by the bodies or their standards-developing groups. Such notices shall be provided in an appropriate and timely fashion und should include a clcar and meaningful description of the purpose of the mecting or activity. The media used for those notices shall be selected or devised to reach persons reasonably expected to have an interest in the subject including. for examplc: consumers: small business representatives: manufacturers: labor. suppliers; distributors; testing laboratories; industrial, institutional, and other users; environmental and conservation groups: Federal agency officials; and State and local regulatory. procurement and code officials. The notice shall also identify the name. address, and telephone number of a contact person or office in the voluntary standards body who/which will be able to provide, upon request, further information on the meeting or activity.

(2) Voluntary standards bodies shall provide adequate public notice in an appropriate and timely fashion of the initiation. final review, adoption or approval of all new and revised voluntary standards, and of the proposed withdrawal of voluntary standards through media characterized in paragraph (b)(1) of this section. Such notice must describe clearly the purpose and scope of the relevant standards.

As required in paragraph (b)(1) of this section, the standards body reasonably must assure itself that the public notice will reach interested persons in an appropriate and tirnely fashion and will identify a contact person or office in the standards body. The same media, publications and format should be used for notices having the same or similar scope or impact.

(3) Voluntary.standards bodies shall conduct open standards meetings, and shall ensure that the opportunity for attendance at these meetings and participation in related standards activities is available to interested persons. Voluntary standards bodies shall provide, at a minimum, an opportunity to all interested persons 10 participate in standards.activities through the submission of written comments relating to the initiation. development, approval, review, revision, or withdrawal of standards. All such written comments received by a voluntary standards body should be acknowledged and transmitted to the appropriate standards-devcloping group' for due consideration. Unreasonable restrictions on membership in standards-developing groups by means of requirements for professional or technical qualifications, or of tracle requirements. or of unreasonable fees. or of other such restrictions must be avoided.

(4) Voluntary standards bodies shall assure that decisions reached in their standards development activities represent substantial agreenient of those who participated in the process, after.a concerted effort to resolve objections. and that such agreements are reached by the participants in accordance with the published procedures of the voluntary standards body and the judgment of the appropriate official(s) duly appointed by that body. Such agreements shall be reached by more than a sample majority, although they do not necessarily require unanimity.

(5) Voluntary standards bodies shall provide prompt consideration of the views and concerns expressed in writing by all interested parties to the voluntary standards body, including proposals for new or revised slandards.

(6) Voluntary standards bodies sháll provide or othervise make available one or more adequate and impartial mechanisms for handling documented substantive and procedural complaints and appeals for use by interested parties. As an alternative, this requirement will be satisfied by a provision for ready access to such complaint/appeal mechanisms operated by an organization other than the one against which the complaint or appeal is lodged. provided that such mechanisms meet the requirements of this paragraph (§ 19.6(b)(6)).

(7) Voluntary standards bodies shall assure that appropriate records, in sufficient detail to enable one subsequently to review and understand what transpired. are made and maintained in the case of: formal discussions; decisions; standards and drafts of standards; lechnical or other rationale for critical requirements of standards (including test methods): complaints/appeals and their resolution: meeting minutes and balloting results. All such records must be retained in accordance with published procedures and be readily accessible to all interested persons on a timely and reasonable basis. Retention of records for at least five (5) years after a standard is approved. reviewed. revised. or withdrawn. normally would be considered reasonable. The "rationale" referred to above should be prepared during the standards development process to document the decisions relating to (i) the need for the standard. (ii) the scope of the standard (including any limits or exclusions). (iii) the critical requirements established in the standard, and (iv) the test methods selected to determine conformance or non-conformance.

(8) Voluntary standards bodies shall publish a disclaimer clearly indicating that participation in any of their activities by Federal agency representatives does not constitute the endorsement by the Federal

Government or any of its agencies of the bodies or the stanuards which they 
develon. The disclinimer shall either: (i) be in tho form of an official policy declaration by the standards bodies prominently set forth in their published official procedures: or (ii) be in the form of an official policy declaration by the standards bodies in any standards literature which they publish that mentions involvement or participation of Federal agency personnel in standards development. approval, or review activities. A voluntary standard or other document which includes a list of its developers and identifies Federal agency representation must include this disclaimer.

(9) Voluntary standards bodies shall publish their official procedures regarding their standards activities, and make those procedures available to interested parties on a reasonable basis.

(10) Voluntary standards bodies shall ensure that their voluntary standards and their standards development procedures are periodically reviewed and revised, as necessary, and that participation in the review process is available to all interested persons in accordance with the other relevant due process and other criteria contained in paragraph (b) of this section. A review of each standard by an appropriate committee or other unit of the standards bodies should be initiated at least once every five years. If a voluntary standards body provides for the withdrawal of a standard under procedures that cause the automatic termination of standards which are five years old or older and are not either revised or reaffirmed. the standards body shall provide adequate public notice of the imminent termination in accordance with the requirements in paragraph (b)(2) of this section.

(11) Voluntary standards bodies shall give preference to the use of performance criteria, measurable by examination or testing, in standards development when such criteria may reasonably be used in lieu of design. materials, or construction criteria. For purposes of demonstrating compliance uith this requirement. as a minimum. the published operating procedures of the voluntary standards body should contain a statement to the effect that "preference will be given to the use of performance criteria. measurable by examination or iesting. in standards development when such criteria muy reasonably be used in lieu of design. matcriais. or construction criteria."

(c) In applying to the Secretary for a Calenory A listing. a voluntary standiards body must certify that it and all of $i$ 's standards-developing groups meet the due process and other basic criteria identified above in paragraph (b) of this section and shall include with its application itg official operating procedures, as published pursuant to paragraph (b)(9) of this section. In applying for a Cagetory $B$ listing a voluntary standards body must certify that all of its identified standardsdeveloping groups for which it secks listing meet the due process and other basic critcria identified above in paragraph (b) of this section and shall include with its application its official operating procedures. In applying for a Category A or B listing. the voluntary standards body should. in order to assist the Secretary in reviewing the application, list the paragraph or section numbers of its published operating procedures which correspond to each of the numbered paragraphs in paragraph (b) of this section.

(d) The voluntary standards body shall transmit to the Department copies of all subsequent changes in its official procedures as soon as they have been approved by the body.

(e) The Secretary will provide. upon request or when he otherwise detemines it to be necessary and appropriate. guidance as to whether specific procedural requirements of voluntary standards bodies or their standardsdeveloping groups will meet the due process and other criteria established in paragraph (b) of this section. Such guidance with be published through notices in the Federal Register, either in full. or in summary form. If published in summary form. the notice will specify the manner in which persons may obtain copies of the full guidance provided.

\section{\$ 19.7 Listing process.}

(a) The Department will review the published operating procedures submitted by the voluntary standards body and the Secretary will determine whether such procedures demonstrate compliance with the due process and other basic criteria of paragraph (b) of $\$$ 19.6. If a voluntary standards body certifies that it does conform to the criteria set forth in paragraph (b) of $\$$ 19.6. the Secretary will list it unless. upon review of the operating procedures submitted by the body. it is clear that the body does not conform.

(b) The Secretary will notify the applicant of a proposed denial of the listing application. That notice will state the specific reasons for the proposed denial.

(1) A voluntary standards body may request reconsideration of its

application for listing by submitting such request within thirty (30) days of receipt of the Secretary's notice of a proposed denial of the listing application. Such request for reconsideration shall be accompanied by a detailed statement of the reasons for reconsideration. If upon reconsideration. the determination to deny the applicant's request for listing is unchanged, or if reconsideration is not requested. the proposed denial shall become finul thirty (30) days after the issuance of a denial decision to the voluntary standards body, provided that the body does nol request a hearing within the thirty (30) day period.

(2) If, however, the voluntary standards body requests a hearing within the thirty (30) day period following the issuance of the denial decision. a hearing under 5 U.S.C. 556

(the section of the Administrative Procedure Act which establishes requirements for formal hearings conducted by a Federal Administrative Law Judge) will be ordered and the decision on the proposed denial shall be stayed pending the outcome of that hearing. A request for such a hearing shall be addressed to the Secretary of Commerce. U.S. Department of Commerce, Washington, D.C. 20230. In the event of such a request, the Secretary will designate an Administrative Law Judge to conduct proceedings under 5 U.S.C. 556. Following the conclusion of the Administrative Law Judge's proceedings, and upon receipt of his recommendations, the Secretary will render a written decision and will notify the standards body of that decision.

(3) A voluntary standards body may. within thirty (30) days of receipt of a notice of a proposed denial. of the listing application. submit to the Secretary draft amendments to their procedures in an effort to conform to the requirements of paragraph (b) of $\$ 19.6$. If the Secretary finds that the draft amendments will meet the requirements of paragraph (b) of $\$ 19.6$, the Secretary will notify the voluntary standards body and will stay further action on the proposed denial of the listing application. Upon receipt of the amended procedures. as approved and published by the voluntary siandards body, the Secretary will reconsider the application for listing and. if the amended procedures are found io conform to the requirements of paragraph (b) of $\$ 19.6$. the Secretary will proced to list the standards body.

(4) If upon receipt of the draft amended procedures. the Secretary finds that the subject procedures stil! do not conform to the requirements of paragraph (U) \$ 19.6, the Secretary will notify the applicant of a pruposed denial of the listing application with a statement of the reasons therelore. Within thirty (30) days of the notice of a 
proposed denial. the voluntary standards body may request a consultation with the Secretary for the purpose of developing specific amendments to their procedures that will conform to the requirements of paragraph (b) of $\S$ 19.6. If the parties involved in such consultation determine that acceptable amendments cannot be developed, the voluntary standards body may request reconsideration under paragraph (b)(1) of this section. If the consultation results in the development of an amendment acceptable to the Secretary, the Secretary will reconsider the application for listing and, if the amended procedures. as approved and published by the voluntary standards body. are found to conform to the requirements of paragraph (b) of $\S 19.6$. the Secretary will proceed to list the standards body.

(5) If the proposed amendment does not conform to the requirements of paragraph (b) of $\$$ 19.6. and no consultation is requested within thirty (30) days of receipt of a notice of a proposed denial, and no request for reconsideration is filed within the same thirty (30) day period, the denial will become final thirty (30) days after the issuance of a denial decision to the voluntary standards body. The voluntary standards body may. at any time thereafter, reapply for listing under the provisions of $\$ 19.10$.

(c) The Secretary will list those voluntary standards bodies and those standards-developing groups for which the certification and the published operating procedures provide evidence of compliance with the criteria contained in paragraph (b) of $\S 19.6$. The Secretary will inform in srriting all those voluntary standards bodies which have been listed. The operating procedures and any other evidence submitted by the standards bodies on which the decisions are made to list the bodies and groups will be available in the Department for public inspection.

(d) The Secretary, within approximately four months after the effective date of these Procedures. will publish in the Federal Register a notice which identifies the listed voluntary standards bodies and the listed standards-developing groups.

Subsequent listings will be published on a quarterly basis for approximutely two years. and semiannually thereafter in accordance with $\$ 19.11$. Such notices will identify a specific location in the Department where interested persuns may inspect the self-certification stulements. the published operating procedures, and any other infurniation or malerials submitted in cunnection with the applications for listing. In eddition, within one weck after the listing of a voluntary stundards body. the Secretary will transmit a notice to all members of the Interagency Committee on Standards Policy for . transmittal to the heads of their agencies identifying the names of the listed voluntary standards bodies and their listed standards-developing groups. The Secretary will also transmit such information to any other agencies which indicate a desire to be informed.

(e) Voluntary standards bodies and their standards-developing groups which are listed by the Secretary of Commerce will be eligible for the types of Federal support defined in paragraph (h) of $\$ 19.4$. However, the extent of such support will be subject to the limitation that the granting of Federal support to a voluntary standards activity shall be limited to that which is clearly in furtherance of an agency's mission and responsibility and is compatible with the agency's priorities and budget limitations. Normally, the total amount of Federal support given shall be no greater than that of all non-Federal participants in that activity except where it is in the direct and predominant interest of the Federal Government to develop a needed standard or revision thereto, and such development appears unlikely to occur in the absence of such Federal support.

\section{\$19.8 Delisting process.}

(a) Any interested person may petition the Secretary to remove a voluntary standards body or one or more of its listed standards-developing groups from the list. Such a petition shall be in writing and shall cite the specific criteria in paragraph (b) of $\S 19.6$ which the petitioner believes have not been met by the body or groups. As a precondition for a petition to delist. the petitioner shall have exhausted all remedies available within the voluntary standards body regarding the subject matter of the petition. All available supporting documenlation and other relevant information shall be provided in support of the petition. To the extent possible. the petition should also provide the names. employment addresses, and employment telephone numbers of all parties materially involved. Such petitions must be based on actions or inactions that occurred after the date that the voluntiry standards body (or a group thereof) is listed by the Secretary. Any such petition should be aduressed to the Secretary of Commerce. U.S. Department of Commerce. Washington. D.C. 20230. In addition. the Secretary may initiale investigations. on the basis of information received either from Federal agencies or from other sources. which subsequently may lead to delisting actions pursuant to the procedures of this subpart. If the petition is directed to a procedural matter. the Secretary may find it appropriate to advise the petitioner of the existence of the Department's dispute resolution service described in subpart $B$ of this part 19.

(b) The Secretary will evaluate and act as expeditiously as possible on all petitions for delisting. The Secretary may request additional information. may consult with the Department of Justice and the Federal Trade Commission in evaluating such petitions, and will notify the petitioner in writing of the decision reached. after due consideration whether to process the petition, and the reasons therefor. The Secretary may. upon finding it appropriate to do so, request all records from a voluntary standards body that are pertinent to the review of a petition for delisting.

(c) If the Secretary determines that the petition warrants investigation, the Secretary will as soon as possible inform, in writing, the voluntary standards body concerned of the nature of the petition. Thereafter, the Secretary will arrange for an investigation and notify the voluntary standards body of its scope. If the Secretary determines that the petition warrants no further action. the Secretary will so inform the petitioner in writing, and the reasons therefor. That determination shall constitute the final review by the Department, unless the petitioner elects within thirty (30) days after receipt of the Secretary's notification to request Departmental reconsicieration of that decision by writing to the Secretary of Commerce. U.S: Department of

Commerce. Washington, D.C. 20230. The decision of the Secretary on this request shall constitule the final adminsitrative review of the executive branch of the Federal Govemment. (See also $\$ 19.23$ of Subpart B.) This decision would not prohibit other Federal agencies Irom taking separate legal actions under their statutory authurities.

(d) If the investigation pursuant to paragraph (c) of this section indicales non-compliance ivith any of the due process and other basic criteria cited in paragraph (b) of $\$ 19.6$. the Secretary will provide the voluntury standirds body concerned with (1) a statement indicating the precise rature of the alleged non-compliance. and (2) a copy of the petition and the identity and location of all documents. milerials. and other reluted information submilted with 
the petition or received or developed thereafter.

(e) Following receipt of the

information provided.by the Secretary in accordance with paragraph (d) of this section. the standards body concerned shall have sixty $(60)$ days in which to respond to the statement of alleged noncompliance. If the standards body fails to respond in the sixty $(60)$ day period. or if the Secretary determines that the response received is not persuasive, the Secretary will issue, in writing. to that body and concurrently to the petitioner. a Preliminary Finding of NonCompliance with the specified due process and other basic criteria identified in paragraph (b) of $\S 19.6$. This Preliminary Finding of Non-Compliance will include a description of the corrective action(s) that must be taken by the body or standards-developing group concerned in order to qualify for withdrawal of the Preliminary Finding of Non-Compliance by the Secretary.

(f) If the standards body concerned does not provide. within sixty (60) days following receipt of the nctification of Preliminary Finding of Non-Compliance. adequate evidence that the prescribed corrective action identified in the Preliminary Finding of Non-Compliance has been taken by that body, or if the Secretary deems that the corrective action taken is insufficient. the Secretary will issue a Final Finding of Non-Compliance to the body concerned. and concurrently to the petitioner. if no hearing has been requested under paragraph $(\mathrm{g})$ of this section. The notification of Final Finding of NonCompliance shall constitute notification of the Department's decision to delist the body or standards-developing group thereof. Removal of a standardsdeveloping group of a voluntary standards body will not in itself constitute cause for the removal from the list of any other groups of that body or of the body itself. but will result in a change in the listing of a Category $\mathrm{A}$ organization to a Category B organization.

(g) The Secretary will refrain from issuing a Final Finding of NonCompliance if the organization concerned requests a hearing under the provisions of 5 U.S.C. 556 within thirty (30) days following receipt of the nolification of Preliminary Finding of Non-Compliance. A request for a hearing should be addressed to the Secretary of Commerce. U.S.

Department of Commerce. Washing!on. D.C. 20230. In the event of such a request, an Administrative Law Judge will be designated by the Secretary to conduct a proceeding under 5 U.S.C. 550 and to recommend a decision. At that point in time. the petitioner will be provided with copies of all papers filed subsequent to the receipt of the petition for delisting for the purpose of participating in the hearing at the invitation of the Administrative Law Judge. Further action on the Preliminary Finding of Non-Compliance shall be stayed pending the outcome of that proceeding. The decision of the Secretary following the proceeding will be in writing. will be sent to the organization concerned and to the petitioner, and will constitute the final administrative action of the executive branch of Federal Government.

(h) The Secretary will publish in the Federal Register within thirty (30) days of the decision to issue a Final Finding of Non-Compliance and delisting notification, a notice of such a finding and shall. within one week of such delisting action. similarly notify in writing the members of the Interagency Committee on Standards Policy for transmittal to the heads of their agencies, and any other Federal agencies which indicate a desire to be notified, as well as the standards body and the petitioner. The delisting action resulting from the Final Finding of NonCompliance will become effective thirty (30) days after the publication of the notice in the Federal Register. Such Federal Register notice and notification to Federal agencies will include a statement to the effect that all Federal executive agencies and their

representatives shall cease, as of the effective date of the delisting action, any and all participation in or the furmishing of any other form of support to the delisted body or group thereof. unless such participation is otherwise required by law.

(i) The delisting of a voluntary standards body or a standardsdeveloping group because of the issuance of a Final Finding of NonCompliance against it under paragraph (f) of this section will lead to eariy termination of all Federal agency support of that voluntary standards body or group. If the body itself is delisted. such termination will include cessation of all participation of Federal agencies in the standards and standards-related activities of all boards, councils and stundards development committees and groups of that body.

(i) In order to facilitate termination of existing Federal agency contracts and grunts with. or the provision of other support by the Federal agencies to. delisted voluntary standards bodieg and groups. Federal agencies should ensure that future contracts, grants or other arrangements involving standards and standards-related matters. bearing upon relations between the agencies and voluntary standards bodies contains a provision which clearly entitles the Federal agency to terminate "for cause" (in contrast to termination "for the convenience of the government") any contract, grant, or other arrangement with a voluntary standards body or group which, during the life of the contract, grant, or arrangement becomes and remains delisted by the Department.

¿ 19.9 Voluntary termination of listing.

A voluntary standards body may have its name removed from the list upon its request in writing to the Secretary. Removal of the name of the voluntary standards body shall result automatically in removal of all standards-developing groups of that body from the list, without prejudice. In the event that a voluntary standards body desires to have removed from the list any of its standards-developing groups, it may have such groups removed without prejudice upon written notification to the Secretary. The Federal Register notice of such dclisting action and the Department's notice of such action to Federal agencies will state that the delisting action resulted from a voluntary termination of listing status.

\section{§ 19.10 Reapplication}

If the Department denies an application for listing, or delists a voluntary standards body (or group thereof. or if the name of a voluntary standards body or any standardsdeveloping group is removed from the Department's list as a result of a request for voluntary termination of such listing. that body may reapply for listing at any time. with the provision that suci reapplications shall not be accepted or acted upon by the Department more than once in a period of twelve (12) consecutive months. Such re-application must conform to the relevant parts of $\S \S 19.6$ and 19.7 and be responsive to the reasons given by the Secretary for denying the carlier applicution or to the corrective actions identified pursuant to paragraph (e) of $\$ 19.8$. or should indicate. as aporopriate. whether the previous delisting action by the Department resulted from a voluntary termination of listing siatus. 
8ร 19.1 1-19.20 [Reserved]

Subpart B-Procedures for a Voluntary Dispute Resolution Service for the Rapid Handling of Procedural Complaints by Interested Partles Against Voluntary Standards Bodies Listed by the Department of Commerce

\section{$\$ 19.21$ Purpose.}

(a) The purpose of this subpart is to establish procedures for the operation of a Department of Commerce-sponsored voluntary dispute resolution service regarding procedural complaints by interested parties against voluntary standards bodies, as specified in OMB Circular A-119 ("Federal Participation in the Development and Use of Voluntary Standards," issued January 17. 1980 (45 F.R. 4326. January 21. 1980). This dispute resolution service is designed to implement that Circular's section $7 \mathrm{a}(6)$ which requires the Secretary of Commerce to:

"Establish a program which shall make available a department-sponsored voluntary dispute resolution service for the rapid handling of procedural complaints by interested parties against listed voluntary standards bodies. As a precondition to invoking that service, a complainant must seek relief from. and have exhausted all available sources of remedy within. the affected voluntary standards body. Such a service shall have, among its requirements. the agreement of both complainant and respondent to use the service and their consent to accept the determinations of the service as the sole and final administrative. review by the executive branch."

(b) Nothing in these procedures shall be interpreted as providing any party with an opportunity to unreasonably delay. inhibit. or othervise interfere with the normal and lawful process of voluntary standardization. or any action evailable under the law with regard to any matter involving the establishment or use of the voluntary standards.

(c) These procedures will not be used to resolve any compliaints which are based upon the provisions in Section 441 of the Trade Agreements Act of 1979.

\section{$\$ 19.22$ Objective of procedures.}

(a) The objective of these dispute resolution service procedures is to facilitate the timely resolution of complaints periaining to procedural errors allegedly committed by listed voluntary standards bodics.

$\$ 19.23$ Definitions.

(a) Departasent means the U.S.

Department of Commerce.

(b) Secretory means the Secretary of Commerce or the Secretary's designee. (c) Interested party means an individual, govemment agency. association, company, corporation, firm, partnership, or other organizition named or admitted as a party, or properly seeking and entitled as of right to be admitted as a party to a proceeding under these procedures, due to allegations of procedural error(s) having been committed.

(d) Complainant means an interested party as defined in paragraph (c) of this section who has submitted a complaint to the Secretary under these procedures.

(e) Slandard means a prescribed set of rules, conditions, or requirements concerned with: the definition of terms: classification of components:

delineation of procedures: specification of materials, performance, design, or operations; or measurement of quality and quantity in describing materials. products, systems. services or practices.

(f) Voluntary standards are

established generally by private sector bodies and are available for use by any person or organization. private or govermmental. The term includes what are commonly referred to as "industry standards" as well as "consensus standards" but does not include professional standards of personal conduct, private standards of individual firms, or standards mandated by law, such as those contained in the United States Pharmacopeia and the National Formulary, es referenced in 21 U.S.C. 351.

(g) Voluntary standards bodies means nongovernmental bodies which are broadly-based, multi-membered organizations, including, for example, nonprofit organizations, industry associations, and professional and/or technical societies which develop. establish, or coordinate voluntary standards.

(h) Standards-developing groups means committees, boards, or any other principal subdivision of voluntary standards bodies, established by such bodies for the purpose of developing. revising, or reviewing standards and which are bound by the procedures of those bodies.

(i) Procedural comploint refers to a complaint which relates to the procedural aspects of the standards devclopment and/or review and/or approval process. It excludes complaints relating to substantive aspects of a standard such as, for example. the level of performance sclected by the standards developing group for a particular component. Accordingly, a procedural complaint means a complaint that alleges denial of any of the due process and other basic criteria of Section $6 c$ of the Circular or of paragraph (b) of $\$ 19.6$ of the

Department of Commerce's "Procedures for Listing and Delisting Voluntary

Standards Bodies and Thcir Groups" (15

C.F.R. Part 19, Subpart $A$ ) in the development, review, or approval of standurds or refusal to develop new or revised standards as well as a complaint that alleges denial of any other standards development and/or review and/or approval procedure established by the voluntary standards body or group concerned.

(i) Circular means OMB Circular A119 entitled "Federal Participation in the Development and Use of Voluntary Standards." dated January 17, 1980 and effective on that date.

(k) List or listed means a compilation of voluntary standards bodies and standards-developing groups thereof which have been accepted by the Secretary as complying with the due process and other basic criteria cited in Section $6 c$ of the Circular and of the Department of Commerce's "Procedures for Listing and Delisting Voluntary Standards Bodies and Their Groups" (15 C.F.R. Part 19. Subpart A).

(1) Sole and final administrative review by the executive branch means that once a complaint has been processed under this subpart no Federal executive branch agency shall have any obligation to give any further edministrative review to that complaint. except as otherwise may be provided by law. The term should not be interpreted to affect any subsequent judicial or quasi-judicial review of the complaint or review for law enforcement purposes as, for example, by a court of law or by the Federal Trade Commission or the Department of Justice. Additionally, this term should not be interpreted as preventing the Department from considering a petition for delisting under $\$ 19.8$ of subpart A. Nor should this term be interpreted as obligating any party to implement any recommendations made by the representative of the Secretary (pursuant to the conciliation process) or the mediator, if any, under these procedures.

(m) Due process and other basic criteria has reference to requirements described in section $6 c$ of the Circular, as supplemented by paragraph (b) of $\$ 19.6$ of the Department's "Procedures for Listing and Delisting Voluntary Standards Bodies and Their Groups" (15 CFR. Part 19. Subpart $A$ ).

(a) Final cation with respect to the development of voluntary standards means the concluding sicp in the development and upproval of such standards by the voluntary standards body in accordance with the published procedures of that body. Final action 
with respect to the approval or disapproval of a request for a new or revised standard means the final decision by the voluntary standards body on such a request.

\section{Precondition to submitting} complaint.

Prior to submitting a complaint under these procedures. the complainant must have sought relief from and have exhausted all remedies available within the concerned voluntary standards body.

\section{$\$ 19.25$ Limitation.}

The Department wil! not process any complaint where the final action on the provisions in question was taken by the voluntary standards body concerned before the effective date of these procedures.

\section{$\$ 1926$ Submitting a complaint.}

(a) Any interested party may request the Department to process a procedural. complaint under this subpart. Such a request must be written and sent to the Secretary of Commerce. U.S. Department of Commerce. Washington, D.C. 20230. All requests shall:

(1) identify the standard(s). proposed standard(s). and the procedures of the voluntary standards body involved:

(2) describe fully the nature of the complaint including, to the extent known. the positions of any other parties in interest who are or may become, directly or indirectly, affected by the matter which is the subject of the complaint. In such cases the complainant shall, where possible. provide the name. employment address. standards group affiliation. and employment telephone number of each such party:

(3) describe fully any previous attempts made to resolve the complaint. including appeals within the voluntary standards body, and the results of those attempts:

(4) describe in as specific terms as possible the consequences to the complainant of the non-resolution of the complaint to complainant's satisfuction:

(5) indicatc agreement to accept the determination by the dispute resolution serice as the sole and final administrative review of the complaint by the exccutive branch: and

(6) provide any other available and pertinent supporing information.

(b) In addition to taking action under $\$ 19.27$ the Secretary will determine whether the complaint warrants investigation under the provisions for delisting in paragruph (a) $\$ 19.8$ of subpart $A$.
\$19.27 Action upon receipt of complaint.

(a) The Secretary will evaluate the complaint together with the supporting information received. The Secretary will seek information regarding the complaint from the voluntary standards body involved and will solicit the agreement of that body, as well as the complainant, to use this dispute resolution service and to accept the determination by that scrvice as the sole and final administrative review of the complaint by the executive branch. If . either party does not agree to utilize the dispute resolution service, there shall be no further action taken by the Department.

(b) The Secretary may request additional information, if needed. from the involved parties.

(c) When in the opinion of the Secretary the complainant's submission of information required by $\S 19.26$ is complete, the Secretary may: (1) determine that the complaint merits . processing under these procedures, or (2) decline to accept the complaint, in which case the Secretary shall indicate in writing to the complainant the reasons for so declining. Such declinations may be expected to occur in cases, for example: where, in the judgement of the Secretary based on the information submitted and obtained. it is unlikely that processing under these procedures will make a significant contribution to the successful resolution of the complaint: where the complaint is not "procedural' within the scope of this service: where the voluntary standards body concerned refuses to agrce to use the service or to consent to accept the determinations by the service as the sole and final administrative review by the executive branch: or where, in the discretion of the Secretary, the subject of the complaint is a matter which should be directed to the Department of Justice or the Federal Trade Commission. The complainant may resubmit a complaint to the Department of Commerce if, after dirccting it to the Department of Justice or the Federal Trade Commission, such agencies decide not to take any action. In the event of a declination by the Secretary to accept a complaint. the complainant may make a written request for departmental reconsideration to the Secretary of Commerce. U.S.

Department of Commerce. Washington. D.C. 20230. within 30 (thirty) day's of receipt of the declination. The decision of the Secretary on such a request shill be final.

(d) A complainant whose complaint was nut accepted by the Department may resubmit the complaint for processing by the Department whenever the complainant has new information or evidence of a significant nature. In resubmitting the compliaint. the compluinant must clearly identify the nature of the new information or evidence and how It relates to the reasons previously given for not accepting the complaint.

(e) If the Department accepts a complaint for processing under these procedures. the Secretary will so inform the complainant and the respondent voluntary standards body in writing. The Secretary may request copies of any relevant records, including the appeal record. from the voluntary standards body concerned. The Secretary's letters to the complainant and respondent standards body concerned will indicate that the dispute resolution service involves a two step procedure. The first step consists of an informal

investigation/conciliation process as set forth in $\S 19.29$ of these procedures. If this investigation/conciliation process is unsuccessful and if both the

complainant and voluntary standards body agree, a mediator or mediation panel may be appointed in accordance with $\S 19.30$ of these procedures. as the second and final step of this procedure.

$\$ 19.28$ Responsibilities of complainant and respondent if a complaint is accepted by the Department.

If the Department accepts a complaint for processing under these procedures. the complainant and the respondent voluntary standards body shall: (a) cooperate fully and in good faith with the Department. the mediator (if any). and other parties involved to reach a mutually acceptable resolution of the complaint in a timely fashion: (b) provide, upon request by the Secretary. additional and availoble pertinent data or other information, except that there shall be no requirement to iurnish proprietary information: (c) promply inform the Department or mediator. as appropriate. regarding pertinent events or actions taken by the complainant or the voluntary standards body concerned which occur during the processing by the dispute resolution service but which occur without the Department's dircct involvement or knowiedge. and (d) inform the Department. upon request. of any action taken pursuant to recommendations. if any, of the Secretary made under this service.

$\$ 1929$ Investigation/concillation.

(a) If the Department accepts a complaint under these procedures. the Secretary will designate a qualified representative who shall perform investigation and conciiiation functions. 
including consultations with the complainant. the respondent voluntury standards body. and any other parties involved in an effort to clarify the areas of disagreement, and attempt to effect a mutually acceptable resolution of such areas within a two-month period following the representative's appointment. The Secretary's representative may seek assistance from any appropriate source. Such assistance. if any, may be provided on a

reimbursable basis.

(b) At any appropriate point in the investigation/conciliation process the Secretary's representative may make recommendations to the party(ies) which appear to reflect a reasonable resolution of any or all of the areas of disagreement. The parties involved should consider those recommendations in good faith.

(c) If the parties reach a mutually acceptable agreement during the conciliation process, the Secretary's representative will record the specific nature of that agreement and will transmit copies of that record to the parties involved. If no agreement is reached. or if a partial conciliation is reached, the representative will record such results. includizg any issues which remain in disagreement, and will transmit a copy of that record to the parties. Copies of all documents prepared in these proceedings will. without unreasonable delay, be filed with the Secretary.

(d) In the event that the investigation/ conciliation effort does not resolve all areas of disagreement, the representative, in transmitting the copy of the investigation/conciliation record to the parties, will inform the parties of their prerogative of requesting a mediator or mediation panel under these procedures.

\subsection{Mediation.}

(a) If pursuant to paragraph (d) of 819.29. both parties indicate to the Secretary in writing that they desire a mediator or meciation panel. and if the Secrelary believes that mediation may resolve the areas of disagrecment, the Secretary may appoint a mediator or mediation panel in a further altempt to resolve the complaint. Sclection of a mediator or mediation panel may be accomplished in consultation with the Federal Mediation and Conciliation Service. The mediator(s) so appointed may be an employee(s) of the Federal Mediation and Conciliation Serice. enother Federal agency. individuals from the privale sector. or other source, but shall not be employees of the Department of Commerce. The services of the niediator(s) may be subject to contract, which may include provisions for necessary clerical and other support costs. An cffort will be made by the Secretary to secure a mediator(s) who will be acceptable to the parties involved and who will avoid the appearance of a "conflict of interest" situation with respect to the subject matter and the parties involved in the dispute.

(b) The Secretary will provide the mediator(s) with the record of the investigation/conciliation process which shall identify all remaining areas of disagreement, including the positions of the parties on each such remaining area, and will transmit or otherwise. make available to the mediator(s) all other available information pertinent to the resolution of the identified areas of disagreement. The Secretary's letter of appointment will also specify a target date for the completion of mediation: such date generally will be not more than three months from the date of the " appointment of the mediator(s).

(c) At the start of the mediation process, the mediator(s) will encourage the parties to agree in advance to be bound by the agreements reached during the mediation process. If such agreement from the parties is forthcoming, the mediator(s) will record such agreement and shall inform the Secretary accordingly.

(d) The mediator(s) will endeavor forthwith and within the designated time frame to facilitate a mutually acceptable resolution of the remaining areas of disagreement identified by the Secretary. In so doing, the mediator(s) may hold meetings, may communicate with each party on an individual or group basis, and may utilize any other reasonable lawiul means, including technical assistance, to resolve the areas of disagreement. Such technical assistance may be provided on a reimbursable basis.

(e) The Secretary may, for good and sufficient reasons, grant one extension of time for completion of mediation pursuant to the written request by the mediator(s). Such a request shall specify the reasons for the requested extension. Any extension generally shall be limited to a maximum of two months.

(I) If, during the mediation process. the parties reach agreement on all the areas of disagreement identified by the Secretary, the mediator(s) will record the nature of the agrecment for each area, have each party sign and date the agreement, and will transmit copies of that record to the Secretary and to the parties.

(8) If the time period (including any extension provided) (or mediation expires with one or more areas of disagreement still remaining, the incdiator(s) will terminate the mediation process and will record the areas of agreement (if any). With regard to each of the remaining areas of disagreement. the mediator(s) will record the specific nature of such disagreement and make a factual report of the mediation process. The report will be transmitted by the mediator(s) to the Secretary and to the parties involved. The report will not contain any information which was submitted to the mediator in confidence.

(h) Upon receipt of the report from the mediator(s), the Secretary, in

appropriate cases, may develop and transmit to the involved parties recommendations to resolve the areas of disagreement. Such recommendations may include the submission of the unresolved issues on areas of disagreement to arbitration.

\section{\$19.31 Publication and records.}

(a) The Secretary will cause to be published in the Federal Register, at least annually, a summary of each of the cases processed under these procedures, including any recommendations made by the Secretary to resolve any remaining issues, unless the parties in any case agree in writing that the dispute has been amicably resolved to their mutual satisiaction, and that agreement is filed with the Secretary.

(b) The Secretary will keep a record of each complaint received. including the action taken. if any, by the parties as a result of this dispute resolution service.

\section{\$ 19.32 Technical réteree service.}

Nothing in these procedures shall be construed to inhibit any party from directly seeking, on its own initiative and at any time, the technical referee services of the National Bureau of Standards regarding methods of measurement, test results, and interpretation of test results in accordance with Title 15, CFR, Part 200.103 .

\section{§૬ 19.33-19.40 [Reserved]}

[FR Doc. 80-16684 Filed 5-70-80. 8:45 am] BIUUMG COOE 3510-13-H 


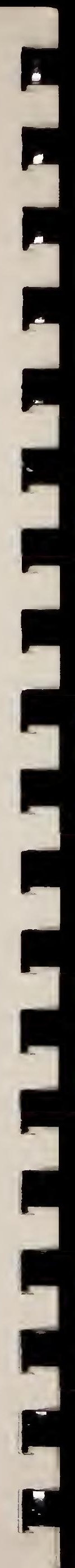


NBS-114A (REV. 9-78)

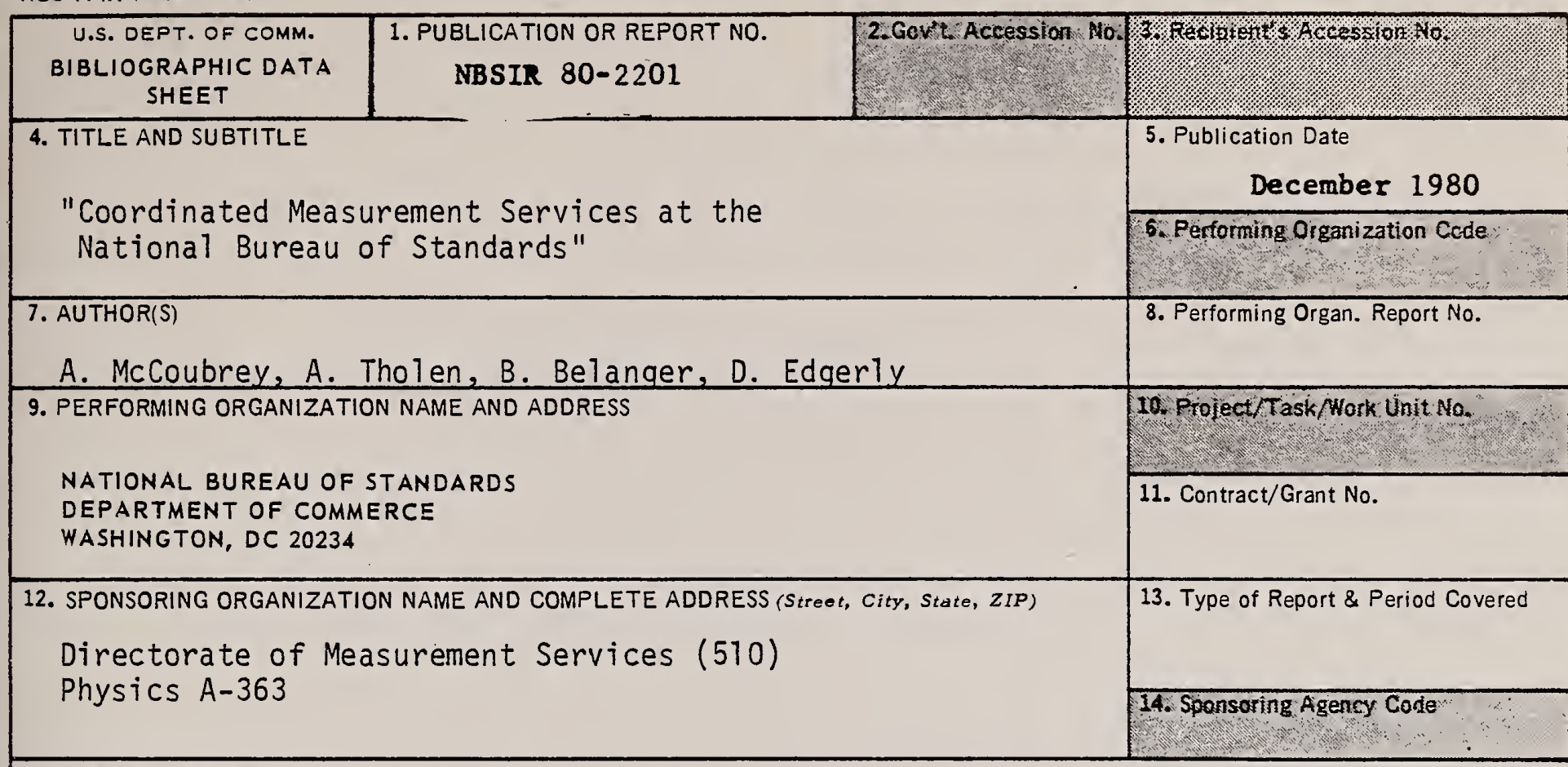

15. SUPPLEMENTARY NOTES

Document describes a computer program; SF-185, FIPS Software Summary, is attached.

16. ABSTRACT (A 200-word or less factual summary of most significant infomation. If document includes a significant bibliography or literature survey, mention it here.)

The document provides an overview of the coordinating activities of the Directorate of Measurement Services as they are required to meet the needs of industry, State and local governments, and other Federal agencies. Critical issues are identified, accomplishments are highlighted, and plans for program development are reviewed.

17. KEY WORDS (six to twelve entries; alphabetical order; capitalize only the first letter of the first key word unless a proper nams; separated by semicolons)

Calibrations; International standards; Measurement Assurance Programs (MAP's); Measurement services; OIML; Voluntary standards; Weights and measures.

\begin{tabular}{|c|c|c|}
\hline $\begin{array}{l}\text { 18. AVAILABILITY } \\
\text { X For Official Distribution. Do iNot Release to NTIS }\end{array}$ & $\begin{array}{l}\text { 19. SECURITY CLASS } \\
\text { (THIS REPORT) } \\
\text { UNCLASSIFIED }\end{array}$ & $\begin{array}{l}\text { 21. NO. OF } \\
\text { PRINTED PAGES }\end{array}$ \\
\hline $\begin{array}{l}\text { - Order From Sup. of Doc., U.S. Government Printing Office, Washington, DC } \\
20402 \text {, SD Stock No. Siv003-003- }\end{array}$ & $\begin{array}{l}\text { 20. SECURITY CLASS } \\
\text { (THIS PAGE) }\end{array}$ & 22. Price \\
\hline $\begin{array}{l}\text { — Order From National Technical Information Service (NTIS), Springfield, } \\
\text { VA. } 22161\end{array}$ & UNCLASSIFIED & \\
\hline
\end{tabular}




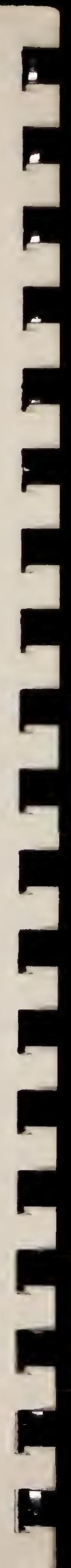





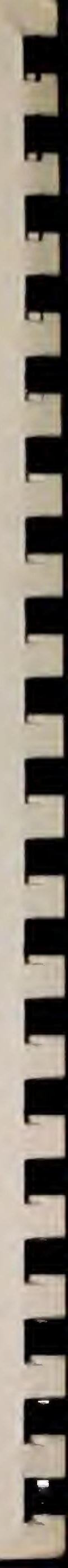

